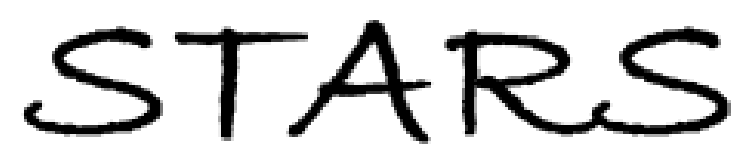

University of Central Florida

STARS

\title{
Game On: The Impact Of Game Features In Computer-based Training
}

Renee DeRouin-Jessen

University of Central Florida

Part of the Psychology Commons

Find similar works at: https://stars.library.ucf.edu/etd

University of Central Florida Libraries http://library.ucf.edu

This Doctoral Dissertation (Open Access) is brought to you for free and open access by STARS. It has been accepted for inclusion in Electronic Theses and Dissertations, 2004-2019 by an authorized administrator of STARS. For more information, please contact STARS@ucf.edu.

\section{STARS Citation}

DeRouin-Jessen, Renee, "Game On: The Impact Of Game Features In Computer-based Training" (2008). Electronic Theses and Dissertations, 2004-2019. 3772.

https://stars.library.ucf.edu/etd/3772

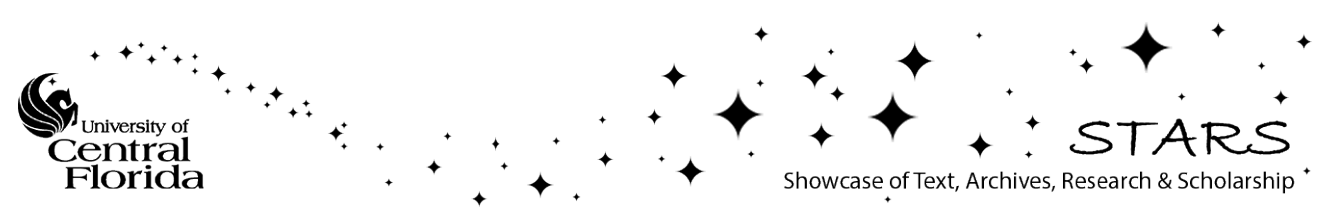


GAME ON:

THE IMPACT OF GAME FEATURES IN COMPUTER-BASED TRAINING

by

\section{RENÉE E. DEROUIN-JESSEN}

B.S. Flagler College, 2001

M.S. University of Central Florida, 2004

A dissertation submitted in partial fulfillment of the requirements for the degree of Doctor of Philosophy in Psychology

in the Department of Psychology in the College of Sciences at the University of Central Florida

Orlando, Florida

\section{Fall Term}

2008

Major Professor: Barbara A. Fritzsche 
(C) 2008 Renée E. DeRouin-Jessen 


\begin{abstract}
The term "serious games" became popularized in 2002 as a result of an initiative to promote the use of games for education, training, and other purposes. Today, many companies are using games for training and development, often with hefty price tags. For example, the development budget for the U.S. Army recruiting game, "America's Army" was estimated at $\$ 7$ million. Given their increasing use and high costs, it is important to understand whether game-based learning systems perform as billed.

Research suggests that games do not always increase learning outcomes over conventional instruction. However, certain game features (e.g., rules/goals, fantasy, challenge) might be more beneficial for increasing learner motivation and learning outcomes than other game features. This study manipulated two specific game features: multimedia-based fantasy (vs. text-based fantasy) and reward (vs. no reward) in a computer-based training program on employment law. Participants $(N=169)$ were randomly assigned to one of the four experimental conditions or to a traditional computer-based training condition.

Contrary to hypotheses, the traditional PowerPoint-like version was found to lead to better declarative knowledge outcomes on the learning test than the most game-like version, although no differences were found between conditions on any of the other dependent variables. Participants in all conditions were equally motivated to learn, were equally satisfied with the learning experience, completed an equal number of practice exercises, performed equally well on the declarative knowledge and skill-based practice, and performed equally well on the skill-based learning test. This suggests that adding the
\end{abstract}


"bells and whistles" of game features to a training program won't necessarily improve learner motivation and training outcomes. 
This dissertation is dedicated to my loving and supportive husband, Tom, and to my wonderful parents and family-thank you for always believing in me. 


\section{ACKNOWLEDGMENTS}

This dissertation would not have been completed without the help of several wonderful research assistants who worked tirelessly to collect the data: Jennifer Pearson and Pamela Fitzgerald (Lab Managers), Lauren Alfano, Josh Dichkewich, Diana Hernandez, Ryan Huff, Kaylarin Marcus, Wesley McBride, Eddie Oakes, Dolores Romero-Aldana, and Aaron Schiller. Brent Hartmann and Tom Jessen also spent months developing the different versions of the computer-based training programs. I owe them both a debt of gratitude for their help on this project. In addition, I would like to thank my Dissertation Committee members (Drs. Eduardo Salas, Robert Pritchard, and Rudy McDaniel) and my fellow work team members (Richard Rhein, Megan Braxton, Robert Mobley, and Mary Proia), for the time, help, and energy they offered me throughout the dissertation process. Last but certainly far from least, I would like to acknowledge the extensive support of my Dissertation Chair and Advisor, Dr. Barbara Fritzsche. Her guidance during my dissertation and throughout my graduate career has helped me become the researcher (and person) I am today. 


\section{TABLE OF CONTENTS}

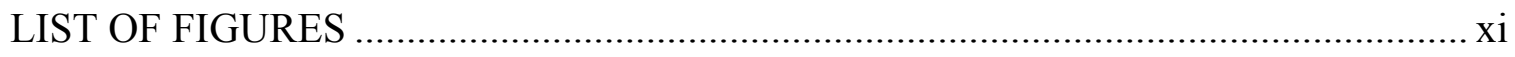

LIST OF TABLES ..........................................................................................

LIST OF ACRONYMS/ABBREVIATIONS ....................................................... xiii

CHAPTER ONE: INTRODUCTION ................................................................ 1

CHAPTER TWO: LITERATURE REVIEW .......................................................... 5

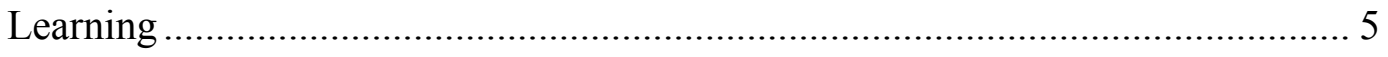

What is Learning and How Does it Occur? ......................................... 6

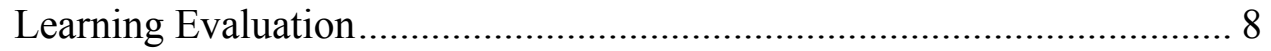

Learning/Instructional Design Principles .......................................... 10

Video/Computer Games: Their Origins, Definition, and Differentiation from

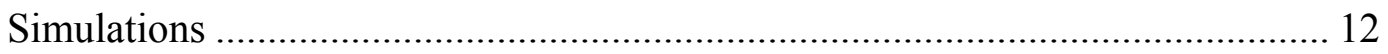

A Brief History of Games ................................................................ 12

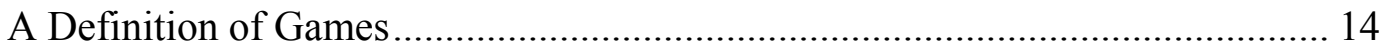

Games vs. Simulations ...................................................................... 16

What We Know About Games ...................................................................... 18

Games Offer Several Advantages over Other Forms of Instruction........ 19

Games do not Always Lead to Increased Learning ............................. 21

Inconsistent Findings Might be a Result of Moderators, Including

Different Game Features..................................................................... 22

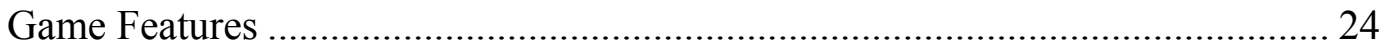

Game Features Referenced in the Research Literature......................... 25

Empirical Research on Game Features ................................................. 30 
Models/Theories of Game Features, Motivation, and Learning..... 39

Garris et al.’s (2002) Input-Process-Outcome Model of Games and

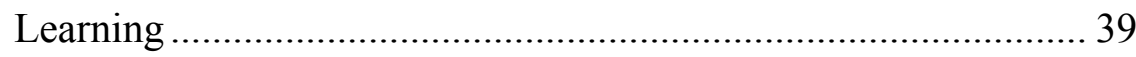

Pritchard and Ashwood (2008) Model of Motivation.................. 41

Game Features Investigated in this Study: Multimedia-Based Fantasy and

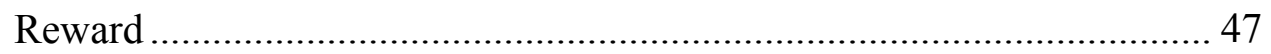

Multimedia-based Fantasy ................................................. 48

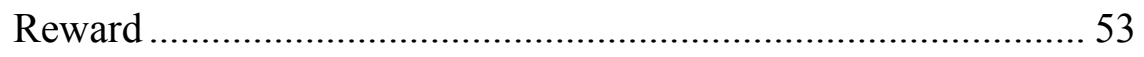

Interaction between Multimedia-based Fantasy and Reward ....... 57

Motivation as a Mediator between Game Features and Learning and between Game Features and Training Satisfaction ............... 58

Motivational Outcome Variables as Mediators between Game

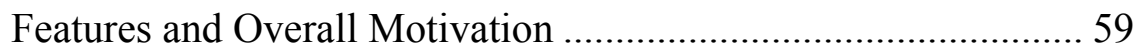

Number of Practice Exercises Completed as a Mediator Between

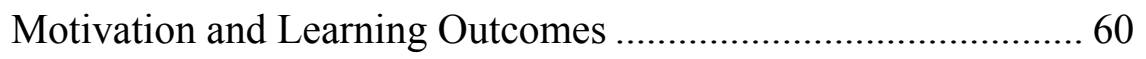

Training Programs offering both Multimedia-based Fantasy and Reward versus Traditional Computer-based Training Programs.. 60

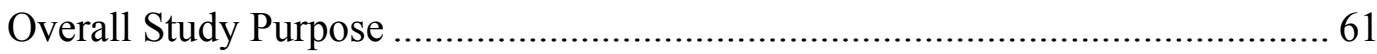

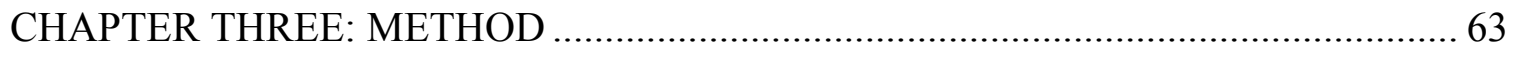

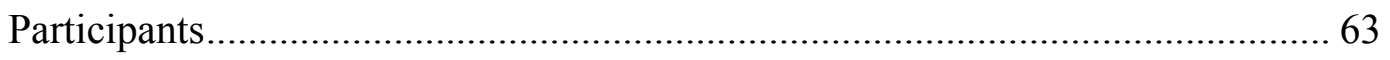

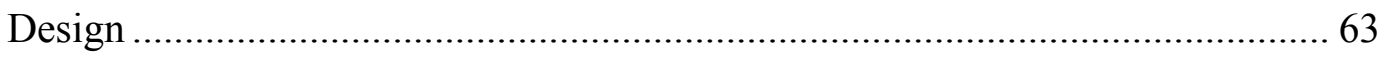

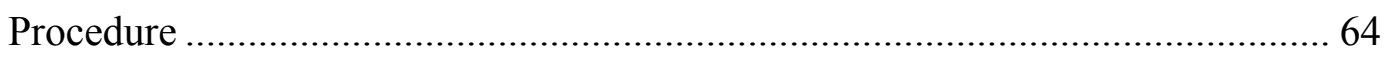

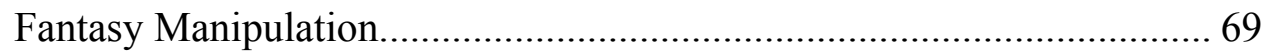


Reward Manipulation............................................................................. 70

Traditional Computer-Based Training Program Condition ........................ 71

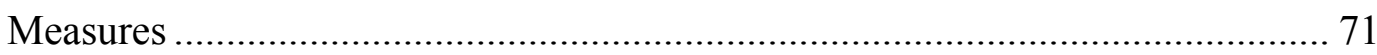

Demographics Questionnaire ................................................................... 71

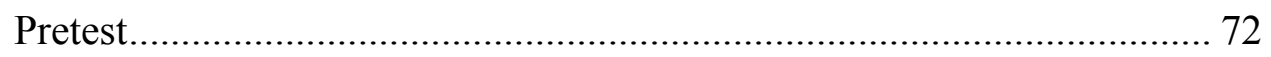

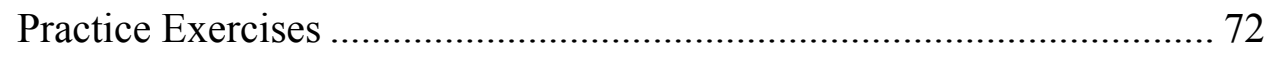

Overall Training Motivation ..................................................................... 74

Feeling of Achievement ........................................................................ 75

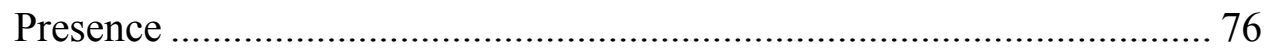

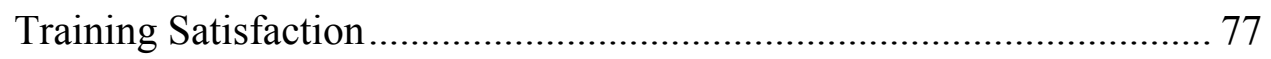

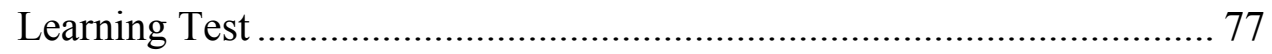

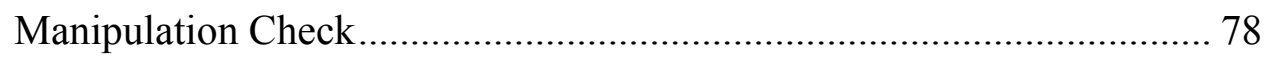

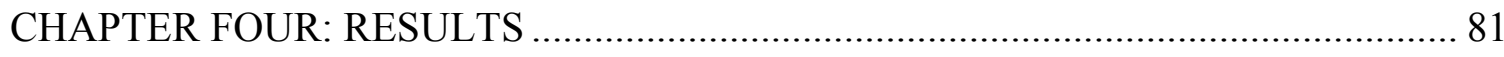

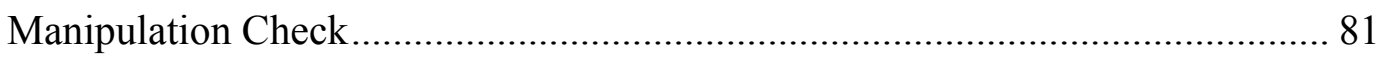

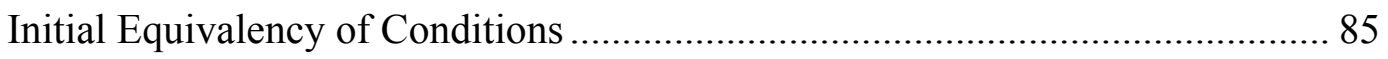

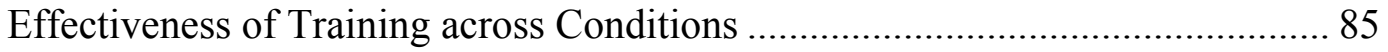

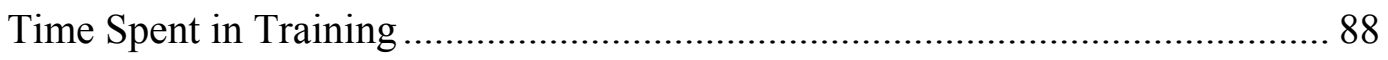

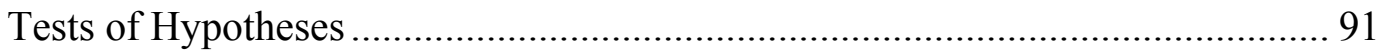

Additional Analyses of Dependent Variables by Sex.......................................... 96

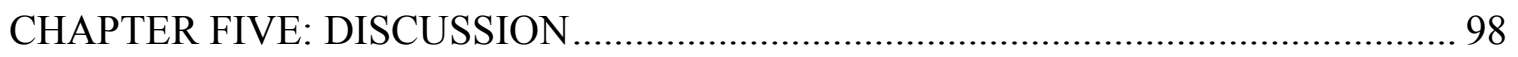

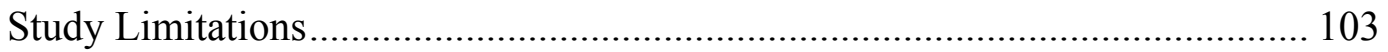

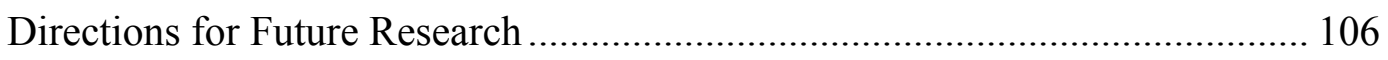

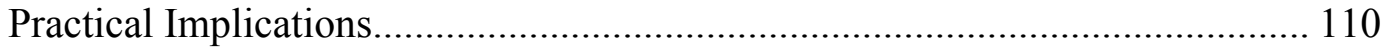


Conclusion 111

APPENDIX A: INFORMED CONSENT 113

APPENDIX B: DEMOGRAPHICS FORM ……………………............................ 116

APPENDIX C: LEARNING OBJECTIVES HANDOUT ………................................. 119

APPENDIX D: TRAINING DEBRIEFING FOR EXPERIMENTAL CONDITIONS. 121 APPENDIX E: TRAINING DEBRIEFING FOR TRADITIONAL, COMPUTER-

BASED PROGRAM CONDITION 123

APPENDIX F: STUDY DEBRIEFING 125

APPENDIX G: ADDITIONAL EMPLOYMENT LAW RESOURCES 128

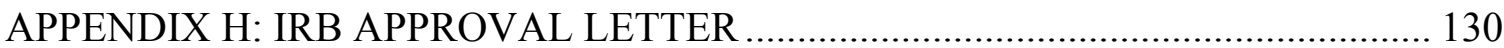

APPENDIX I: PERMISSION LETTER FROM SAGE PUBLICATIONS .................... 132

APPENDIX J: PERMISSION LETTER FROM TAYLOR \& FRANCIS ....................... 134

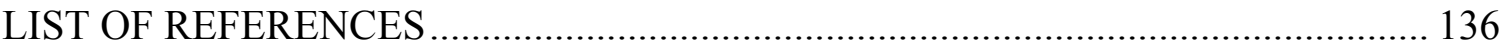




\section{LIST OF FIGURES}

Figure 1: Garris et al.'s (2002) Input-Process-Outcome Model of Games and Learning. 40

Figure 2: Pritchard and Ashwood (2008) Model of Motivation ................................... 42 


\section{LIST OF TABLES}

Table 1: Definitions of Game Features ................................................................... 26

Table 2: Means, Standard Deviations, Reliabilities, and Intercorrelations Among the

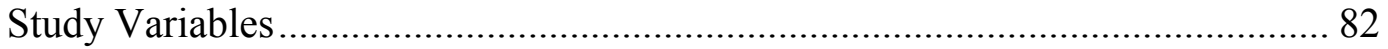

Table 3: Scheffé Post Hoc Tests Comparing Pretest Scores between Conditions............ 86

Table 4: Scheffé Post Hoc Tests Comparing Pretest-Posttest Differences between

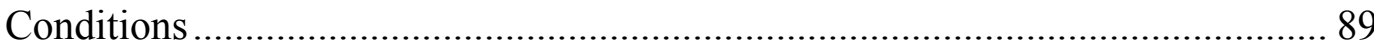

Table 5: Time Spent in Training in Each Condition................................................... 91

Table 6: Comparison of the Most Game-like Condition to the Traditional Computerbased Training Condition.............................................................................. 96 


\section{LIST OF ACRONYMS/ABBREVIATIONS}

ADA

ADEA

COTS

EEO

EEOC

MMORPG

PC
Americans with Disabilities Act of 1990

Age Discrimination in Employment Act of 1967

Commercial Off-The-Shelf

Equal Employment Opportunity

Equal Employment Opportunity Commission

Massively Multiplayer Online Role-Playing Game

Personal Computer 


\section{CHAPTER ONE: INTRODUCTION}

In 2007, Americans spent $\$ 18.8$ billion on video and PC-based games. This figure represented an increase in sales of $40 \%$ over the previous year (The NPD Group, 2008). In addition to the money Americans invest in video games, they also report spending a significant amount of time playing these games. Boys between the ages of 8 and 12, for instance, spend approximately 16 hours per week playing video games and girls of the same age report playing video games for 10 hours per week (Dolliver, 2007). Although the hours spent playing games decrease as one enters adulthood, video game usage is still prevalent among adults. A recent poll by the Associated Press and America On Line revealed that $40 \%$ of U.S. adults play computer or video games (Slagle, 2006), and the average age of game players today is 33 years old (Entertainment Software Association, 2006). Among U.S. game players, specifically, adult women spend an average of 7.4 hours per week playing computer or video games and adult men spend 7.6 hours per week (Entertainment Software Association). All in all, video games constitute a large part of America's economy and culture.

In spite of (or maybe because of) the prevalence of video games in America's economy and culture, heated debates rage over the pros and cons of this technology. On the positive side of the debate, there are acknowledgements of how games can improve visual processing and attention skills in children (e.g., Roach, 2003; "Video Games Boost Vision," 2003), how playing video games might actually reduce errors made by surgeons (e.g., Dobnick, 2004), how video games can increase critical thinking skills (e.g., Borja, 2006), and even how video games can help children undergoing chemotherapy by focusing their attention away from any pain or discomfort they are experiencing 
(“Computer Games do Have Benefits," 2005). On the negative side, research has shown that video games are associated with increased aggression (e.g., Anderson \& Dill, 2000; Anderson, Carnagey, Flanagan, Benjamin, Eubanks, \& Valentine, 2004), psychological desensitization to violent acts (Carnagey, Anderson, \& Bushman, 2007), and increased risk-taking (particularly with regard to driving after playing racing games; Fischer, Kubitzki, Guter, \& Frey, 2007).

Despite the arguments for and against video games, they are becoming increasingly popular not only for recreation and entertainment but also for training and educational purposes. Currently, the military uses video games for training ("Military Training is Just a Game," 2003), and the Central Intelligence Agency is planning to develop a video game that will help its analysts "think like terrorists" (Gertz, 2003). Many companies are also making the switch toward using games for training and employee development. For instance, Cisco Systems uses a computer game that involves creating a computer network for aliens on Mars to teach networking skills to technicians; Canon, Inc. uses a computer game similar to the game Operation to teach repairmen how to install different parts into copiers; and Cold Stone Creamery uses video games to help its employees learn customer service skills and how to portion out servings (Jana, 2006).

The use of games for training is expected to increase significantly in the near future. A recent poll of 151 chief learning officers revealed that many companies expect to incorporate simulations and games into their training courses as a way of increasing learner engagement. Specifically, almost half reported that they planned to use simulations for learning in the next year and nearly a third planned to utilize learning games (Meister, 2006). 
So why are organizations using video games for training? One of the reasons that video games are becoming so popular in the corporate and government training market is that they appear to offer a unique way of increasing learner motivation during training. Specifically, the literature suggests that video games possess a certain set of characteristics and features that serve to increase player motivation (more will be discussed about this in the second chapter).

The potential for video games to increase learner motivation has specific applications for training offered through online or other computer-based methods. These types of training modalities suffer from a very high rate of attrition (e.g., Flood, 2002), and, therefore, would benefit from the inclusion of instructional techniques that might improve learner motivation to continue studying the subject matter.

In this dissertation, two different features of video/computer games (i.e., multimedia-based fantasy and reward) were systematically investigated to determine whether they impact learner motivation and training outcomes or whether they serve only as "bells and whistles" without any substantive contribution. The research background on both of these features is described in Chapter 2. In order to study these features, a computer-based training program was developed in which these features were manipulated. As the literature in this area is fairly new and only a limited number of studies have examined how individual features of video games impact motivation and training outcomes, this dissertation offers several contributions to both research and practice.

From a research standpoint, this study helps researchers begin to understand the factors that contribute to training motivation and training outcomes. Specifically, this 
study provides researchers with an empirical test of whether reward and multimediabased fantasy influence learning motivation and training outcomes above and beyond that provided by basic learning principles/instructional design features (e.g., clear, timely feedback; practice that permits mistakes). From an applied standpoint, this dissertation informs practitioners about the benefits or drawbacks of incorporating these two features into new or existing computer-based training programs. Eventually, the results of this study can be combined with the results of other studies to help practitioners determine which features to invest in when developing training programs and which features are unlikely to impact motivation and training outcomes. 


\section{CHAPTER TWO: LITERATURE REVIEW}

The chapter begins with a brief review of the learning literature. Next, gaming history is covered as well as a description of what video/computer games are and how they differ from simulations. It then moves on to a discussion of what research tells us about video/computer games, specifically, what potential advantages games offer, what the research tells us about games and learning, and possible reasons why games have not been found to be consistently beneficial. I then identify some of the different features that are proposed to make games particularly motivating, review the empirical research on these game features, and identify two models/theories that might be used to explain how game features work to increase motivation and training outcomes. After that, I describe two specific game features (i.e., multimedia-based fantasy and reward) and how these features might impact motivation and training outcomes. The chapter concludes with a discussion of the purpose of the particular study and specific research hypotheses.

\section{Learning}

Learning is the goal of all educational and organizational training programs. It is what we strive for when we set out to master a new concept and what we hope is occurring when we teach others how to perform a new task. It is the foundation of any good instructional program. This is why I begin with a brief review of what learning is and how it takes place, learning evaluation, and instructional design principles. 


\section{What is Learning and How Does it Occur?}

Although it is difficult to find a universally accepted definition of learning (Hergenhahn \& Olson, 2005), it can be defined very broadly as "a process of change that occurs as a result of an individual's experience" (Mazur, 2001, p. 1). Researchers have described this process of change more specifically as a "relatively permanent change in behavior potentiality which occurs as a result of reinforced practice" (Kimble, 1961, p. 6). In other words, learning makes it more likely that certain behaviors will be performed.

The center of all learning is the brain. At its simplest level, learning occurs when one neuron fires a signal to another neuron, creating a connection between the two neurons. As more complicated associations are made and additional neurons are added to the network, a "neural network" is formed. Through repeated use, the neural network increases in strength, allowing us to more efficiently remember events, objects, and people (Sprenger, 1999).

Many different theories have been proposed of how and why learning occurs (e.g., constructivist theories, cognitive theories, associationist theories), one of the most well known of which is reinforcement theory. Reinforcement theory falls under the realm of the behaviorist/associationist theories. In reinforcement theory, learning occurs from the repeated association of a particular behavior and a reinforcer or punisher. Positive and negative reinforcers increase the probability that particular behaviors will be performed again. Candy and prizes are examples of positive reinforcers. When valued, these items increase the likelihood that certain behaviors will reoccur. An example of a negative reinforcer would be rain on the day an individual forgets to bring an umbrella. The next 
time this individual leaves the house, he/she will likely remember an umbrella in order to avoid being rain-drenched for the rest of the day (Mazur, 2001).

Punishers, in contrast, decrease the probability that certain behaviors will be performed. There are two types of punishers: positive punishers and negative punishers. An example of a positive punisher would be requiring someone to wash the dishes as a result of failing to pass a school test. In this case, behavior (failing the test) would be followed by an unpleasant response (having to wash dishes), which would lessen the likelihood that the student would fail another school test. An example of a negative punisher would be losing television privileges for forgetting to complete a homework assignment. In this example, the behavior (forgetting to complete the homework assignment) would result in the loss of a positive stimulus (television privileges). Losing this positive stimulus would reduce the likelihood that the individual would forget to complete another homework assignment in the future (Mazur, 2001).

An interesting finding is that reinforcers and punishers do not need to be experienced first-hand in order for learning to occur. Learning can also occur from watching others experience certain consequences for their behavior. This theory is called "Social Learning Theory" (Bandura, 1977). Through social learning theory, individuals observe the outcomes others receive from their behaviors and then decide whether to model those behaviors in their own lives. According to Bandura (1977), "Learning would be exceedingly laborious, not to mention hazardous, if people had to rely solely on the effects of their own actions to inform them what to do. Fortunately, most human behavior is learned observationally through modeling: from observing others, one forms an idea of 
how new behaviors are performed, and on later occasions this coded information serves as a guide for action." (p. 22).

Reinforcement theory and social learning theory are only two of numerous learning theories that have been proposed. Although many of these learning theories appear to be in conflict with one another (e.g., behaviorist theories, cognitive theories), each offers a unique perspective that adds to the literature on how and why learning occurs. In-depth reviews of these and additional learning theories can be found in Driscoll (2000), Hergenhahn and Olson (2005), Tennant (1997), and Walker (1996).

\section{Learning Evaluation}

Learning can be evaluated in many different ways. Kirkpatrick (1976) suggests that learning should be evaluated in terms of four hierarchical levels: reactions, learning, behavior, and (in the case of organizational training) results. These four levels have been used widely in the evaluation of training and instruction (e.g., Frash, Kline, Almanza, \& Antun, 2008; Indira, 2008; Liebermann \& Hoffmann, 2008), and practitioners have since added a fifth level to Kirkpatrick's model (i.e., return on investment; Phillips, 1997). One of the difficulties in applying Kirkpatrick's model, however, is the selection of appropriate assessments for measuring each outcome level. Although Kirkpatrick recommends that evaluation take place at each of the four levels, no specific guidance is given for how to measure success at each level (Kraiger, Ford, \& Salas, 1993).

In response to this, Kraiger et al. (1993) developed a classification scheme of learning outcomes and methods for evaluating each outcome. This classification scheme was based on Bloom's (1956) and Gagne's (1984) taxonomies of learning and includes three main learning outcomes: cognitive, skill-based, and affective learning outcomes. 
The first of these three learning outcomes, cognitive learning outcomes, refers to the verbal knowledge, knowledge organization, and/or cognitive strategies that learners develop during an instructional course. Declarative knowledge outcomes (or knowledge of "what"; Wilson et al., in press) fall under the realm of cognitive learning outcomes and typically involve demonstration of fact-based, informational knowledge. Kraiger et al. (1993) recommend that cognitive learning outcomes are evaluated through any of a variety of different methods, including power tests, speed tests, and recognition/recall tests.

Skill-based learning outcomes occur after cognitively based learning outcomes are developed (Wilson et al., in press). According to Kraiger et al. (1993), the specific skills learned are likely to be either technical or motor skills. Skill-based learning outcomes can be evaluated through such assessment methods as hands-on testing, structured situational interviews, and targeted behavioral observations.

Lastly, affective learning outcomes include both attitudinal and motivational outcomes. Affective outcomes are not simply the reactions or attitudes learners have toward the instruction provided. Rather, they are affective and emotional outcomes that might be changed as a result of the instructional course (e.g., a stronger appreciation for music after taking a course in music theory). Kraiger et al. (1993) recommend that affective learning outcomes be evaluated through free recall measures, free sorts, or selfreport.

Surprisingly, the Kraiger et al. (1993) classification scheme has not received the same attention that the Kirkpatrick (1976) model has received, although it offers significant benefits over Kirkpatrick's four levels. One of the benefits of the Kraiger et al. 
classification scheme is that it provides a way of categorizing learning outcomes according to the type of learning gained during the training. In addition, it offers specific recommendations for how to evaluate these learning outcomes.

\section{Learning/Instructional Design Principles}

From research and theory on learning and training, several learning/instructional design principles have been developed. First, the literature suggests that practice should be included within instructional programs. Practice helps to focus learner attention on the instructional material (Byars \& Rue, 2000) and can help in the development of automaticity, the ability to perform different skills mechanically with little thought (Driscoll, 2000).

Second, learning should take place in an environment in which learners feel comfortable making mistakes (Salas and Cannon-Bowers, 2000). Learners need to feel that making mistakes is a natural part of learning and that, in fact, they might learn from these mistakes. Research by Yerushalmi and Polingher (2006) suggests that instruction might involve learning activities that help learners focus on why certain mistakes were made. Doing so might help learners perform more effectively in the future, as it helps highlight the reasons certain errors occurred and what can be done differently to reduce these errors.

Third, the literature suggests that learners should be given feedback during instruction in order to help them understand what they are doing well and what they need to be doing differently. As Byars and Rue (2000) point out, "Keeping [learners] informed of their progress as measured against some standard helps in setting goals for what remains to be learned" (p. 216). Interestingly, from the research on feedback, it appears 
that giving learners right/wrong feedback alone does not lead to improved outcomes. Providing additional information about the correct answer or helping learners to discover the correct answer, however, does enhance learning outcomes (Bangert-Drowns, Kulik, Kulik, \& Morgan, 1991). Ensuring that feedback is given in a timely manner is also essential (Salas \& Cannon-Bowers, 2000), as this will help learners connect the feedback with the performance.

Fourth, instructional programs should focus on building learner competency on foundational knowledge before moving on to more complex topics. In other words, Salas and Cannon-Bowers (2000, p. 50) recommend that instructional developers "ensure that the underlying knowledge has been trained, before moving to skills. [Learners] must know what the concepts, rules, definitions, or procedures are before applying them to the task." Applying Kraiger et al's (1993) classification scheme to this principle implies that cognitive learning should be developed before attention is placed on skill-based learning. Doing so will provide learners with the knowledge structure necessary for developing more complex skills.

These principles of learning need to be applied to the development of any instructional course or organizational training program in order to ensure learner success. As will be discussed in the following section, video games naturally offer some or more of these learning principles, making them strong candidates as instructional tools. 
Video/Computer Games:

Their Origins, Definition, and Differentiation from Simulations

\section{A Brief History of Games}

Although video and computer games have only been around since the $1950 \mathrm{~s}$ (KCTS Television, n.d.), games have been played as a form of entertainment for thousands of years. For instance, game boards have been uncovered from ancient Sumerian cemeteries and Egyptian tombs, dating back to approximately 2600 B.C. and 1600 B.C., respectively (Avedon \& Sutton-Smith, 1971). In addition, versions of the game Tic-Tac-Toe have been discovered carved into the seats of cathedrals across the United Kingdom; these games appear to have been a popular pastime of churchgoers since the early 1400s (Avedon \& Sutton-Smith).

The first video game to be reported in the literature appeared in 1949, as part of a doctoral dissertation by A. S. Douglas (Smith, 2007). The game was called Noughts and Crosses and, like the games carved into the cathedral seats in England, this game was a form of Tic-Tac-Toe. Noughts and Crosses offered players a new form of game entertainment and marked the beginning of a revolution in the way games were presented. Since then, many other video games have taken their place in gaming history. Among the most memorable are Pong, introduced by Atari in 1975; Pac-Man, originally called Puck-Man by the Japanese but renamed Pac-Man before being released to the American public in 1980; Donkey Kong, developed by Nintendo in 1981; and Tetris, developed by a Russian mathematician in 1985 (KCTS Television, n.d.).

As video games increased in popularity during the 1970s and 1980s, game developers began to see the value in using computer-based games for teaching and 
learning as well as entertainment. As a result, a focus on the use of games for "edutainment" began, and games such as "Oregon Trail" and "Where in the World is Carmen Sandiego?" were developed. These games were meant to capitalize on the association of games with leisure and amusement, in addition to offering players a new way of learning (CNET Networks Entertainment, 2004).

In the last several years, the focus has been on the application of video games for addressing more complex, thought-provoking issues. These games, often referred to as "serious games," are "simulations that transcend traditional video and computer game fodder (gunplay, slick cars, and sports) and delve into heftier issues (responding to genocide, promoting democracy, and training first responders)" (Schollmeyer, 2006, p. 439).

The term "serious games" became popularized in 2002 as a result of an initiative to promote the use of games for education, training, and other purposes (i.e., the Serious Games Initiative) along with the online release of the U.S. Army recruiting game, “America’s Army” (Susi, Johannesson, \& Backlund, 2007; www.americasarmy.com). Today, serious games offer a unique way of blending instruction and video game technology. According to the U.S. Transportation Security Administration (2007, p. 4), "Serious games rely on drama, storyline, humor and characters to create a compelling experience that, from a training point of view, develop memory hooks; learners not only remember what happened, but also why it happened. If undertaken appropriately, serious games are a method for embedding new knowledge and/or skills that can then be immediately applied in the workplace." 
Serious games have applications in fields ranging from health care to military training (Scanlon, 2007). And, although the serious games field is fairly new, its impact is already being felt in the training and educational communities. For instance, several books have been written on the topic (e.g., Bergerson, 2006; Iuppa \& Borst, 2006; Michael \& Chen, 2006) and websites (e.g., www.seriousgamessource.com, www.socialimpactgames.com) and meetings (e.g., Serious Games Summit at the Game Developers Conference, Apply Serious Games Conference) have been created to help support the development and use of serious games around the world.

\section{A Definition of Games}

According to Cruickshank and Telfer (1980, p. 75), games are "contests in which both players and opponents operate under rules to gain a specified objective." In addition, games have been defined as "voluntary activi[ties], obviously separate from real life, creating an imaginary world that may or may not have any relation to real life and that absorbs the player's full attention. Games are played out within a specific time and place, are played according to established rules, and create social groups out of their players" (Michael \& Chen, 2006, p. 19). Computer-based learning games, in particular, have been defined as "rule-governed, goal-focused, microcomputer-driven activit[ies] incorporating principles of gaming and CAI" (Driskell \& Dwyer, 1984, p. 11).

Games differ widely in their form and function. For example, games can be either single- or multi-player (Naish, 2003). In single-player games, individuals generally race against a clock or compete against their own personal scores to win. In multi-player games, individuals might compete against all other players for a prize or participate in a team that works together to accomplish a common goal. Games can take place in a 
variety of settings, employing characters that are fictional or non-fictional, human or other forms. Moreover, games can cover an assortment of different genres (adventure, strategy, action, role-playing, action, sports, racing, simulation, to name a few; Amory, Naicker, Vincent, \& Adams, 1999; Byers, 2007; Dickey, 2006), and they can require players to follow a specific path (linear sequencing) or allow them to take any of several different routes (non-linear sequencing) to reach a goal (Byers).

Because games differ so widely in their form and function, they are used for a range of purposes. In particular, some games are designed to teach specific skills. The game, "Management Possible" (see www.managementpossible.com), for example, uses an espionage scenario to train employees on management skills. Other games, such as "Objection!" (see www.objection.com) and "BARNGA" (see www.thiagi.com), train players on criminal defense attorney skills and effective cross-cultural communication. These types of games stand in stark contrast to games that are intended purely for entertainment. Games that would fall into this category would include a large portion of computer/video games available in the market today, such as Super Mario Bros (http://mario.nintendo.com) and the Legend of Zelda (www.zelda.com).

Another aspect along which games vary is the mode through which they are presented to learners, i.e., the way in which players access the game. There are a variety of machines available on the market for offering video games to players. Naish (2003) references a few different types, including gaming machines, computers, cell phones, or personal digital assistants.

Past research has also found that electronic video games vary along three different dimensions. In an early study investigating the perceived dimensionality of video games, 
Bobko, Bobko, and Davis (1984) used multi-dimensional scaling to compare a variety of then-popular video games. The games included Frogger, Pac Man, Stargate, Tempest, Frenzy, Donkey Kong, Asteroids, Centipede, Zaxxon, and Space Invaders.

After pair-wise comparisons of each of these games to each other and to what participants' conceived of as "ideal" game, the games were found to vary on the following dimensions: destructiveness (i.e., the degree to which the game required the player to actively destroy opposing forces to win, e.g., Space Invaders, as opposed to avoiding personal destruction, e.g., Donkey Kong), dimensionality (i.e., the extent to which players could move in different dimensions of physical space ranging from only one dimension, e.g., Centipede in which players can move only from left to right, to three dimensions, e.g., Stargate), and graphic quality (i.e., the level of resolution and color employed within the game, ranging from relatively little use of color and low resolution, e.g., Asteroids, to extensive use of color and high-quality resolution, e.g., Tempest).

Overall, when examining the participants' perceptions of what constitutes an "ideal" game according to the three dimensions, the ideal game was categorized as utilizing graphics with color and high resolution, between two and three physical space dimensions, and either avoidance or active destruction of opposing forces.

\section{Games vs. Simulations}

In order to fully understand what video games are, it is important to also understand what they are not. In particular, it is important to differentiate games from simulations. As mentioned previously, games involve "imaginary world[s] that may or may not have any relation to real life" (Michael \& Chen, 2006, p. 19). These worlds are meant to immerse players within the context of the game (Michael \& Chen), but they are 
not necessarily meant to be authentic simulations of reality (Crookall, Oxford, \& Saunders, 1987; Prensky, 2001a). In fact, the setting of a video game can be any number of things, including a futuristic world in which the characters fly around by jet-propelled backpacks, a medieval world in which dragons and monsters lurk around every corner, even a magical world where unicorns and wizards fly in to aid players in their mystical quest. These types of settings can be used to attract players and to absorb them in the gaming activities; however, their primary purpose is not to provide accurate representations of real life systems.

In contrast, a program can be a simulation of reality and not a game. According to Salas, Burgess, and Cannon-Bowers (1995), the purpose of a simulation is to "artificially [duplicate] the conditions that would be encountered in an actual situation or environment" (p. 455). Some of the most popular simulations are used for training in the aviation and military fields (e.g., Boeing MD-90 Electronic Flight Deck simulator, Link Simulation and Training's F/A-18 Tactical Operational Flight Trainers; Salas \& CannonBowers, 2001). These simulations attempt to accurately represent scenarios that individuals might experience when flying commercial or military aircraft.

Games also differ from simulations with regard to the different features they possess. In particular, although both games and simulations offer learners immediate feedback and relatively risk-free environments for trying otherwise dangerous tasks (e.g., Crawford, 1984; Driskell \& Dwyer, 1984; Sato \& Hansom, 2006; Wu, 1992), simulations often lack important features characteristic of games, such as rules/goals, competition, and rewards (Prensky, 2001a). These features may have implications for learner motivation, satisfaction, and learning outcomes, and, as a result, suggest that training 
games might be more appropriate than simulations in certain circumstances. For example, training games might more suitable than simulations when motivation to learn is low and use of a game could increase attention to the material or when realism and physical fidelity are not of primary importance.

\section{What We Know About Games}

As can be seen from the introduction and the discussion of gaming history, games are becoming increasingly popular as a means of instruction. They are being used in military, corporate, and educational settings, and millions of dollars are spent each year on the research and development of game-based learning systems (e.g., "Destineer Gets \$12 Million for Game,” 2006). But what exactly do we know about games?

First, we know that games offer several advantages over other forms of instruction. These advantages range from being fun and enjoyable to potentially increasing motivation and training outcomes. Second, we know that despite the many potential benefits games offer, the research findings for game-based learning environments are mixed. In particular, games have not always been found to enhance learning. Third, we know that the inconsistent findings of game-based learning research might be the result of particular moderators, including game features. In other words, the mixed results of game studies might be explained by different variables, such as the specific game features, involved in each study. In this section, I discuss each of these topics in turn and the relevant research supporting them. 


\section{Games Offer Several Advantages over Other Forms of Instruction}

Games offer several potential advantages over alternative forms of instruction. One of these advantages is that games are fun (Garris, Ahlers, \& Driskell, 2002). According to Prensky (2001a), games have a quality about them that makes them pleasurable. In fact, a significant amount of gaming research over the last three decades has been dedicated to understanding just what it is about games that makes them so entertaining (e.g., Amory et al., 1999; Malone, 1980, 1984; Malone \& Lepper, 1987). The literature suggests that there are many characteristics of games that make them appealing; more about these features will be discussed later in the game features section.

A second advantage of games is that they have the potential to increase learner motivation during training tasks. The sheer amount of time individuals spend playing video games provides an indication of the motivational impact of games. For example, on average, game players in Massively Multiplayer Online Role-Playing Games (i.e., Internet-based games in which players assume roles/missions that involve interacting with players from across the globe; MMORPGs) spend approximately 22 hours per week in online worlds (equivalent to a part-time job), and a majority of players have spent 10 or more consecutive hours playing these games (Yee, 2006a). Many people even report experiencing time loss as a result of playing their favorite games (Wood, Griffiths, \& Parke, 2007).

Because games are so motivating, they subsequently offer a means of reducing learner attrition from training programs. One training medium that suffers from a high rate of attrition is online learning (a.k.a. e-learning, Web-based training, Internet-based training). Online learning refers to "learning delivered by Web-based or Internet-based 
technologies" (American Society for Training and Development, n.d.). According to Carr (2000), estimates of attrition rates can be 10-20\% greater for distance education courses than for traditional face-to-face courses. The attrition rate is also high for online learning courses offered at corporate institutions. Flood (2002) estimates that as many as $80 \%$ of employees drop out of online learning programs prior to course completion. Because video and computer games have the ability to capture a person's attention for significant periods of time (e.g., Yee, 2006a), games might be used in online learning to reduce high dropout rates.

In addition to being fun, increasing motivation, and potentially reducing learner attrition, games may increase learning. Games have several features that make them good learning tools. For instance, games require players to actively participate in the activity; unlike media such as radio or television, players must continually respond to a range of stimuli presented to them (Driskell \& Dwyer, 1984). In a video game developed for training, this active participation requires players to be mentally involved in the game, which increases the possibility that learning will occur (Ricci, Salas, \& Cannon-Bowers, 1996). Another characteristic of video games is that they offer players immediate feedback about their performance. Whether they win points, lose lives, or advance to another level, players are given instantaneous and continual information about their progress in the game (Driskell \& Dwyer). The literature on the science of training suggests that timely, precise feedback is an important component of any good training program (e.g., Salas \& Cannon-Bowers, 2000), as it offers learners critical information about their performance and clues about what they should do differently to improve. 
Because feedback is an intrinsic feature of video games, games may be particularly applicable for use in training contexts.

Although games may be useful for a wide range of training purposes, they may be particularly useful in training certain topics. For example, technical material might benefit significantly from being offered in a video game versus traditional face-to-face or text-based formats (Prensky, 2001a). This type of material can often appear dry and uninteresting to learners; offering it through a game might help to focus learner attention on the subject matter. According to Prensky, material that is particularly difficult might also benefit from game-based learning. Games can be built to offer continuous and adaptive practice items as well as the ability to observe and manipulate complex models and figures. Thus, they may be well suited for training challenging topics.

\section{Games do not Always Lead to Increased Learning}

Despite the many potential benefits described previously, the research findings for learning in game-based environments are mixed. Whereas some researchers have found that using computer games for education and training produces greater learning outcomes and/or learner satisfaction than conventional forms of instruction (e.g., Ricci et al., 1996; Yip \& Kwan, 2006), other researchers have not found these benefits (e.g., Ebner \& Holzinger, 2007; Rosas et al., 2003).

Randel, Morris, Wetzel, and Whitehill (1992) conducted a quantitative review of the literature on the use of games for education, examining 67 empirical studies published from 1963 to 1991 . A majority of these studies were in the field of social sciences. Almost three-quarters of the social science studies (33) indicated no benefit in learning outcomes for the use of games over traditional forms of instruction. Of the 13 studies that 
did find a significant difference in learning outcomes, 10 showed positive results for instructional games while three showed negative effects. Within the math and language arts fields, however, findings were significantly more positive for the use of learning games. Studies examining the use learning games for instruction in these areas generally found significant differences in learning gains for games over conventional instruction.

Randel et al. (1992) also reviewed studies investigating the use of games for teaching logic, physics, and biology. The findings reported suggest that games can be beneficial for instruction in physics concepts but show little difference when used to teach biology or logic; however, it is hard to generalize from these studies as only one study was reviewed in each of the three disciplines.

A recent meta-analysis by Vogel, Vogel, Cannon-Bowers, Bowers, Muse, and Wright (2006) found positive results for the use of computer games and simulations as learning tools. In conducting their meta-analysis, the authors specifically chose studies that used computer games or simulations for training and that compared the effectiveness of these modalities to traditional classroom-based instruction. Overall, the authors found that simulations and computer games were superior to traditional forms of teaching with regard to learning and attitudes toward learning. Furthermore, users tended to prefer the simulation and computer game-based methods to the more conventional teaching methods.

Inconsistent Findings Might be a Result of Moderators, Including Different Game Features

There are many potential moderators that might be used to explain the mixed findings in game-based learning research. One likely moderator is the training content 
used in each study. For example, Randel et al.'s (1992) review of the literature on gamebased instruction revealed that the most positive results were found for games used to teach math and language arts. Both of these topics are fairly technical. As I mentioned previously, certain topics lend themselves to training via video or computer games better than other topics. Technical topics, in particular, are likely to be benefit significantly from training via video or computer games, as the use of a game could help to focus and engage learner attention on the subject matter. Topics that are difficult to learn are also likely to benefit from instructional games. The ability to learn difficult material by manipulating complex models and figures in a game is likely to increase learning outcomes over alternative forms of instruction (Prensky, 2001a).

Individual differences in learners might also be used to explain the mixed results of game-based learning research. For example, learners who are experienced with using computer or video games for entertainment are likely to achieve better learning outcomes in game-based learning environments than learners with less gaming experience. This might be the case, because experienced gamers can focus more of their attention on the content of the training than on the mechanics of the game itself whereas learners with less experience have to master both the content and the mechanics.

Support for this can be found in the literature on experts versus novices (Klein \& Peio, 1989). When making decisions, experts are able to draw upon their experiences to quickly recognize an appropriate course of action given the circumstances. Doing so can cut down on the amount of trial and error experts undergo as well as the cognitive load involved with weighing different options. Novices, in contrast, do not have this set of mental resources they can sift through to identify an appropriate course of action. Rather, 
they must think through a specific set of alternatives, weighing the pros and cons of each before arriving at a decision. In a video game, being able to identify scenarios that are similar to other games an individual has played in the past will likely make it easier for an experienced game player to make decisions quickly and to focus on other aspects of the game at hand (e.g., the actual training content). As a result, experienced game players might perform better in game-based learning programs than novice gamers.

The inconsistent findings for learning outcomes in gaming research could also be a function of the specific game features used in each study. Certain game features (e.g., rules/goals, fantasy, challenge) might be more beneficial for increasing learner motivation and learning outcomes than other game features. In particular, some game features might lead learners to become immersed or involved within a training program; as a result, these game features could result in greater motivation, and, subsequently, better learning outcomes than games without these features. More about game features and the research that has been conducted on game features, motivation, and learning outcomes will be described in the following section.

\section{Game Features}

There are many features of games that might impact trainee motivation, satisfaction, and learning outcomes. In the following sections, I point out the specific features that have been identified in the research literature and review the limited empirical research on game features. I then discuss two models that can be used to explain how game features operate to increase motivation and learning in game-based instruction. I conclude by describing the specific game features that will be investigated in this study. 


\section{Game Features Referenced in the Research Literature}

Several attempts have been made by authors to outline the specific characteristics of games (see Table 1-adapted from Wilson et al., in press-for definitions of these characteristics). Garris et al. (2002), for instance, identified six primary characteristics of video games: fantasy, rules/goals, sensory stimuli, challenge, mystery, and control. Inclusion of these characteristics within simulations and training programs is argued to make them appear more "game-like" (in Garris et al.’s words). Alternatively, Vogel, Greenwood-Ericksen, Cannon-Bowers, and Bowers (2006) suggested that there are five attributes that games offer over other types of computer-assisted instruction; specifically, motivation, reward, interactivity, score, and challenge.

In a study in which Reserve Officers Training Corps personnel and military recruits were asked to identify the motivating characteristics of a video game, Belanich, Sibley, and Orvis (2004) found that four features were repeatedly mentioned by participants as being particularly motivating; these features were realism, challenge, exploration, and control.

A more recent article by Wilson et al. (in press) reviewed the extant literature on video game characteristics, arriving at a total of 18 different game features. These features included adaptation, assessment, challenge, conflict, control, fantasy, interaction with equipment, interpersonal interaction, social interaction, language/communication, location, mystery, pieces/players, progress/surprise, representation, rules/goals, safety, and sensory stimuli. According to Wilson et al., each of these features can be linked to different cognitive, skill-based, and affective learning outcomes (for specific links of each of these features to learning outcomes, please see Wilson et al., in press). 
Table 1: Definitions of Game Features

\begin{tabular}{|c|c|c|}
\hline Feature & Definition(s) & Source(s) \\
\hline Adaptation & $\begin{array}{l}\text { Game difficulty adjusts to the skill level of } \\
\text { the player. }\end{array}$ & Prensky, 2001a \\
\hline $\begin{array}{l}\text { Assessment/Rewards/ } \\
\text { Scores }\end{array}$ & $\begin{array}{l}\text { Information provided to players about their } \\
\text { performance during the game. Can be used to } \\
\text { motivate them to achieve higher levels of } \\
\text { performance. }\end{array}$ & $\begin{array}{l}\text { Chen \& Michael, } \\
\text { 2005; Vogel, } \\
\text { Greenwood- } \\
\text { Ericksen et al., } \\
2006\end{array}$ \\
\hline Challenge & $\begin{array}{l}\text { The difficulty/complexity of the game. Good } \\
\text { games involve objectives that cannot easily be } \\
\text { accomplished. }\end{array}$ & $\begin{array}{l}\text { Garris et al., 2002; } \\
\text { Vogel, Greenwood- } \\
\text { Ericksen et al., } \\
2006\end{array}$ \\
\hline Conflict & $\begin{array}{l}\text { Stumbling blocks presented in the game to } \\
\text { prevent players from accomplishing their } \\
\text { objectives. }\end{array}$ & Crawford, 1984 \\
\hline Control & $\begin{array}{l}\text { The player's capacity for power or influence } \\
\text { over elements of the game and the game } \\
\text { environment. }\end{array}$ & $\begin{array}{l}\text { Belanich et al., } \\
\text { 2004; Garris et al., } \\
2002\end{array}$ \\
\hline Exploration & $\begin{array}{l}\text { Ability to search for new information in a } \\
\text { game. }\end{array}$ & $\begin{array}{l}\text { Belanich et al., } \\
2004\end{array}$ \\
\hline
\end{tabular}




\begin{tabular}{|l|l|l|}
\hline \multicolumn{1}{|c|}{ Feature } & \multicolumn{1}{|c|}{ Definition(s) } & \multicolumn{1}{c|}{ Source(s) } \\
\hline Fantasy/Location & $\begin{array}{l}\text { Fantasy involves the creation of an imaginary } \\
\text { world, potentially with characters and events } \\
\text { that players would not ordinarily interact with } \\
\text { or experience. Location involves the } \\
\text { particular space (physical, virtual, or no } \\
\text { (Equipment) }\end{array}$ & $\begin{array}{l}\text { Malone \& Lepper, } \\
\text { space) in which the game takes place. }\end{array}$ \\
\hline Interaction/Interactivity & $\begin{array}{l}\text { The manipulability of a game. Different } \\
\text { moves by a player are reflected by } \\
\text { corresponding changes in the program. These } \\
\text { changes may be presented in the form of } \\
\text { feedback to the player about the } \\
\text { appropriateness of particular actions. }\end{array}$ & Ericksen, 2008; \\
(Interpersonal/Social) & $\begin{array}{l}\text { Prensky, 2001a; } \\
\text { technology; this interaction is generally either } \\
\text { collaborative (players work in teams) or } \\
\text { competitive (players challenge each other). } \\
\text { Moreover, game playing may not occur face- } \\
\text { to-face. Game players can be either physically } \\
\text { or virtually co-located (the latter occurs when } \\
\text { players are only present through game } \\
\text { characters). }\end{array}$ & Vogel, Greenwood- \\
Ericksen et al.,
\end{tabular}




\begin{tabular}{|c|c|c|}
\hline Feature & Definition(s) & Source(s) \\
\hline $\begin{array}{l}\text { Language/ } \\
\text { Communication }\end{array}$ & $\begin{array}{l}\text { The specific vocabulary used in the game and } \\
\text { rules regarding player communication (games } \\
\text { often differ from each other on these aspects). } \\
\text { Some common types of communication are } \\
\text { verbal and text. }\end{array}$ & Owen, 2004 \\
\hline Motivation & $\begin{array}{l}\text { The extent to which games absorb learners, } \\
\text { engrossing them in the subject matter } \\
\text { presented. }\end{array}$ & $\begin{array}{l}\text { Vogel, Greenwood- } \\
\text { Ericksen, et al., } \\
2006\end{array}$ \\
\hline Mystery & $\begin{array}{l}\text { Involves the stimulation of curiosity in game } \\
\text { players. There are several ways to enhance } \\
\text { mystery during a game, two of which are } \\
\text { giving players only partial information and } \\
\text { presenting them with contradictory } \\
\text { information. }\end{array}$ & $\begin{array}{l}\text { Garris et al., 2002; } \\
\text { Malone \& Lepper, } \\
1987\end{array}$ \\
\hline Pieces or Players & $\begin{array}{l}\text { Objects or people (e.g., avatars, other players) } \\
\text { included in the game. }\end{array}$ & Owen, 2004 \\
\hline Progress and Surprise & $\begin{array}{l}\text { Progress refers to the status of a player in a } \\
\text { game relative to specific goals and objectives. } \\
\text { Surprise results from unexpected factors that } \\
\text { enter the game and can impact a player's } \\
\text { progress. }\end{array}$ & Owen, 2004 \\
\hline
\end{tabular}




\begin{tabular}{|l|l|l|}
\hline \multicolumn{1}{|c|}{ Feature } & \multicolumn{1}{|c|}{ Definition(s) } & \multicolumn{1}{|c|}{ Source(s) } \\
\hline Realism & $\begin{array}{l}\text { The extent to which high-quality graphics and } \\
\text { other effects are used to create immersing } \\
\text { game worlds. }\end{array}$ & Belanich et al., \\
\hline Representation & $\begin{array}{l}\text { The extent to which a game takes on a } \\
\text { subjective reality in the mind of the player. }\end{array}$ & Crawford, 1984 \\
\hline Rules/goals & $\begin{array}{l}\text { Game rules are specific regulations dictating } \\
\text { what players are permitted to do within a } \\
\text { game. These rules provide the framework for } \\
\text { game goals. Game goals are the objectives } \\
\text { players attempt to accomplish within a game } \\
\text { and should be specific, unambiguous, and } \\
\text { difficult in order to be effective. }\end{array}$ & Larris et al., 2002; \\
\hline Story & $\begin{array}{l}\text { Ability to experience risky situations in a } \\
\text { relatively inconsequential manner. }\end{array}$ & Crawford, 1984 \\
Sensory stimuli & $\begin{array}{l}\text { The components of the game that excite the } \\
\text { senses. } \\
\text { contextualize the information they receive. }\end{array}$ & Garris et al., 2002 \\
\hline Safety & Ericksen, 2008 \\
\hline
\end{tabular}




\section{Empirical Research on Game Features}

The empirical research on game features thus far is limited, although a few researchers (e.g., Greenwood-Ericksen, 2008; Malone, 1981; Parker \& Lepper, 1992) have begun to investigate the impact of different gaming features on learning outcomes and motivational appeal. The earliest published attempts at empirically investigating game features were conducted by Thomas W. Malone in the early 1980s.

In Malone's (1981) paper, he reports the results of two studies, both of which were conducted as part of his doctoral dissertation. In the first study, the author examined the various features of the Atari game, Breakout, to determine which features made the game so appealing. Breakout is a computer-based game in which players use a paddle to bounce balls toward a brick wall. If the ball connects with the bricks, the bricks disappear (or "break"), allowing the ball to advance through the wall. The goal is to eventually smash enough bricks to break through to the other side, hence the name, "Breakout."

In designing the study, the author narrowed his list of game features to three: (a) the appeal of actually seeing bricks break by hitting them with a ball, (b) the amusement of hitting the ball with the paddle, and (c) the challenge associated with receiving information about game scores. In order to test the three features, the author created six versions of the game, in which the three features were provided in "all sensible combinations" (Malone, 1981, p. 345; for specific details about each combination, please see Malone, 1981). College-level students were asked to play the games and to rank order the games by preference.

By regressing rankings on the various versions of the game, Malone (1981) found that the feature that had the greatest impact on game rankings was breaking the bricks. 
The two other features lagged far behind. The author provides an explanation of why "breaking bricks" might have been so popular. In particular, the author notes, "A partially destroyed wall of bricks presents a visually appealing fantasy goal and, at the same time, is a graphic score-keeping device telling how close the player is to attaining that goal. It thus provides a goal, a visual effect, fantasy, and scoring all at the same time" (Malone, 1981, p. 348).

What the author suggested in his explanation is that "breaking bricks" did not represent a unidimensional game feature; rather, it provided players with the benefits of a few different features at once. Although Malone's (1981) study did not test the features associated with breaking the bricks individually, it represents an early attempt at teasing out the motivational appeal of specific game features.

In the second study, Malone (1981) investigated the features present in the game, Darts. Darts is an educational, computer-based game designed to provide instruction in mathematical fractions. In the traditional version of this game, players are presented with a vertical line with a number placed at both ends (e.g., a "3" on the bottom of the line and a " 4 " on the top). Balloons are positioned at several different places along this line, and players are asked to type in the fraction that represents the particular points at which the balloons are located. When players type in the correct fractions, they are rewarded by seeing arrows fly at the balloons to pop them. Circus music adds to the feeling of reward, as it is played at the end of every round in which the balloons are popped in less than four attempts at estimating the fractions.

To find out which features of the Darts game were most appealing/motivational to learners, Malone (1981) created eight different versions of the game. The first version of 
the game was essentially a stripped-down version in which learners were presented only with a line with numbers on either end and rectangles in place of the balloons. Players were asked to type in the fractions representing the rectangles' locations on the line but no feedback was given on whether these answers were correct. To create the seven other versions of the game, Malone added features successively to the program. The first feature to be added was performance feedback. When this feature was added, players were given information about whether the fractions they typed in were right or wrong. The second feature to be added was scoring. This feature gave players information about how many attempts they made and how many fractions were correct for each round. When the scoring feature was added, it was added to the non-interactive drill version with the performance feedback rather than to the original non-interactive drill version.

The five additional features were likewise added to the game one at a time. These features included constructive feedback (players were given more detailed feedback about how close they were to the correct fractions), extrinsic fantasy ${ }^{1}$ (players could see an arrow fly by and pop a balloon on another side of the screen when they guessed the correct fraction), music (music was played at the beginning of the game and after players completed a level in four tries or less), graphic representation (players were given graphic information about each their guesses through marks on the line), and intrinsic fantasy ${ }^{2}$ (when players guessed the correct fraction, arrows flew over to the balloons on the line,

\footnotetext{
${ }^{1}$ Extrinsic fantasy is present when the skill being taught is not directly linked to the fantasy provided. In the case of the Darts game, the skill would be guessing where rectangles are located on a line and the fantasy would be seeing balloons pop on the side of the screen when guesses are correct. The skill and the fantasy here are not directly related. More will be discussed about extrinsic (a.k.a., exogenous) fantasy later in the chapter.

${ }^{2}$ Intrinsic fantasy is present when the skill being taught is directly related to the fantasy context. In Darts, the skill would be guessing the location of balloons on a line and the fantasy would be popping them with arrows when guesses are correct. Here, the skill and the fantasy are directly linked. More will be discussed about intrinsic (a.k.a., endogenous) fantasy later in the chapter.
} 
popping them; i.e., the original version of the Darts game). Malone (1981) notes that all previously added features remained in the game as new features were added, unless the addition of a new feature made a previous feature unnecessary. For example, when the intrinsic fantasy feature was added, the extrinsic fantasy feature was removed, as having two similar fantasies in the game would have been unnecessary.

Eighty fifth-grade students participated in the study and were randomly assigned to one condition. Participants were given the opportunity to play either the version of the Darts game to which they were assigned or a Hangman game (they could switch back between the two games as often as they liked during two sessions of 20 minutes each). The Hangman option was provided to see whether students would choose to play with their version of the Darts game over the Hangman game.

Malone (1981) asked students to provide a rating of how much they liked their version of the Darts game on a scale from one to five and whether they preferred Darts to Hangman. Moreover, the amount of time students chose to play with the Darts game over the Hangman game was recorded.

Planned comparisons were made between consecutive versions of the game, as one feature was added in each successive version. Therefore, comparisons were only made between a particular game version and the version directly preceding it. The author found that when the data were analyzed separately for males and females, the females were surprisingly found to spend significantly less time playing the Darts game after intrinsic fantasy was added to the game. In other words, they spent more time in the game prior to when the intrinsic fantasy was added (before intrinsic fantasy was added, all other features had already been added into the game and extrinsic fantasy was still 
present). In addition, the females spent more time playing the game when music was added, suggesting that the addition of music was interesting to the female learners.

The male participants were found to spend less time playing the game when constructive feedback was added. Perhaps the male participants did not like being told how close they were to the target and preferred to guess. Moreover, the males reported liking the game more and they spent more time playing the game when extrinsic fantasy was added. This is interesting as it implies that the addition of extrinsic fantasy was appealing to the male learners.

The author notes that when the data are examined through other types of analyses (e.g., multiple regression, utility analysis that takes into account choice behavior), the reduction in the amount of time males spent playing the game when constructive feedback was added and the increase in the amount of time the females spent playing the game when music was added essentially disappear. The author concludes that the only reliable results are for the differences in time spent playing the game when intrinsic and extrinsic fantasy were present and the preference of the males for the extrinsic fantasy version.

In an effort to explain why the female students significantly reduced the amount of time they spent in the game when intrinsic fantasy was present, the author surmised that the girls might have viewed the Darts game as a "boy's game." In the extrinsic fantasy version, the arrows were only shot when a fraction was guessed correctly. However, in the intrinsic version of the fantasy, arrows were shot after each and every guess. It could be that the girls disliked seeing the arrows fly across the screen, and this happened more often in the intrinsic than the extrinsic fantasy conditions. This is an 
interesting finding, as it implies that not all fantasies are equally appealing to everyone. Moreover, the additional results that Malone (1981) found for males (i.e., that they spent more time playing the version with the extrinsic fantasy and rated the extrinsic version more highly than the previous version that did not involve arrows flying at balloons), suggests that extrinsic fantasy can be motivating to game players.

Rather than examining several different game features at once, Parker and Lepper (1992) took a more focused approach to testing the impact of game features on motivational appeal and learning outcomes. The authors conducted two studies on the effects of using a fantasy context to present basic graphics programming skills to children. The first of these studies focused on how fantasy contexts might increase the motivational appeal of video games whereas the second addressed how fantasy contexts might enhance learning outcomes.

In the first study, third and fourth grade students received training on the graphics programming commands in three different fantasy contexts: a pirate fantasy context, a detective fantasy context, and an astronaut fantasy context. There was also a no-fantasy context, in which the same instruction was provided as in the fantasy contexts but no fantasy pictures or storyline were included. The students were interviewed after interacting with all four of the instructional programs and asked to rank order their preferences. Two days following this initial presentation of the material, the students were asked to choose one of the four versions of the program to play again.

The results suggested that students preferred the fantasy context over the nofantasy context, although the specific fantasy provided did not matter. This was the case for both for students' rank-ordered preferences of the four versions and for students' 
choices of which version they would like to play again. No differences were found between males and females.

In Parker and Lepper's (1992) second study, the authors used the same fantasy contexts (pirate, detective, astronaut) to teach graphics programming skills to third grade students. In this study, random assignment was used to place students in one of three different conditions: a no-fantasy condition, an individualized-fantasy condition, and an assigned-fantasy condition. Students in the individualized-fantasy condition were asked to choose which of the three fantasy contexts they would prefer for their instruction. Students in the assigned-fantasy condition were not permitted to select the fantasy in which their instruction was framed; instead, the fantasy they received was chosen for them. After students were given time to interact with the material, they were asked to take a learning test to assess their knowledge of graphics programming (knowledge the training was specifically aimed at teaching) and general geometric concepts (knowledge that might be generalized from the training). Two weeks later, students were given a second set of learning tests, which were intended to measure learner retention of the instructional material.

The results of Parker and Lepper's (1992) second study give support to the premise that fantasy can impact learning outcomes. Specifically, the authors found that using a fantasy-based context (whether individually chosen by participants or assigned) led to greater learning outcomes than a non-fantasy-based context, although this only occurred for knowledge of basic graphics programming (the specific training content) and not general geometric concepts (the generalized training content). Learner retention of the material two weeks later was also greater for students in the fantasy conditions 
rather than the non-fantasy conditions, and this result was consistent for knowledge of both graphics programming and general geometric concepts.

The most recent examination of gaming features on learning outcomes was conducted by Greenwood-Ericksen (2008). The author created a synthetic learning environment to teach African American history, specifically discussing slavery and the Underground Railroad. Two gaming features were varied: the presence of a storyline to help guide the presentation of material and the degree of interactivity with the learning content. The first variable was manipulated by either using a narrative to tie the information together (story presence) or providing only a list of facts to the participant (story absence). The latter was manipulated by presenting the material through either the synthetic learning environment (high interactivity) or through text only (low interactivity).

After participants completed the instructional portion of the study, they were evaluated on what they had learned. The author examined learning outcomes in terms of recall and recognition of the instructional material. Results indicated that interactivity and story interacted to affect learning outcomes. When interactivity was low, the presence or absence of story did nothing to impact learning outcomes (neither positively nor negatively). However, when interactivity was high, story had interesting effects on learning. Specifically, participants who were in the story presence, high interactivity conditions recalled less information from the instruction they had received than participants who were in the story absence, high interactivity condition. Moreover, participants who were in the latter group achieved better learning outcomes than participants in any of the other three groups. As a result, it appears that using 
instructional media with high interactivity can improve learning outcomes over media with low interactivity. However, combining interactivity with a story that guides the presentation of material can significantly reduce learning outcomes.

So what do all of these studies on game features tell us? Although it is hard to make firm conclusions about game features from such a small number of studies, a few conclusions can be drawn. First, certain features are more appealing than others. In particular, games that involve fantasy contexts and visual information about progress toward goals are have been found to be more appealing than games with other features (e.g., Malone, 1981), and fantasy has been found to be more appealing than games without fantasy (e.g., Parker \& Lepper, 1992). More research should be done in this area to find out which game features are most appealing (and, subsequently, more motivational) to learners. Second, combining certain features does not always lead to increased outcomes. As Greenwood-Ericksen (2008) found, when both interactivity and story were included within the learning environment, story decreased performance when high interactivity was present. This suggests that the addition of game features in an instructional program might not automatically lead to better learning outcomes. Researchers should investigate if and when this happens with other game features so that these features are not used in combination for learning programs.

Third, game features can be linked to learning outcomes. In particular, fantasy has been associated with increased learning (e.g., Parker \& Lepper, 1992) and so has interactivity (e.g., Greenwood-Ericksen, 2008). Researchers are likely to find that additional game features have an impact on learning outcomes. Fourth, more work needs to be done in which game features are studied individually and in interaction to find out 
which ones actually increase motivation and learning outcomes. We currently have only a limited understanding of which game features impact motivational appeal and learning. Additional research in this area will provide us with a better conceptualization of which features impact motivation and training outcomes and the conditions under which they are most effective.

\section{Models/Theories of Game Features, Motivation, and Learning}

In order to test the impact game features have on motivation and training outcomes, it is important that research design be based upon a sound model. In the area of game research, two models of motivation and learning outcomes, are particularly applicable to the study of game features: Garris et al.'s (2002) input-process-outcome model of games and learning and the Pritchard and Ashwood (2008) model of motivation. In this section, these models and theories are outlined with specific attention to their relation to game research.

Garris et al. 's (2002) Input-Process-Outcome Model of Games and Learning

To help explain how game features can impact learning, Garris et al. (2002) developed an input-process-outcome model of games, motivation, and learning (see Figure 1; Garris et al., 2002, p. 45). The authors defined the primary game inputs as stemming from the instructional content (the material actually covered in the game) and game characteristics (the various features that differentiate games from other forms of instructional media). Each of these inputs is hypothesized to impact the "game cycle," which is the process (and motivational) component of the model. 
INPUT

PROCESS

OUTCOME

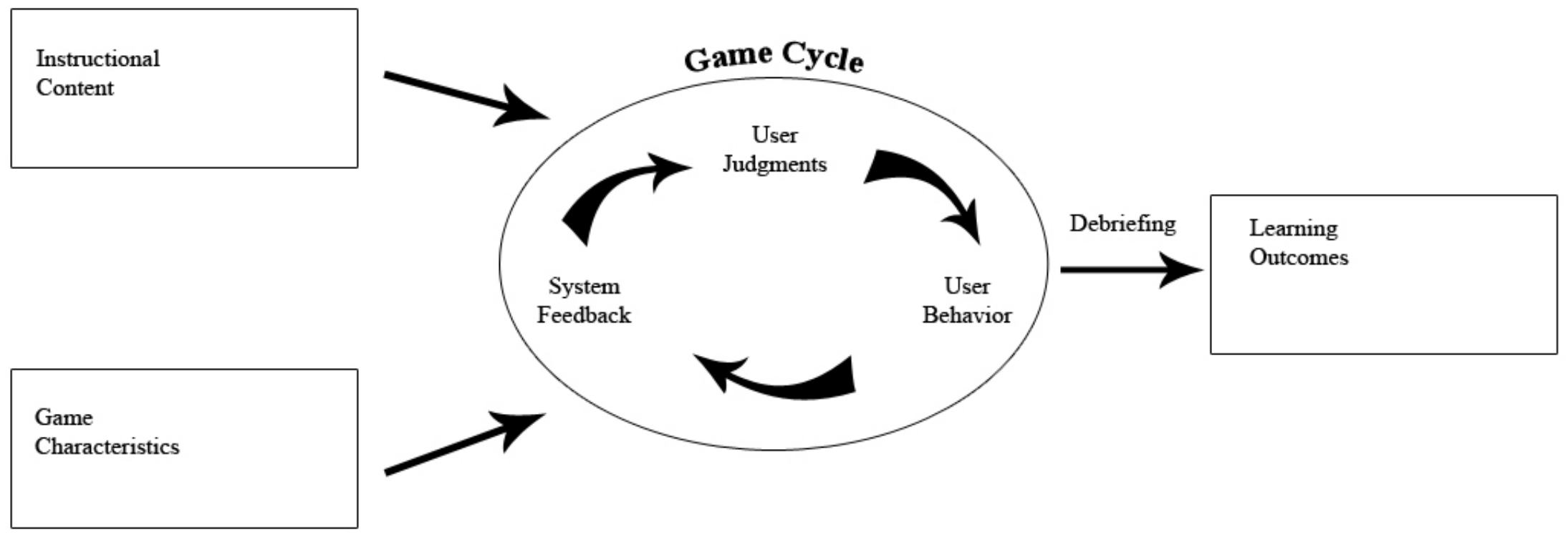

Figure 1: Garris et al.’s (2002) Input-Process-Outcome Model of Games and Learning 
The game cycle is composed of user judgments, user behavior, and system feedback. Here, user judgments refer to user reactions to the game, such as increased interest, confidence, enjoyment, and task involvement. These judgments are expected to lead to user behaviors, which consist of decisions to continue playing the game or to expend more effort in the game. User behaviors, in turn, lead to system feedback or information about how the person is performing in the game. System feedback can then result in learners making more user judgments, causing the cycle to begin again.

After one or more iterations of the game cycle, debriefing occurs. Specifically, during debriefing, the events of the game are discussed and analyzed. Debriefing aids learners in making the transfer from what they have learned in the game to the real world. It also helps connect the game cycle to learning outcomes, which make up the outcome component of the Garris et al. (2002) model. These learning outcomes reflect what players have learned during the course of the game and include cognitive, skill-based, and affective learning outcomes. However, although the Garris et al. model describes how the learning process takes place, it does not explain why these features are motivating.

Pritchard and Ashwood (2008) Model of Motivation

A model of motivation that can help explain why game features are motivating is the Pritchard and Ashwood model (see Figure 2; Pritchard \& Ashwood, 2008, p. 20). The Pritchard and Ashwood model of motivation was chosen over other general motivation theories (e.g., reinforcement theory, equity theory, Vroom's Valence-InstrumentalityExpectancy theory; Adams, 1963; Skinner, 1969; Vroom, 1964), learning theories (e.g., constructivist theory, social learning theory, Bandura, 1977; Bruner, 1966), and training 


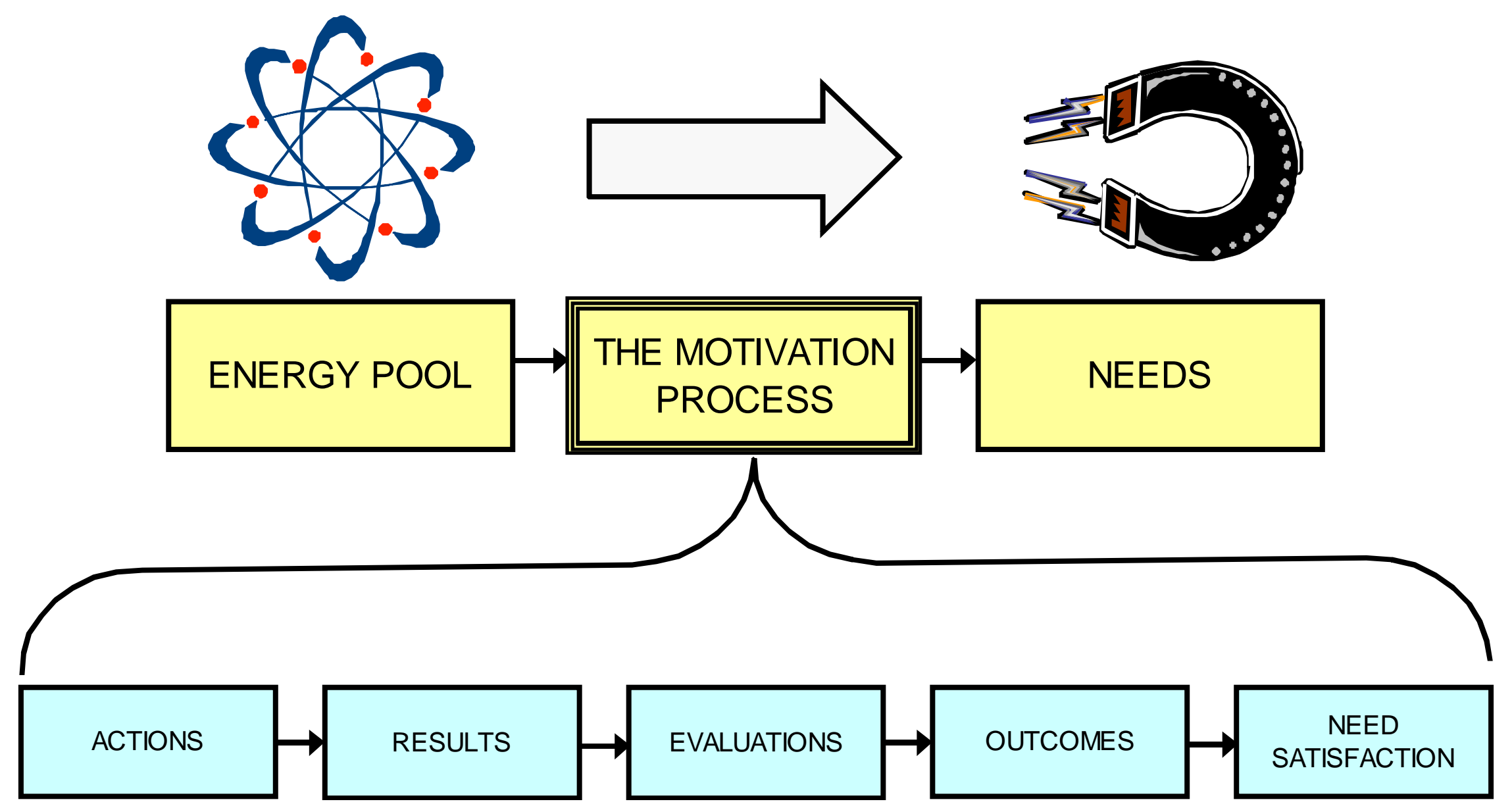

Figure 2: Pritchard and Ashwood (2008) Model of Motivation 
motivation theories (e.g., Colquitt, LePine, \& Noe, 2000; Mathieu, Tannenbaum, \& Salas, 1992) for two reasons.

First, the Pritchard and Ashwood (2008) model breaks the motivation process down into a series of steps, one of which (i.e., outcomes) is particularly applicable to the study of game features. Specifically, the outcomes step helps clarify how game features might result in variables, such as increased involvement, excitement, presence, or achievement, which, subsequently, can enhance learner motivation (more on this is discussed in the description of the model provided later in the chapter).

Because the Pritchard and Ashwood (2008) model measures outcomes in the motivation process, it can be applied across game features. It is likely that different game features will impact different outcomes in the motivation process. Although other theories of motivation and learning might be used to explain how a few game features impact outcomes in the motivation process (e.g., reinforcement theory might explain how rewards impact certain outcomes and goal setting theory might explain how rules and goals lead to various outcomes), these theories are not easily applicable to all game features. In particular, it would be difficult to explain how fantasy impacts motivation through an equity theory approach and it would be challenging to explain how sensory stimuli impact motivation through a social learning theory approach. The Pritchard and Ashwood model, in contrast, is applicable to all game features, as it takes into account how individual game features impact specific outcomes. As a result, this model can be used in future studies of game features to help explain why these features are expected to increase learner motivation. 
Second, it is important to note that training motivation theories, such as the integrated theory by Colquitt et al. (2000), are based upon more general theories of motivation. In fact, the Naylor, Pritchard, and Ilgen model of motivation [Naylor, Pritchard, \& Ilgen, 1980; the predecessor of the Pritchard and Ashwood (2008) model] was used in the development of Colquitt et al.'s training motivation model. Therefore, general motivation theories, such as the Pritchard and Ashwood model, have specific applications to the study of training motivation.

In the Pritchard and Ashwood (2008) model, motivation is defined as "the process used to allocate energy to maximize the satisfaction of needs" (Pritchard \& Ashwood, 2008, p. 14). In other words, motivation is driven by the desire to fulfill certain needs, and it is the way we distribute our energy resources to best meet these needs that determines our motivation. Needs can be almost anything but might include achievement, autonomy, power, or affiliation. These needs are said to act like a magnet, pulling and directing our energy towards their fulfillment (Pritchard \& Ashwood).

In Pritchard and Ashwood's (2008) basic motivation model (the top half of Figure 2), every individual is seen as having a pool of energy. Through the motivation process, individuals utilize energy from this pool to satisfy certain needs. In the bottom half of Figure 2, the authors break down the specific steps involved in the motivation process.

The first step is action. The action step refers to the physical or mental behaviors an individual performs (e.g., navigating a game character through a series of obstacles, creating a succession plan for an organization, writing the first chapter of a dissertation). To perform these behaviors, an individual utilizes a certain amount of energy from his/her resource pool. All choices to be made regarding actions (e.g., which actions to 
perform, the amount of effort to put forth in completing them, and how long to work on them) are left up to the individual performing them.

Actions lead to results. Results are the products of an individual's actions (e.g., a computer program developed following months of research and development). Results are not uniformly positive in terms of their impact on an individual or an organization. For example, the computer program mentioned previously could have a negative impact if the program enters the market at the same time that a more advanced (and less expensive) program does or if customers refuse to buy it. However, in terms of motivation, what really matters is how an individual's results are assessed and appraised by others (particularly those who can provide rewards or punishments for certain results). This brings us to the next step in the motivation process: evaluations.

According to Pritchard and Ashwood (2008), evaluations are "assessments of the value that results create" (p. 32). In a business setting, evaluations represent the worth of a particular result to an organization. When a result is highly valued, it is likely to be evaluated very positively by others in the organization. In contrast, if a result is not highly valued, evaluations might range from neutral to negative.

If a result is evaluated positively, it is likely to lead to certain outcomes, the next step in the Pritchard and Ashwood (2008) model. Outcomes are the consequences of good and bad evaluations, and they can vary significantly depending on the context. For instance, in a workplace setting, an outcome could be any number of things, such as a promotion, raise, day off, or, in the case of a bad evaluation, employment termination; in an educational setting, these outcomes would differ (e.g., outcomes might include getting extra recess time, not having to take a final exam, leaving class early). 
The final step in the motivation process is need satisfaction. According to Pritchard and Ashwood (2008), "the more need satisfaction we expect from an outcome, the more attractive the outcome." In other words, if an individual expects that an outcome will significantly meet one of his/her needs, this outcome is likely to be valued.

The portion of the Pritchard and Ashwood (2008) model that appears most applicable to game features and motivation is the outcomes component. It is likely that including certain game features within a training program will lead to particular outcomes (e.g., enjoyment, involvement). These outcomes may differ and/or their presence may be felt more strongly or weakly depending on the specific game features employed. For example, it is likely that including social interaction within a training program (a game feature that can be enhanced by using multiple players who work together to accomplish a common goal) will lead to particular outcomes, such as friendship or a greater appreciation for teamwork. These outcomes may not be the same for training programs that involve mystery or progress/surprise, which instead are likely to lead to outcomes such as excitement and exhilaration.

When game players experience these outcomes, they are likely to be motivated to continue experiencing these outcomes. In the case of a game used for training, this motivation would involve motivation to learn the material and to perform well in the training course. This motivation will help keep learners engaged and interested in the course material. As a result, they are likely to perform better during training than learners not experiencing these outcomes. 
Game Features Investigated in this Study: Multimedia-Based Fantasy and Reward

As can be seen from the research on games and game features described in the previous sections, there is a large base of literature comparing game-based instruction to non-game-based instruction and a relatively small base of literature investigating game features. It is time for research to focus more on game features so that it is possible to identify which game features contribute to learning, above and beyond the principles of good instructional design. This study focuses on two specific game features: multimediabased fantasy and reward.

Multimedia-based fantasy was chosen for investigation, because it is one of the most visible features of video/computer games. When players are introduced to a new game, the multimedia-based fantasy component is likely to be the first game characteristic to which they are exposed. Several researchers have described fantasy as an important game characteristic (e.g., Garris et al., 2002; Malone \& Lepper, 1987; Owen, 2004), although only a few have actually studied its impact on learning and motivation (e.g., Malone, 1981; Parker \& Lepper, 1992). In the following sections, I describe more about multimedia-based fantasy and how it is likely to influence a variety of motivational and training outcome variables.

Reward was also chosen for examination in this study, as this feature provides learners with important information about their performance in computer-based games (Vogel, Greenwood-Ericksen et al., 2006). Earning points and reaching new levels for completing tasks correctly in a game are rewards that game players take very seriously. Websites have been dedicated to publishing top scores for video gamers (e.g., http://members.aol.com/pbjurman/highscores.html, http://www.twingalaxies.com/), and, 
the creators of the Guinness Book of World Records have even decided to create a video game edition of the world-famous book that recognizes players' high scores on various games (Arendt, 2007). Only a limited amount of research has investigated the impact of rewards in computer-based instruction (e.g., Malone, 1981), and this feature is likely to have a tremendous impact on learner motivation and performance. In the following sections, I also discuss more about reward and its implications for motivation and training outcomes.

\section{Multimedia-based Fantasy}

According to Malone and Lepper (1987, p. 240), a fantasy environment "evokes mental images of physical or social situations not actually present (e.g., darts and balloons or being the ruler of a kingdom)." Fantasy offers players an escape from reality and requires them to engage their imaginations while playing the game (Wilson et al., in press). Moreover, fantasy allows players to experience new and novel situations and to respond to these situations risk-free (Driskell \& Dwyer, 1984; Garris et al., 2002). Gee (2003) refers to this lack of risk as the "psychosocial moratorium" that games offer. Essentially, this means that the consequences one faces within the game exist in the fantasy world only; they cannot and do not operate in the real world.

The literature has characterized fantasy as falling into one of two types:

endogenous and exogenous (or intrinsic and extrinsic; Malone, 1980, 1981, 1984; Malone \& Lepper, 1987; see Habgood, Ainsworth, \& Benford, 2005, for a debate on this topic). Endogenous fantasy requires a strong connection between the actual skill being trained and the fantasy presented (Malone \& Lepper, 1987). As Malone (1984) notes, in endogenous fantasies, "problems are presented in terms of the elements of the fantasy 
world, and players receive a natural kind of constructive feedback" (p. 86). An example of an endogenous fantasy would be the Darts game in which players have to estimate the location of a balloon on a number line (the estimate would be in the form of a fraction; Malone, 1980). When players estimate the location correctly, they are able to pop the balloon. The skill being learned in this case would be estimating fractions. Because the darts fantasy corresponds directly with this skill, the fantasy would be characterized as an endogenous fantasy.

In contrast, exogenous fantasy does not require a robust connection between the skill being learned and the fantasy learners experience (Malone \& Lepper, 1987). For example, a baseball game might be developed to teach word spelling (Malone, 1980). Progressing along the bases could be made commensurate with spelling words correctly. In this type of game, the fantasy would be unrelated to the actual skill being taught (i.e., spelling); thus, the baseball fantasy would be characterized as an exogenous fantasy. Because of the implicit link between the fantasy and the content of the training, endogenous fantasy has been proposed to be more motivating than exogenous fantasy (Malone, 1980; Malone \& Lepper, 1987), although Malone's (1981) study did not find this result.

Fantasy can also differ in the way it is presented to learners. For instance, fantasy can be described through written text or presented through more complex, multimediabased formats. Fantasy offered through text relies on a written portrayal of fantasy and requires that readers create the specific images and sounds of the fantasy in their own minds. In contrast, as the name implies, a multimedia-based format utilizes a variety of different instructional media, such as text, color, audio, and images (American Society 
for Training and Development, n.d.; Reeves, 1992) and allows viewers to read, see, and hear a fantasy as created by the multimedia developer. An analogy of the difference between the two can essentially be described as the difference between reading a book and seeing the movie. In a book (or text-based) version, readers follow along with the fantasy described for them by the author, but they must also use their imaginations to create the sights and sounds portrayed in the text. In contrast, in a movie (or multimediabased) version, the viewer follows along with a visual and audio fantasy that is created for them by the filmmaker. This fantasy is designed to stimulate a variety of different senses.

Multimedia-based fantasy is one game characteristic that is likely to impact motivation and training outcomes, such as the number of practice exercises completed, performance on practice exercises and learning tests, and training satisfaction. The Pritchard and Ashwood (2008) model of motivation can help to explain why the first of these variables, motivation, might result from using multimedia-based fantasy within a training program.

As mentioned previously, the component of the Pritchard and Ashwood (2008) model that is most applicable to the study of game features is the outcomes component. Outcomes can range from a feeling of achievement to a promotion at work. One outcome that is expected to result from including multimedia-based fantasy within a training program is a sense of presence. Presence has been defined as the "sense that one is within the game world, as opposed to experiencing oneself as a person outside the game, manipulating controls or characters” (Ryan, Rigby, \& Przybylski, 2006, p. 350). Although learners in both text-based fantasy and multimedia-based fantasy are likely to 
feel a sense of presence within the training program (particularly when asked to assume certain roles and responsibilities within the program), learners experiencing the fantasy through a multimedia presentation are likely to feel a stronger sense of presence, as they are able to see, hear, and, depending on the system, even move their character around the fantasy environment. Presence is likely to have certain psychological benefits for learners, including increased enjoyment and involvement during training tasks (Lombard $\&$ Ditton, 1997). The increased presence that individuals feel in multimedia-based versus text-based fantasy environments is likely to result in greater levels of overall motivation. Individuals feeling a sense of motivation in the game will likely be interested in completing additional activities that enhance their sense of presence and motivation. In a training program involving multimedia-based fantasy, one of these activities might entail completing practice exercises that involve interacting with other characters in the game, visiting additional areas of the game world, and testing the knowledge they've gained during the program. In the Garris et al. (2002) model, this additional practice might be considered part of the "game cycle;" in the game cycle, learners make the choice to continue playing the game or to expend more effort in the game. If participants choose to exert more effort (i.e., to complete more practice), this extra practice is likely to enhance their understanding of the training material.

Empirical research on multimedia-based instruction in general supports the idea that multimedia-based fantasy will increase learning outcomes (in terms of performance on both the practice exercises presented during training and learning test results). In particular, research has shown that using animation plus text produces better learning outcomes than using text alone, as graphics that supplement text help learners better 
process the material presented (e.g., Mayer, 1989; Mayer, Bove, Bryman, Mars, \& Tapangco, 1996; Mayer \& Gallini, 1990). Moreover, using animation plus narration has been shown to improve learning outcomes over narration alone, as the combination of pictures and words help learners to verbally and visually unite the concepts (e.g., Mayer \& Anderson, 1991). In a game-based setting, we can consider animation to be represented by the visual images of the characters and the fantasy setting. If using narration plus animation as well as text plus animation can increase learning outcomes, it is likely that employing multimedia-based fantasy (i.e., fantasy with animation, text, and narration) will improve learning outcomes over fantasy that uses text alone.

In addition to increasing motivation and learning outcomes, multimedia-based fantasy is also likely to lead to increased satisfaction with the training program. Learners in multimedia-based fantasy environments are able to see and hear virtual characters in while in training, and the sensory excitement associated with this is likely to make the learning environment more pleasurable and interesting to learners. Moreover, multimedia-based fantasy settings have been proposed to increase feelings of presence in learners, which has likewise been hypothesized to enhance learner enjoyment (Lombard \& Ditton, 1997). Learners in text-based fantasy environments, in contrast, only have a single sense stimulated (i.e., their sense of sight), and they are not given dynamic graphics, images, and sounds to help them conceptualize the fantasy described to them. As a result, learners given only written descriptions of fantasies are likely to enjoy training less and to evaluate it less highly than learners who are exposed to professionally designed multimedia-based fantasy environments. 
To date, it appears that only a limited amount of research has been done on the impact of fantasy on learning outcomes and motivation (e.g., Malone, 1981; Parker \& Lepper, 1992) and no research has empirically examined the impact of multimedia-based fantasy over text-based fantasy on motivation, satisfaction, the number of practice exercises completed, practice exercise performance, or learning test performance. This study provides an empirical test of the effect of multimedia-based fantasy on each of these variables.

Hypothesis 1: The inclusion of multimedia-based fantasy in a computer-based training program is expected to lead to (a) greater learner motivation, (b) a stronger feeling of presence, (c) greater satisfaction with the learning experience, (d) greater numbers of practice exercises completed, (e) greater performance on practice exercises, and (f) greater learning outcomes than text-based fantasy.

\section{Reward}

A video game feature that is likely to be a major motivating factor is reward. Rewards, in the form of points or other types of visible recognition, serve as a type of feedback during game playing on how well a player is performing (Vogel, GreenwoodEricksen et al., 2006). In addition, rewards can result in a feeling of success. While interviewing Pac-Man players about the motivational properties of the game, for instance, Bowman (1982) found that one of the players reported feeling a sense of accomplishment represented by the (i.e., points) Pac-Man offered. This player commented, "[During PacMan] you rack up medals for your achievement, disguised as points” (p. 14).

Unlike reality, in which rewards might be few and far between, in video games, rewards are constantly being offered for successful performance. As Johnson (2005) 
points out, "In the gameworld, reward is everywhere. The universe is literally teeming with objects that deliver very clearly articulated rewards: more life, access to new levels, new equipment, new spells" (p. 36).

Like multimedia-based fantasy, reward is likely to have a significant impact on learner motivation, the number of practice exercises completed, performance on practice exercises and learning tests, and satisfaction in computer-based training. The first of these variables, motivation, can also be explained through the Pritchard and Ashwood (2008) model.

As mentioned previously, the outcome component of the Pritchard and Ashwood (2008) model is the component most applicable to the study of game features. Outcomes in this model are the internal and external positive or negative events that occur during or after performance. While outcomes/rewards are important in understanding the motivating power of game features, the components that precede outcomes in the Pritchard and Ashwood model (i.e., actions, results, evaluations) help to explain how this game feature impacts motivation. The first step in the model, actions, involves the physical or mental behaviors an individual performs. In a training program, the actions taken by a learner might involve answering items in a set of practice exercises. Answering practice exercise items requires that individuals draw from their pool of energy in order to focus their attention on the material and to choose the correct answers. The next step in the Pritchard and Ashwood model involves results. Results are the products of an individual's actions. In a training program, results might be indicated by performance on practice exercises, i.e., whether practice exercises are answered correctly or incorrectly by a learner. One's raw score on these practice exercises represents a result. 
Results lead to the next step in the Pritchard and Ashwood (2008) model: evaluations. Evaluations represent a comparison of the level of results to some standard. So, whereas results are descriptive, e.g., $87 \%$ correct, evaluations translate that description into an evaluation from good to bad. Giving feedback that $87 \%$ correct is a good score is an evaluation. Performance on practice exercises (a result) might be evaluated in certain ways during training. In a training program offering rewards, evaluations for answering practice exercises correctly might consist of gaining expertise points, earning fake money, getting promoted to new levels in the training program, or some other indicator of how well the trainee is performing. Evaluations for responding incorrectly to practice exercises, in contrast, might consist of offering zero or negative expertise points, a zero-level increase or even a decrease in money earned, or holding a player from progressing to the next level in the training program.

The next step in the Pritchard and Ashwood (2008) model is the outcomes component. Outcomes are described as the consequences of good or bad evaluations. One potential outcome of earning a good evaluation during training (e.g., earning rewards) is experienced achievement. Two recent surveys of MMORPG users (e.g., Yee, 2006a, 2006b) revealed that many users play these games for the sense of achievement they feel. Winning items during the game (e.g., virtual objects, points) implies wealth and power (Yee, 2006a, 2006b), which leads to this feeling of achievement. Training programs that offer rewards representing one's status within the game, therefore, should lead to a feeling of achievement on the part of the learner. This feeling of achievement, in turn, is likely to lead to greater learner motivation during the game. 
This motivation is likely to lead to better learning outcomes (in terms of practice exercise and learning test performance) for learners receiving rewards. The Garris et al. (2002) model of games, motivation, and learning can be used to explain this. Because individuals receiving rewards are likely to be more motivated during training, they are likely to be more persistent and to spend more time interacting with the material than learners not receiving rewards for their performance. In addition, this motivation might lead them to complete more practice. As a result, they are likely to achieve better learning outcomes.

The impact of rewards on learning outcomes can also be explained through the research on learning and human behavior. This literature suggests that providing positive reinforcement for desired behaviors will encourage the future performance of these behaviors (e.g., Skinner, 1938, 1953). This reinforcement might take the form of praise, immediate prizes, tokens that can be saved up and used to claim prizes in the future (see the literature on token economies; e.g., Broden, Hall, Dunlap, \& Clark, 1970; O'Leary \& Becker, 1967) or, in the case of most games, points earned and the ability to reach new levels.

If, in a training program, rewards in the form of points are given for answering questions correctly, they are likely to reinforce behaviors associated with earning these rewards, such as studying the material carefully and memorizing facts in order to answer questions correctly. Consequently, offering rewards during a training program provides a strong potential for increasing learner outcomes in training. In particular, by focusing learner attention on the subject matter being presented, rewards have the potential to improve learning outcomes. 
Another variable that is likely to be influenced by offering rewards during computer-based training is learner satisfaction. Learners who are given rewards during training are recognized and praised for their efforts. Receiving this recognition and praise is likely to increase learners' overall evaluation of the training.

Like multimedia-based fantasy, only a limited amount of research has been conducted on the impact of reward on motivational appeal (e.g., Malone, 1981) and no research has been conducted on the individual influence of reward on training outcomes. This study, therefore, provides an empirical test of the effect of reward on motivation, satisfaction, the number of practice exercises completed, and performance on both practice exercises and a learning test.

Hypothesis 2: The presence of reward in a computer-based training program is expected to lead to (a) greater learner motivation, (b) a stronger sense of achievement, (c) greater satisfaction with the learning experience, (d) greater numbers of practice exercises completed, (e) greater performance on practice exercises, and (f) greater learning outcomes than the absence of reward.

\section{Interaction between Multimedia-based Fantasy and Reward}

As is demonstrated in the study by Greenwood-Ericksen (2008), game features can have multiplicative effects on learning outcomes. Therefore, in addition to having individual effects on learner motivation and training outcomes, multimedia-based fantasy and reward are expected to interact to affect these outcome variables. As multimediabased fantasy and reward are each expected to positively benefit motivation and training outcomes when used alone, it is expected that this positive impact will be enhanced when training combines these game features. In particular, when training involves both 
multimedia-based fantasy and reward, individuals are likely to be significantly more motivated, to complete more practice exercises, to perform better on the practice exercises and learning test, and to be more satisfied with the training course than learners who are given training text-based training without reward.

Hypothesis 3: In a computer-based training program, fantasy presentation format and the presence/absence of reward are expected to interact to affect (a) learner motivation, (b) satisfaction with the learning experience, (d) the number of practice exercises completed, (e) performance on the practice exercises, and (f) learning outcomes, such that the difference between text-based fantasy and multimedia-based fantasy on each of these outcome variables will be significantly greater when reward is present than when it is absent.

Motivation as a Mediator between Game Features and Learning and between Game Features and Training Satisfaction

As proposed in several models of training motivation (e.g., Colquitt et al., 2000) and motivation in learning games (e.g., Garris et al., 2002), motivation may mediate the relationship between game features and learning outcomes and between game features and training reactions. Specifically, game features such as multimedia-based fantasy and reward are likely to lead to increased learner motivation, which, in turn, is likely to improve learning outcomes and training satisfaction. The mediating effect of motivation is expected to apply to the relationship between multimedia-based fantasy and learning/reaction outcomes and between reward and learning/reaction outcomes. In particular, it is expected that both multimedia-based fantasy and reward will enhance 
motivation to learn, which, consequently, will lead to greater learning outcomes and training satisfaction in the training course.

Hypothesis 4: The relationship between fantasy presentation format and learning outcomes will be partially mediated by overall training motivation.

Hypothesis 5: The relationship between fantasy presentation format and training satisfaction will be partially mediated by overall training motivation.

Hypothesis 6: The relationship between reward and learning outcomes will be partially mediated by overall training motivation.

Hypothesis 7: The relationship between reward and training satisfaction is expected to be partially mediated by overall training motivation.

Motivational Outcome Variables as Mediators between Game Features and Overall Motivation

Game features are likely to lead to specific motivational outcome variables. In the context of a training program, these outcome variables are likely to enhance learner motivation. With respect to the game feature of fantasy presentation format, it is expected that multimedia-based fantasy will lead to greater feelings of presence in the fantasy world than text-based fantasy, which, in turn, will result in greater levels of motivation. Likewise, the presence of reward is expected to increase feelings of achievement during the training program relative to the absence of reward, which, subsequently will lead to increased motivation.

Hypothesis 8: The relationship between fantasy presentation format and overall training motivation will be partially mediated by outcome variables in the motivation process, specifically, a sense of presence in the fantasy environment. 
Hypothesis 9: The relationship between reward and overall training motivation will be partially mediated by outcome variables in the motivation process, specifically, a feeling of achievement during training.

Number of Practice Exercises Completed as a Mediator Between Motivation and Learning Outcomes

Individuals who are motivated in the training are likely to complete more practice exercises than individuals who are unmotivated. In turn, completing more practice is likely to lead to better performance on the learning test, if these practice exercises are similar in content and form to those in the practice. It is expected, therefore, that the relationship between motivation and learning outcomes will be mediated by the number of practice exercises learners complete.

Hypothesis 10: The relationship between motivation and learning outcomes will be partially mediated by the number of practice exercises that participants complete.

Training Programs offering both Multimedia-based Fantasy and Reward versus Traditional Computer-based Training Programs

Although traditional computer-based training programs (i.e., programs utilizing Microsoft Word or PowerPoint with minimal imagery and little to no audio or sound) have been found to improve self-efficacy and student attitudes over traditional lecturebased instruction (e.g., Susskind, 2003), these programs lack the engaging and motivational qualities of multimedia-based fantasy and reward described previously. As these qualities are likely to increase the amount of practice learners are willing to perform, their satisfaction with and performance during the learning program, and their learning outcomes, it is likely that building both multimedia-based fantasy and reward 
into a computer-based training program will result in better motivation and training outcomes than a traditional computer-based training program that lacks these game features.

Hypothesis 11: The combination of multimedia-based fantasy and reward in a computer-based training program is expected to lead to (a) greater overall training motivation, (b) greater satisfaction with the learning experience, (c) greater numbers of practice exercises completed, (d) greater performance on the practice exercises, and (e) greater learning outcomes than a traditional computer-based training program.

\section{Overall Study Purpose}

In response to the paucity of research on game characteristics, calls have gone out in the educational and training research communities for additional research on game features. In particular, a recent report by the Federation of American Scientists states, "Research is needed to develop a sound understanding of which features of games are important for learning and why, and how to best design educational games to deliver positive learning outcomes" (Federation of American Scientists, 2006, p. 5). This study provides empirical data regarding the efficacy of two game features for enhancing learner motivation and training outcomes: multimedia-based fantasy and reward.

Specifically, this study investigated whether including multimedia-based fantasy and reward within a training program impacted learner motivation during training, the number of practice exercises participants complete, performance on practice exercises, and learning test results. To test the effects of game features on motivation, outcomes in the motivational process were measured as well overall motivational levels. Learning outcomes were evaluated through recognition of the information presented during 
training (a measure of declarative knowledge-a cognitive learning outcome) and through hands-on testing (a measure of skill-based learning). These learning outcomes were measured in both the practice exercises given throughout the training and in the learning test given at the end.

All of the game features listed in Table 1 have been proposed to increase motivation and/or learning outcomes during training. To date, however, the literature on this subject has been primarily theoretical, identifying and describing the features that set video games apart from traditional training but not experimentally testing them. Only a few studies (e.g., Malone, 1981; Parker \& Lepper, 1992; Greenwood-Ericksen, 2008) have attempted to investigate the impacts of game features on motivational appeal, satisfaction, and learning outcomes.

As a result, this study continued the research begun by the small group of researchers mentioned previously and examined the effectiveness of using specific game features in training programs. Specifically, this study offered a systematic investigation of whether two game features-multimedia-based fantasy and reward-enhance overall learner motivation during training and outcomes in the motivation process, increase the number of practice exercises learners complete, boost training satisfaction, and improve practice and learning test results. 


\section{CHAPTER THREE: METHOD}

\section{Participants}

Participants were 169 students who were recruited from the research participant pool of a large southeastern university. For their participation, students received research participation credit and the opportunity to win a prize (i.e., a \$50 gift certificate to a local mall, restaurant, or electronics store; these prizes were awarded to the highest performer in each of the five conditions). Of the 169 participants, $59.2 \%$ were Caucasian, $17.2 \%$ were Hispanic/Latino, 12.4\% were African American/Black, 6.5\% were Asian American, and $4.7 \%$ categorized themselves as "Other" (e.g., Indian/ Norwegian, African American/Caucasian, Middle Eastern). A majority of the participants were female $(69.8 \%)$ and ranged in age from 17 to 35 years old $(M=19.41$ years, $S D=2.89)$.

Participants came from a variety of majors courses of study, including accounting, mathematics, aerospace engineering, communication, theatre, health sciences, information technology, and psychology. About half of these students played video games on a regular basis; specifically, $45 \%$ of them reported playing video games between 1 and 35 hours a week $(M=2.11$ hours a week, $S D=4.77)$.

\section{Design}

The study involved a two (multimedia- or text-based fantasy) by two (reward versus no reward) between-subjects design. Participants were randomly assigned to one of four experimental conditions: text-based fantasy, no reward; text-based fantasy, reward; multimedia-based fantasy, no reward; multimedia-based fantasy, reward; or to a 
traditional computer-based training condition that served as a baseline measure of learning, satisfaction, and learner motivation during computer-based instruction. The traditional computer-based training program did not involve the use of fantasy or reward.

The purpose of creating four experimental conditions was so that the independent effects of fantasy and reward on overall learner motivation and training outcomes could be systematically investigated, as well as the multiplicative impact of fantasy and reward on the dependent variables. In addition, the condition that used a more traditional training format allowed for a comparison of the benefits of each of these game features and their combinations over conventional computer-based training.

Procedure

Five versions of a computer-based training program were developed, corresponding to each of the four experimental conditions and the traditional computerbased training program condition. In order to investigate the impact of game features above and beyond the features of good instructional design, all five versions of the training: 1) included immediate feedback, 2) allowed learners to practice the material, 3) presented declarative knowledge first as the foundation for the skill-based learning, and 4) permitted mistakes. The only variables that were manipulated across conditions were fantasy presentation format and reward.

The training content itself focused on employment laws that govern selection practices. As training in employment law is fairly technical and involves the memorization of facts and vocabulary specific to the field of selection, this material was well suited for presentation via a learning game (see Prensky, 2001a). In the interest of providing a training program that can be completed in a timely manner, the training 
program covered only three employment laws: the Americans with Disabilities Act of 1990 (ADA), the Age Discrimination in Employment Act of 1967 (ADEA), and Title VII of the Civil Rights Act of 1964 (Title VII).

The pretest, the learning test, and the content and practice exercises of the training program were first pilot-tested on a group of students representative of those who would be participating in the study. As a result of this pilot test, the practice exercises and learning test questions were made slightly more difficult in order to ensure that a ceiling effect did not occur. In addition, after the computerized version of the training program was developed, it was tested again by a representative sample of students to ensure the functionality and ease of use of the programs. A few features were added (e.g., arrows on the ground telling participants where they needed to go next, text reminding them how to respond to different characters) and objects were moved around the fantasy world in order to allow participants to better traverse the environment.

When participants arrived at the study location, they were greeted by the research assistant and asked to complete an informed consent (see Appendix A), a demographics form (see Appendix B), and a pretest measuring their prior knowledge of the three EEO laws. They were then asked to read a description of the objectives of the training program (see Appendix C). After completing these items, participants were taken to a computer station to start the training program.

The training program began with an introduction, which described the participant's role during the training (a newly hired Equal Employment Opportunity Commission Compliance Officer who needs to learn about federal EEO law). The participant also received information outlining the goals of the training: (a) to gain 
knowledge of federal employment laws that govern hiring practices and (b) to practice evaluating job interview questions and applications for compliance with these laws.

To ensure that participants were motivated to learn, they were told that the highest performers in the study would be eligible to win a prize (i.e., a $\$ 50$ gift card to one of the three restaurants/stores mentioned previously). In addition, they were told: "The training will be useful to you for at least two reasons. The first is that in the future, you will graduate and seek employment. It is in your best interest to have a good understanding of employment legislation in order to protect yourself from unfair hiring practices. The second is that someday, you may participate in the hiring of other employees. It is your legal obligation to know the laws, which protect both you and your applicants."

Before moving into the actual content of the training, participants were given a short demonstration of how to use the training program. For participants in the text-based fantasy and traditional computer-based training conditions, this training was very brief (approximately 1 minute or less), as the technology used for this program only involved basic computer skills (e.g., using the keyboard to type out written responses to items, using the mouse to click "continue" and to select answers from a list of options). For participants in the multimedia-based fantasy condition, the training was longer but still somewhat brief (approximately five to ten minutes), as the training system involved some system-specific skills (e.g., how to move the character, how to speak and respond to other characters) but did not take a significant amount of time to master.

The setting of the training program was a town, referred to as "Fairness Town," composed of several businesses and stores that the participant's new boss asked them to visit. In the first half of the program, participants learned about EEO laws by speaking to 
business owners and employees about their past encounters with the EEOC. In describing their experiences, the characters provided participants with an overview of the ADA, ADEA, and Title VII.

Participants interacted with the characters in the program by typing in or selecting responses to the characters' questions. In one store, in fact, they needed to speak with the different characters in the store in order to retrieve a password that would open a trunk. The trunk directly addressed the participants in a whispery voice, asking them for the password. After providing the password, the trunk opened, providing participants with a list of the five classes protected by Title VII. In another store, participants had to find a book, which contained information about the ADA. When participants located the book, the book opened and the two sides of the book became wings, allowing the book to float. The book spoke to the participants, providing them with facts and figures about the ADA. Throughout the first part of the program, participants were followed around by a mentor character named Lumina, who periodically asked them questions about what they had learned. The mentor was presented as a glowing ball of light, which floated and spoke in an ethereal voice. Feedback and reward (depending on condition) were provided after each response.

In the second part of the training program, participants were given the opportunity to apply their knowledge of the three EEO laws by evaluating employer interview questions and application items for compliance with EEO legislation. Specifically, participants were given sample interview questions and application items for two companies in Fairness Town and were asked to identify when a question or item violated EEO law. When an item did, participants were asked to indicate which law it violated. As 
feedback is a characteristic of effective learning programs and not specifically a feature of videogames, feedback on the accuracy of responses and the correct answer was offered to all participants during the practice exercises.

As participants in the multimedia-based fantasy version needed to physically move their character around each business and from business to business and participants in the text-based fantasy simply read about their character's movements, it was expected that participants in the multimedia-based fantasy condition would take longer to complete the training program than participants in the text-based fantasy condition.

After participants completed the training program, they were debriefed about the purpose of the training program, as recommended by Garris et al. (2002). This debriefing was provided in a text-based format and was used to help participants make the link between what they experienced in training and the "real world" (see Appendices D and E). Participants were then asked to complete a series of measures, including the motivational outcome measures (i.e., achievement and presence), the overall training motivation measure, and the training satisfaction measure.

Following these measures, participants completed a learning test, which was very similar in content to the practice exercises. In the learning test, participants were again asked several informational questions about EEO legislation (measures of declarative knowledge) and were also asked to evaluate potential interview questions and employment applications for EEO compliance (measures of skill-based learning). Participants were then given one final measure to complete (the manipulation check). The study concluded with a debriefing of the purpose of the study (see Appendix F). In addition, participants were given a list of additional employment law resources they 
could consult, should they be interested in receiving more information on selection legislation (see Appendix G).

\section{Fantasy Manipulation}

Fantasy was manipulated by altering the way the training content was presented to participants. Although the actual material presented to all trainees was the same (i.e., all participants received the same information about EEO laws and the same practice

questions), half of the participants received the material over the computer in a text-based format (i.e., they read about characters and objects in Fairness Town; text-based fantasy) and the other half received it in a multimedia-based format (i.e., they heard and saw characters and objects in Fairness Town; multimedia-based fantasy). In order not to confound fantasy with storyline, participants in the text version of the training were given the same scenarios as participants in the multimedia-based fantasy condition; the only factor that differed was the graphic and audio presentation of the material.

The testbed for the multimedia-based fantasy version was created from a commercial off-the-shelf (COTS) video game called Neverwinter Nights ${ }^{\mathrm{TM}}$ (http://nwn.bioware.com). Neverwinter Nights ${ }^{\mathrm{TM}}$ is a role-playing game (i.e., a game in which players take on specific roles and are asked to complete particular missions; Dickey, 2006) created by Bioware that can be adapted by users for the development of their own games. In the traditional version of Neverwinter Nights ${ }^{\mathrm{TM}}$, players encounter a medieval world full of characters ranging from wizards to dragons. In the training program developed for this study, players interacted with the business owners and employees of various companies in a small town. In order to accomplish this, a game 
designer adapted the original Neverwinter Nights ${ }^{\mathrm{TM}}$ game to create the appropriate context to support the training.

The text-based fantasy training program was developed using Visual Basic and, as mentioned previously, only involved a written presentation of the material. Practice exercises and immediate feedback were still provided in this version of the training as well as rewards for participants in the "text-based fantasy, high reward" condition.

\section{Reward Manipulation}

In the reward condition, the reward feature was manipulated by giving participants praise/recognition and points in the form of virtual dollars (i.e., increases in their character's annual salary) for every question they answered correctly throughout the training program. In the first half of the training, each correct response resulted in a $\$ 100$ pay increase. After participants had answered 10 questions correctly, i.e., increased their pay by $\$ 1000$, they were promoted to a higher position (i.e., Compliance Officer Level 2, Compliance Officer Level 3, and so on). In the second half of the training, each correct response resulted in a \$200 pay increase. Participants were promoted more frequently in this condition, as they only had to answer 5 questions correctly in order to be promoted to a new level of Compliance Officer.

In the no reward condition, participants did not receive any rewards for answering questions correctly. They were only given feedback on the accuracy of their responses as well as the correct response. 


\section{Traditional Computer-Based Training Program Condition}

The traditional computer-based training program condition was developed using the same technology as the text-based fantasy condition (i.e., Visual Basic). This condition was created to represent more conventional computer-based training programs (i.e., programs offered through PowerPoint). In this condition, participants received the same information about the ADA, ADEA, and Title VII and the same practice items, although the training was not presented through a fantasy context. In other words, no fantasy storyline, graphics, or sounds were included in this version of the training program, and the presentation was primarily presented through a bulleted list format. In addition, practice and feedback were provided throughout the training program; however, no rewards were offered for answering questions correctly. As participants in the traditional computer-based training condition were given information about the ADA, ADEA, and Title VII through a bulleted list format rather than through an intricate storyline tying the information together, they were expected to take less time to complete the training program than participants in both the text-based fantasy and multimediabased fantasy conditions.

\section{Measures}

\section{Demographics Questionnaire}

Participant demographics information was collected, such as age, sex, ethnicity, class standing, job experience, and previous experience with web-based and computerbased instruction. Participants were asked to rate their familiarity with the ADA, ADEA, 
and Title VII, their computer knowledge, and their Neverwinter Nights ${ }^{\mathrm{TM}}$ expertise. See Appendix B for a full list of the demographics questions.

\section{Pretest}

The pretest assessed what participants already knew about employment legislation before beginning the training program and consisted of true/false and multiple-choice questions. The questions specifically asked about participants' pre-training knowledge of the ADA, ADEA, and Title VII. The number of correct responses to these items was summed to create a total score for the pretest. Some example items are: "What does ADA stand for?" (a) Age Discrimination Act, (b) Americans with Disabilities Act, (c) Antidiscrimination Act, (d) Anti-disabilities Act, or (e) Don't know (answer = B); "It is a good practice to ask a job candidate to provide you with the years that he/she attended high school in order to verify whether the candidate has a high school diploma." True, False, or Don't know (answer = False); and "According to Title VII of the Civil Rights Act, an employer cannot discriminate against an applicant because of his or her marital status." True, False, or Don't know (answer $=$ False). There were a total of 12 items on the pretest.

\section{Practice Exercises}

Similar to the pretest items, the practice exercises were composed of multiplechoice and true/false questions measuring participant declarative knowledge of the three EEO laws presented during training. In addition, participants were asked to apply their knowledge of selection laws in evaluating interview questions and application items for compliance with EEO legislation. Specifically, participants were given a set of interview 
questions, and, for each question on the list, they were asked to indicate which employment law it violated. Available responses included the ADA, ADEA, Title VII, or none of these laws. Participants were asked to do the same thing for an application blank. All practice exercises were optional during the training program; however, participants were told that the practice exercises would help them prepare for the learning test they would take after they completed the training.

The true-false and multiple-choice practice exercises were presented in the first half of the training. The evaluation of the interview questions and application items were only given after the participant had completed learning about the three EEO laws (i.e., the second half of training). Feedback was given to participants about the accuracy of their response and the correct answer after each practice exercise. For each answer that a participant answered correctly, they received 100 points (or $\$ 100$ added on to their base salary). Scores on each of the practice exercises were summed to provide a total score.

Some example items from the first half of the training are: "True or False:

According to the ADA, disabilities can be both physical and mental." (answer = True); "Who is NOT protected by the ADEA? (a) Individuals over 65 years old (the traditional retirement age), (b) Individuals over 90 years old, (c) Individuals 40-65 years old, (d) Individuals under 40 years old, and (e) All of the above" $($ answer $=D)$; and "True or False: Title VII protects individuals against discrimination on the basis of race, color, religion, sexual orientation, and national origin." $($ answer $=$ False $)$.

Example items from the second half of the training include: "Where were you born?" This question may violate: (a) the Americans with Disabilities Act, (b) the Age Discrimination in Employment Act, (c) Title VII of the Civil Rights Act, or (d) None of 
the Above. (answer = Title VII of the Civil Rights Act); and "This job includes a health insurance plan. Can you please give me an overall description of your health history?" This question may violate: (a) the Americans with Disabilities Act, (b) the Age Discrimination in Employment Act, (c) Title VII of the Civil Rights Act, or (d) None of the Above. (answer $=$ the Americans with Disabilities Act). There were 15 declarative knowledge practice exercises given during the training and 23 skill-based practice exercises.

\section{Overall Training Motivation}

Overall motivation experienced in the training program was measured through the Overall Motivational Force (level one assessment) items of the Motivation Assessment Questionnaire (MAQ). The MAQ is an instrument that has been developed to measure the motivation of individuals in workplace organizations and is currently undergoing validation. The MAQ was developed to measure the different components of the Pritchard and Ashwood (2008) model of motivation and can be used to assess motivation at three hierarchically organized levels (the third level of which is the most detailed and provides the most diagnostic information for organizations looking to alter the current motivational state of their employees). For this study, the Overall Motivational Force items from the level one assessment were used, as these items provided the most general assessment of overall motivation (Pritchard, 2006).

Motivational force is defined as a "person's perceptions of the degree to which changing the amount of time and energy devoted to an action will lead to changes in the level of his/her anticipated need satisfaction" (Pritchard, 2006, p. 3). This variable corresponds to the motivational process component of the Pritchard and Ashwood (2008) 
model. Overall Motivational Force, in turn, raises motivational force from the level of individual actions to the level of the job. In particular, Overall Motivational Force refers to "the degree to which changing the overall amount of time and energy devoted to the job will change the overall level of need satisfaction" (Pritchard, 2006, p. 3). In other words, rather than looking at the motivational force behind specific actions, Overall Motivational Force provides an overall measure of workplace motivation.

The items from the Overall Motivational Force scale were adapted slightly for use in this study. In particular, when necessary, the questions were altered so that they referred to the individual's overall motivation during the training program. Example items from the adapted scale include: "Overall, how motivated were you to do a good job in the training?" (Answers are on a five-point scale ranging from $1=$ not at all to $5=$ very highly motivated) and "I consistently put forth the maximum effort possible during the training today" (Answers are on a five-point scale ranging from $1=$ strongly disagree to 5 = strongly agree). The items in the Overall Motivational Force scale were reverse-scored when necessary and summed to create an overall training motivation score. There were 7 items included in this measure with a maximum total score of 36.

\section{Feeling of Achievement}

Feeling of achievement was measured through a three-item measure. Participants were asked to rate their level of agreement with the following items on a five-point scale $(1$ = strongly disagree, 5 = strongly agree $)$ : "I felt a sense of achievement during the training program," "I felt successful in the training I just completed," and "I accomplished quite a bit during today's training." These three items were summed to create an overall measure of a participants' feeling of achievement during the training. 


\section{Presence}

Previous studies of presence in games and virtual reality systems have examined presence as a mediator (e.g., Nowak, Krcmar, \& Farrar, 2008; Persky \& Blaskovich, 2008) and as a dependent variable (e.g., Bouchard, St-Jacques, Robillard, \& Renaud, 2008). In this study, presence was analyzed as both a mediator and a dependent variable, as it was expected that including certain game features in the training program would cause participants to feel like they were mentally and physically present in the fantasy world and that this feeling would improve their motivation to learn the training content.

Presence was measured through the "Player Experience of Need Satisfaction (PENS): Presence” scale developed by Ryan et al. (2006). The PENS: Presence scale measures three types of presence experienced by game players: emotional presence, physical presence, and narrative presence. Three items measure each type of presence for a total of nine items. Ryan et al. reports a coefficient alpha of .85 for the nine items.

The items from the PENS: Presence scale were adapted for use in this study. In particular, any items that discussed actions, such as "moving around" the game, were adapted so that they referred to "interacting with" or "participating in" the learning environment. This change was made to ensure that the items were applicable to participants in the text-based fantasy condition (participants who were not able to physically travel through the learning environment) as well as participants in multimediabased fantasy conditions. In addition, when possible, the items were altered so that they referred specifically to Fairness Town and not simply to a virtual world, and any reference to the program as a "game" was replaced with phrases like "training program" or "learning environment," as not all participants viewed the program as a game. 
Example items from this measure include: "While participating in the training program, I felt as if I was actually in Fairness Town" (physical presence); "I experienced feelings as deeply in the training program as I have in real life" (emotional presence); and "When participating in the training program, I felt as if I was part of the story" (narrative presence). Items were scored on a seven-point Likert-type scale $(1=$ Not at all; $7=$ Very much).

\section{Training Satisfaction}

Satisfaction with the training program was measured through a reactions scale adapted from Ricci et al. (1996). This scale is composed of five items: "This form of instruction was enjoyable," "I learned a lot about equal employment opportunity law during today's training session;" I feel confident I will remember what I learned today;" "I would prefer this form of instruction in my college courses;" and "This program wasted my time" (reverse coded). Ricci et al. report an alpha coefficient of .85 for the five items.

In completing the measure, participants were asked to rate their level of agreement with each of these items on a five-point scale $(1=$ Strongly Disagree; $5=$ Strongly Agree). Ratings for the five items were summed to create a total training satisfaction score.

\section{Learning Test}

Like the practice exercises, the learning test was composed of multiple-choice and true/false questions, which measured the participant's declarative knowledge of the ADA, ADEA, and Title VII. The first 12 items on this test were the same 12 items on the pretest 
so that change in learning could be measured. In addition, skill-based learning was measured as participants were asked to evaluate a set of interview questions and an application blank for EEO violations. Participants did not receive feedback on their answers to the learning test. For every question that a participant answered correctly, he/she received one point. Points were summed across the learning test items to obtain a total score. There were a total of 31 declarative knowledge items on the learning test and 23 skill-based learning items.

\section{Manipulation Check}

To measure whether participants were aware of various manipulations in the study (i.e., reward manipulations, fantasy manipulations), two items assessed participant perception of these variables. These items were: "During the training, I was rewarded for answering questions correctly by: (1) receiving feedback, praise, and 'money' added on to my character's base salary or (2) receiving feedback only" and "The training: (1) took place in a fantasy world in which I was able to physically see, hear, and interact with other characters, (2) took place in a fantasy world in which I was able to read about interactions with other characters, or (3) did not take place in a fantasy world." For each of these questions, participants were asked to select the answer that best described the training they received.

Participants in the reward condition should have chosen answer 1 for the first question, as this condition involved the use of feedback, praise, and points in the form of "money," whereas participants in the no reward and the traditional computer-based training program conditions should have chosen answer 2 , as only feedback was given in these conditions. For the second question, participants in the multimedia-based fantasy 
condition should have chosen answer 1, as learners in this condition interacted with other characters (i.e., avatars) that they were able to both see and hear; participants in the textbased fantasy condition should have chosen answer 2 , as this condition involved only a text-based description of character interactions; and participants in the traditional computer-based training program condition should have chosen answer 3, as this condition did not utilize fantasy in the presentation of training material.

To assess whether the reward feature was motivating to participants, participants were asked to rate their level of agreement with the following statement: "I was motivated to answer questions correctly during the training program so that I could earn 'money' and praise/recognition for my character." The item was scored on a six-point Likert-type scale $[1=$ strongly disagree, $5=$ strongly agree, $6=I$ did not receive 'money' or praise during the training program]. Participant response to this item provided an indication of how motivating the reward feature was to participants. Participants in the no reward and traditional, computer-based training program conditions were expected to choose answer 6 when responding to this item, as they did not receive points in the form of 'money' or praise for answering questions correctly during the training program.

Two additional items measured participants' perceptions of how game-like the training programs appeared to them. In particular, participants were asked to rate on a scale from one to five their level of agreement $(1=$ strongly disagree, $5=$ strongly agree $)$ with each of the following items: "This training system is similar to computer/video games that I've played in the past" and "This training system felt like a game." This information was used to evaluate the effectiveness of the manipulations. In particular, it was expected that participants in the multimedia-based fantasy condition would rate the 
items higher (i.e., would perceive the training program to be more game-like) than participants in the text-based fantasy and traditional, computer-based program conditions, Moreover, participants in the reward condition were expected to rate both of the items higher than participants in the no reward and traditional program conditions. 


\section{CHAPTER FOUR: RESULTS}

All analyses were performed using SPSS 13.0 for Windows at an alpha level of significance of .05 , unless otherwise stated. Table 2 provides the means, standard deviations, reliabilities, and intercorrelations among the study variables. Cronbach's alpha for all measures was acceptable and in line with previous research. An adequate amount of variance was found for each dependent variable, although this variance was somewhat low for the skill-based practice and skill-based learning test items $(S D=.08$ and .07 , respectively). Performance on the declarative and skill-based practice exercises was moderately correlated $(r=.21, p=.01)$ as was performance on the declarative and skillbased learning test items $(r=.27, p=.00)$; this was not surprising given that the declarative knowledge presented during the training was the foundation for the skill-based learning. In addition, a few individual difference variables (e.g., sex, interest in learning about employment law) were found to significantly relate to one or more dependent variables, including motivation, achievement, sense of presence, training satisfaction, and performance on the skill-based practice exercises.

\section{Manipulation Check}

The majority (96\%) of participants correctly identified the fantasy and reward manipulations they experienced during the training. The six participants who did not were removed from the sample. To test the whether the manipulations were effective in making the training program appear game-like, independent samples $t$-tests were conducted comparing participant responses to the item, "This training system is similar to 
Table 2: Means, Standard Deviations, Reliabilities, and Intercorrelations Among the Study Variables

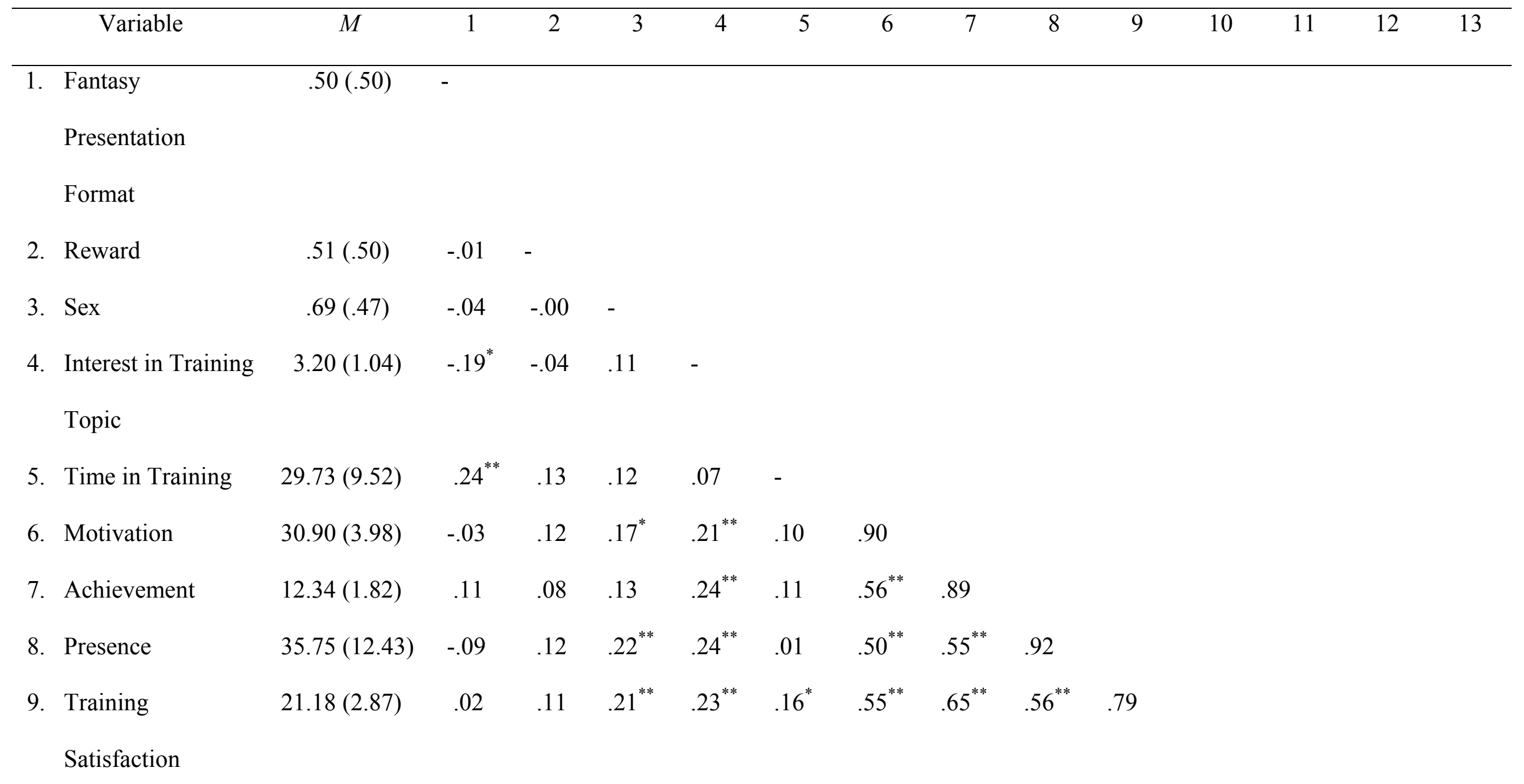




\begin{tabular}{|c|c|c|c|c|c|c|c|c|c|c|c|c|c|c|}
\hline Variable & $M$ & 1 & 2 & 3 & 4 & 5 & 6 & 7 & 8 & 9 & 10 & 11 & 12 & 13 \\
\hline 10. Number of Practice & $35.93(7.45)$ & -.13 & .15 & .02 & .11 & $.27^{* *}$ & $.30^{* *}$ & $.17^{*}$ & .10 & $.24^{* *}$ & - & & & \\
\hline \multicolumn{15}{|l|}{ Items Completed } \\
\hline 11. Declarative & $.81(.12)$ & .06 & .11 & -.04 & .11 & $.20^{* *}$ & $.16^{*}$ & .13 & .05 & .15 & $.40^{* *}$ & - & & \\
\hline \multicolumn{15}{|l|}{ Practice Proportion } \\
\hline \multicolumn{15}{|l|}{ Correct } \\
\hline 12. Skill-based & $.86(.08)$ & .09 & .03 & .02 & $.17^{*}$ & .00 & .10 & $.17^{*}$ & .10 & .02 & -.05 & $.21^{*}$ & - & \\
\hline \multicolumn{15}{|l|}{ Practice Proportion } \\
\hline \multicolumn{15}{|l|}{ Correct } \\
\hline 13. Declarative Test & $.66(.11)$ & .08 & -.09 & .07 & .04 & -.03 & .06 & .09 & -.13 & .10 & -.08 & $.20^{*}$ & .16 & - \\
\hline \multicolumn{15}{|l|}{ Proportion Correct } \\
\hline 14. Skill-based Test & $.92(.07)$ & -.05 & .15 & .01 & .05 & .02 & $.23^{* *}$ & .14 & -.04 & .15 & .13 & $.22^{* *}$ & $.26^{* *}$ & $.27^{* *}$ \\
\hline Proportion Correct & & & & & & & & & & & & & & \\
\hline
\end{tabular}

Note. Reliabilities are on the diagonal. Standard deviations are enclosed in parentheses. $N \mathrm{~s}$ range from 125-163.

${ }^{*} p<.05 .{ }^{* *} p<.01$ 
computer/video games I've played in the past." Participants in the multimedia-based fantasy condition more strongly agreed $(M=3.40$ out of $5, S D=1.00)$ with this statement than participants in both the text-based fantasy $(M=2.65, S D=1.13), t(131)=4.06, p=.00$, and traditional computer-based training conditions $(M=1.70, S D=.88), t(95)=8.04, p=.00$. Likewise, participants in the reward condition more strongly agreed $(M=3.29, S D=1.07)$ with this statement than participants in the no reward $(M=2.75, S D=1.13), t(131)=2.83$, $p=.01$, and traditional computer-based training conditions $(M=1.70, S D=.88), t(96)=7.18$, $p=.00$. When the condition with the most game features (i.e., the condition with both multimedia-based fantasy and reward) was compared to the traditional computer-based training condition, participants in the most game-like version more strongly agreed with the statement $(M=3.62, S D=1.05)$ than participants in the traditional computer-based training condition $(M=1.70, S D=.88), t(62)=7.89, p=.00$. Similar results were found for the item, "This training system felt like a game." Thus, participants in the reward condition, the multimedia-based fantasy condition, and the condition combining these game features viewed the programs as more game-like than participants in the other versions, providing additional support for the study manipulations.

Participants in the reward condition also responded very highly to the item, "I was motivated to answer questions correctly during the training program so that I could earn praise and 'money' for my character" ( $M=4.41$ out of $5, S D=.90)$. This finding suggests that the potential of earning money and praise during training was motivating to participants. 


\section{Initial Equivalency of Conditions}

To ensure that groups were equivalent on pretest scores prior to training, pretest scores were compared across the five conditions. A one-way ANOVA was conducted, in which study condition was the independent variable and pretest score was the dependent variable. Post-hoc tests between each condition revealed no significant differences in participant knowledge of EEO law prior to participating in the training (see Table 3). This finding suggests that the conditions were equivalent in terms of pre-training knowledge of EEO law.

\section{Effectiveness of Training across Conditions}

Before testing the impact of fantasy presentation format and reward on motivation and training outcomes, the effectiveness of the training in teaching all participants about employment law was tested. To do this, pretest scores measured prior to training were compared to posttest scores collected after the training. The pretest was composed of 12 items measuring participant pre-training declarative knowledge of EEO law. These same 12 items were also included at the beginning of the learning test in order to test the effectiveness of the training. A paired samples $t$-test comparing pretest to posttest scores revealed that across the entire sample, participants significantly improved their knowledge of the ADA, ADEA, and Title VII following training, $t(162)=-41.27, p=.00$, $M=4.35, S D=1.85$ for the pretest, $M=10.96, S D=1.06$ for the post-test). This finding suggests that, across conditions, the training was effective in increasing participant knowledge about employment law. 
Table 3: Scheffé Post Hoc Tests Comparing Pretest Scores between Conditions

\begin{tabular}{|c|c|c|c|}
\hline Training Condition (I) & Compared to Training Condition $(\mathrm{J})$ & Mean Difference (I-J) & Standard Error \\
\hline \multirow[t]{4}{*}{ Traditional Version } & Text-based Fantasy, No reward & -.02 & .47 \\
\hline & Text-based Fantasy, Reward & -.57 & .46 \\
\hline & Multimedia-based Fantasy, No Reward & .07 & .47 \\
\hline & Multimedia-based Fantasy, Reward & -.51 & .46 \\
\hline \multirow[t]{4}{*}{ Text-based Fantasy, No Reward } & Traditional Version & .02 & .47 \\
\hline & Text-based Fantasy, Reward & -.55 & .46 \\
\hline & Multimedia-based Fantasy, No Reward & .10 & .46 \\
\hline & Multimedia-based Fantasy, Reward & -.49 & .46 \\
\hline \multirow[t]{4}{*}{ Text-based Fantasy, Reward } & Traditional Version & .57 & 46 \\
\hline & Text-based Fantasy, No reward & .55 & .46 \\
\hline & Multimedia-based Fantasy, No Reward & .65 & .45 \\
\hline & Multimedia-based Fantasy, Reward & .06 & .45 \\
\hline
\end{tabular}




\begin{tabular}{clcc}
\hline Training Condition (I) & Compared to Training Condition (J) & Mean Difference (I-J) & Standard Error \\
\hline Multimedia-based Fantasy, No Reward & Traditional Version & -.07 & .47 \\
& Text-based Fantasy, No Reward & -.10 & .46 \\
& Text-based Fantasy, Reward & -.59 & .45 \\
& Multimedia-based Fantasy, Reward & .51 & .45 \\
\hline Multimedia-based Fantasy, Reward & Traditional Version & .49 & .46 \\
& Text-based Fantasy, No reward &. .06 \\
& Text-based Fantasy, Reward & .45 \\
& Multimedia-based Fantasy, No Reward & .59 \\
\hline
\end{tabular}

${ }^{*} p<.05 .{ }^{* *} p<.01$ 
To test for between-group differences, a one-way ANOVA was conducted in which study condition was the independent variable and change from pretest to posttest was the dependent variable. Post hoc tests revealed no significant between-group differences on learning from pre- to posttest, indicating that the learning gain as indicated by the 12 -item test was equivalent across the five conditions (see Table 4). As will be discussed later in the chapter, however, additional measures of learning did reveal some between-group differences.

\section{Time Spent in Training}

Across conditions, the average time spent in the training course was 29.73 minutes $(S D=9.52)$. As participants in the four experimental conditions were expected to spend more time in training than participants in the traditional, computer-based training condition and participants in the multimedia-based fantasy conditions were expected to spend more time in training than participants in the text-based fantasy conditions, planned comparisons were used to test these predictions. An independent samples $t$-test revealed that participants in all four experimental conditions took longer to complete the training than participants in the traditional computer-based training condition, $t(157)=9.80, p=.00$ (see Table 5 for the means and standard deviations of the five conditions). In addition, participants in the multimedia-based fantasy conditions spent significantly more time in the course $(M=34.33, S D=7.36)$ than participants in the textbased fantasy conditions, $t(131)=2.88, p=.01, M=30.48, S D=8.05)$. 
Table 4: Scheffé Post Hoc Tests Comparing Pretest-Posttest Differences between Conditions

\begin{tabular}{|c|c|c|c|}
\hline Training Condition (I) & Compared to Training Condition (J) & Mean Difference (I-J) & Standard Error \\
\hline \multirow[t]{4}{*}{ Traditional Version } & Text-based Fantasy, No reward & .50 & .52 \\
\hline & Text-based Fantasy, Reward & .65 & .51 \\
\hline & Multimedia-based Fantasy, No Reward & .18 & .52 \\
\hline & Multimedia-based Fantasy, Reward & .74 & .51 \\
\hline \multirow[t]{4}{*}{ Text-based Fantasy, No Reward } & Traditional Version & -.50 & .52 \\
\hline & Text-based Fantasy, Reward & .15 & .51 \\
\hline & Multimedia-based Fantasy, No Reward & -.32 & .51 \\
\hline & Multimedia-based Fantasy, Reward & .24 & .51 \\
\hline \multirow[t]{4}{*}{ Text-based Fantasy, Reward } & Traditional Version & -.65 & .51 \\
\hline & Text-based Fantasy, No reward & -.15 & .51 \\
\hline & Multimedia-based Fantasy, No Reward & -.47 & .50 \\
\hline & Multimedia-based Fantasy, Reward & .09 & .50 \\
\hline
\end{tabular}




\begin{tabular}{clcc}
\hline Training Condition (I) & Compared to Training Condition (J) & Mean Difference (I-J) & Standard Error \\
\hline Multimedia-based Fantasy, No Reward & Traditional Version & -.18 & .32 \\
& Text-based Fantasy, No Reward & .47 & .51 \\
& Text-based Fantasy, Reward & .55 & .50 \\
& Multimedia-based Fantasy, Reward & -.18 & .50 \\
\hline Multimedia-based Fantasy, Reward & Traditional Version & .32 & .52 \\
& Text-based Fantasy, No reward & .51 \\
& Text-based Fantasy, Reward & .50 \\
& Multimedia-based Fantasy, No Reward & .50 \\
\hline
\end{tabular}

${ }^{*} p<.05 .{ }^{* *} p<.01$ 
Table 5: Time Spent in Training in Each Condition

\begin{tabular}{lc}
\hline \multicolumn{1}{c}{ Training Condition } & $M$ \\
\hline Traditional Computer-Based Training & $17.47(6.03)$ \\
Text-based Fantasy, No reward & $29.03(9.26)$ \\
Text-based Fantasy, Reward & $31.84(6.56)$ \\
Multimedia-based Fantasy, No Reward & $33.67(8.92)$ \\
Multimedia-based Fantasy, Reward & $34.97(5.51)$ \\
\hline
\end{tabular}

Note. Standard deviations are enclosed in parentheses.

${ }^{*} p<.05 . * * p<.01$

Tests of Hypotheses

Hypotheses 1, 2, and 3 predicted that fantasy presentation format and reward would have significant main and interactive effects on learner motivation, satisfaction, the number of practice exercises completed, practice exercise performance, and learning outcomes. In particular, multimedia-based fantasy and the presence of reward were predicted to result in greater outcomes for each of these variables than text-based fantasy and the absence of reward, respectively. It was also hypothesized that multimedia-based fantasy and reward would lead to certain motivational outcome variables; specifically, multimedia-based fantasy was predicted to lead to a greater sense of presence in the fantasy world than text-based fantasy, and the presence of reward was predicted to result in a greater feeling of achievement than the absence of reward.

A $2 \times 2$ MANOVA was conducted to test these three hypotheses, in which fantasy presentation format and reward were the independent variables and learning motivation, 
sense of presence, feeling of achievement, training satisfaction, number of practice exercises completed, performance on declarative and skill-based practice exercises, and performance on declarative and skill-based learning test items were the dependent variables. No significant main effects were found for fantasy presentation format, Wilks' Lambda $=.90, F(9,113)=1.42, p=.19$, partial $\eta^{2}=.10$, or reward, Wilks' Lambda=.93, $F(9,113)=1.02, p=.43$, partial $\eta^{2}=.08$, on the dependent variables. In addition, the interaction between fantasy presentation format and reward was not significant (Wilks' lambda $=.94, F(9,113)=.82, p=.60$, partial $\eta^{2}=.06$. Although several potential covariates were identified (e.g., time spent in training, sex, academic year, interest in learning about employment law), adding these covariates to the test of hypotheses 1-3 did not improve results.

Hypotheses 4-7 predicted that the relationship between the game features of fantasy presentation format and reward and each training outcome variable (i.e., learning outcomes and training satisfaction) would be partially mediated by overall training motivation. Hypotheses 8 and 9 , in turn, predicted that the relationship between each game feature and overall training motivation would be mediated by specific outcome variables in the motivation process (i.e., a sense of presence when fantasy presentation format was the offered and a feeling of achievement when reward was present).

These hypotheses were unable to be tested, as no significant predictor-outcome or predictor-mediator relationships were found, both of which are required to test mediation in the Baron and Kenny model (1986). However, several mediator-outcome relationships were supported. Specifically, overall training motivation was found to be significantly related to scores on skill-based items on the learning test $(r=.23, p=.00)$, to scores on 
declarative items in the practice exercises $(r=.16, p=.04)$, and to training satisfaction $(r=.55, p=.00)$. In other words, the greater the participants' motivation to learn the training material, the better they did on the declarative practice exercises and on the skillbased learning test and the more satisfied they were with the training program.

The participants' sense of presence and feeling of achievement were also found to be significantly related to overall training motivation $(r=.50, p=.00$ for presence, $r=.56$, $p=.00$ for achievement). In particular, the greater the participants' sense of being present in the fantasy world and the greater the participants' feeling of achievement during the training, the greater their motivation to learn the training material.

Hypothesis 10 predicted that the relationship between overall motivation and learning outcomes would be mediated by the number of practice exercises that participants completed. Support was found for step 1 in the Baron and Kenny (1986) model, which requires that a significant predictor-outcome relationship be established. In particular, motivation (the predictor) was found to be significantly positively related to performance on both the declarative practice items $(r=.16, p=.04)$ and the skill-based learning test $(r=.23, p=.00)$, suggesting that as motivation increased, so did performance on each of these learning measures. Support was also found for step 2 in the Baron and Kenny model; specifically, a significant positive relationship between overall motivation (the predictor) and the number of practice exercises completed (the mediator; $r=30$, $p=.00$ ). This finding suggests that as motivation increased, so did the number of practice exercises participants completed.

As both prerequisites for testing mediation were met, a multiple regression analysis was conducted using the enter method. Declarative practice exercise proportion 
correct was regressed on both learner motivation and the number of practice exercises completed. The overall model was significant, $F(2,159)=15.61, p=.00, R^{2}=.16$. In particular, the number of practice exercises completed was found to be a significant predictor of declarative practice exercise performance $(\beta=.39, t=5.14, p=.00)$; learner motivation, in contrast, was not $(\beta=.05, t=.62, p=.53)$. As the $\beta$ weight for learner motivation dropped below significance when the number of practice exercises completed was accounted for, this finding implies that the latter variable was functioning as a mediator of the relationship between learner motivation and declarative practice exercise performance.

When skill-based learning test scores were regressed on learner motivation and the number of practice exercises completed during training, the overall model was also significant, $F(2,160)=4.76, p=.01$. However, learner motivation was found to be a significant predictor of skill-based learning test scores $(\beta=.21, \mathrm{p}=.01)$ and the number of practice exercises completed was not $(\beta=.06, \mathrm{p}=.44)$. As a result, we can infer that the number of practice exercises completed was not acting as a mediator of the relationship between learner motivation and skill-based learning test performance.

Hypothesis 10 was, therefore, partially supported, as the number of practice exercises completed was found to significantly mediate the relationship between motivation and performance on the declarative practice exercises. In contrast, the number of practice exercises completed was not found to mediate the relationship between motivation and learning outcomes for the skill-based learning test items, the skill-based practice exercises, and the declarative learning test items [the latter two outcome 
variables were not tested through multiple regression, as no support was found for Step 1 in the Baron and Kenny (1986) test of mediation].

Hypothesis 11 involved a comparison of the traditional, computer-based training program to the most game-like version (the version that involved both multimedia-based fantasy and reward). This hypothesis predicted that participants in the most game-like game version of the training would be more motivated, be more satisfied with the training, perform better on the practice exercises, complete more practice exercises, and perform better on the learning test than the traditional, computer-based version.

To test this hypothesis, separate independent samples $t$-tests were conducted for each dependent variable. Bonferroni adjustment was used to account for the family-wise error rate due to multiple tests. Contrary to hypotheses, the traditional, PowerPoint-like training program resulted in better performance on the declarative items on the learning test than the most game-like program did, $t(62)=3.13, p=00$. Specifically, participants in the PowerPoint-like program scored significantly higher on the declarative items on the learning test $(M=.72$ out of $1.00, S D=.10)$ than participants in the most game-like version $(M=.63, S D=.13)$. This implies that participants in the PowerPoint-like training program learned significantly more factual knowledge about the ADA, ADEA, and Title VII during the training than did the participants in the program with the most game features. No other differences were found with regard to motivation, training satisfaction, practice exercise performance, the number of practice items completed, or skill-based learning test items. See Table 6 for full results. (Hypothesis 11 not supported) 
Table 6: Comparison of the Most Game-like Condition to the Traditional Computerbased Training Condition

$\begin{array}{cc}\text { Traditional } & \text { Most Game-like } \\ \text { Condition } & \text { Condition }\end{array}$

Dependent Variable $M$ M $\quad d f$ Motivation $31.13(3.84)$

$31.26(4.18)$

62

$-.13$

Training Satisfaction

$20.50(2.21)$

$21.53(3.42)$

62

$-1.41$

Number of Practice Items

$\begin{array}{lllll}\text { Completed } & 34.37(10.12) & 37.18(4.01) & 36.97 & -1.43\end{array}$

Declarative Practice

Proportion Correct

$.78(.16)$

$.84(.10)$

62

$-1.79$

Skill-based Practice

Proportion Correct

$.87(.07)$

58

Declarative Learning Test

Proportion Correct

$.72(.10)$

$.63(.13)$

62

$3.13^{* *}$

Skill-based Learning Test

Proportion Correct

$.92(.08)$

$.92(.08)$

62

.34

Note. Standard deviations are enclosed in parentheses.

$* p<.05 . * * p<.01$.

Additional Analyses of Dependent Variables by Sex

Although not specifically hypothesized, a few additional analyses were conducted, comparing scores on the dependent variables by sex. First, as sex was found to significantly correlate with training satisfaction $(r=21, p=.01)$, an independent samples 
$t$-test was conducted, comparing participant ratings of training satisfaction by sex. The mean ratings for training satisfaction were found to differ significantly by sex, $t(161)=-$ $2.71, p=.01$. In particular, female participants $(M=21.58$ out of $25, S D=2.67)$ reported being more satisfied with the training program than male participants $(M=20.29$, $S D=3.09)$.

Second, as sex was found to significantly correlate with both training motivation $(r=.17, p=.03)$ and feelings of presence $(r=.22, p=.10)$, independent samples $t$-tests comparing participant scores on these variables by sex were conducted, revealing similar results. Again, the female participants reported being more motivated ( $M=31.36$ out of $36, S D=3.82), t(161)=-2.19, p=.03$, and feeling more present in the fantasy world, $(M=37.60$ out of $63, S D=11.96), t(131)=, p=.01$, than did the male participants $(M=29.90$, $S D=4.17$ for training motivation, $M=31.61, S D=12.62$ for presence).

Interestingly, an independent samples $t$-test comparing participant interest in learning about employment law by sex did not reveal significant sex differences $(M=3.28$ out of $5, S D=1.01$ for females, $M=3.04, S D=1.10$ for males), $t(160)=1.37, p=.17$, suggesting that males and females were relatively equivalent in terms of their interest in learning about employment law. This result was surprising given that employment law is one component of the field of human resources, a field that tends to be female-dominated (“High Paying Jobs in Female-Dominated Fields," n.d.). 


\section{CHAPTER FIVE: DISCUSSION}

Children growing up in the age of computers have been referred to in the literature as “digital natives.” Digital natives, according to Prensky (2001b, p. 1), are "'native speakers' of the digital language of computers, video games and the Internet."

Digital immigrants, in contrast, are those of us who did not grow up with computers and the Internet; this group has adapted to using new technology but retains an "accent," as they are still newcomers to this electronic world (Prensky).

As digital natives begin to enter the workforce, they will expect engaging and immersive environments from all electronic educational and training programs. As Naish (2003) points out, "[The gaming generation] will not be content to sit and read text off a screen and click a few radio boxes" (p. 19). This generation will demand that instruction be provided in the format to which they're accustomed, using high-quality graphics, audio, and gaming features.

This study was one of the first to examine whether the game features that digital natives regularly use in video and computer-based games can be beneficial for motivation and training outcomes. In particular, this study investigated whether incorporating game features into a computer-based training program actually results in better training. Contrary to hypotheses, these game features did not enhance learning outcomes directly following a training program. Rather, a simple PowerPoint-based training program was found to result in the best declarative learning outcomes.

One explanation for why the traditional PowerPoint-like training program was more effective in improving learning outcomes than the program offering multimediabased fantasy and reward is that the game features might have distracted participants 
from learning the material presented in the training. These game features might have required that participants focus on other facets of the training (e.g., the sights and sounds of the fantasy world, finding items in different places and figuring out how to retrieve them) rather than on learning the training material itself.

Research on attention supports this explanation. In particular, research investigating learner attention while driving has found that the inclusion of auditory and verbal stimuli (similar to driving while talking on a mobile phone) to the task of driving a car decreases visual processing speed and, subsequently, increases the amount of time it takes to perform driving tasks (Puell \& Barrio, 2008). In addition, research investigating the effectiveness of news tickers (i.e., brief news updates that scroll across the bottom of the screen during news broadcasts) reveals that when tickers are present, individuals are less able to comprehend the information presented in the main broadcast (KeefeFeldman, 2007). These research findings suggest that the presence of extra-sensory stimuli can sometimes impinge on performance and comprehension. As a result, including game features that detract from the main goal of the training, i.e., learning the training content, might actually be detrimental to training outcomes.

In addition, in the four experimental conditions, the training material was presented in a narrative format. In the traditional computer-based training version, however, information about the three employment laws was presented through bullet points. Although there are numerous potential benefits of using narrative for presenting instructional material (e.g., it can help provide a structure for learning, it can help learners make strong connections between information presented to them and potentially help motivate learners; Mandler, 1984; Mott, Callaway, Zettlemoyer, Lee, \& Lester, 1999), 
the presentation of the information in bullet-point format might have made it easier for the participants to learn what it was that they needed to know, as they did not have to extract the training content from the fantasy storyline. The former would have taken less effort and would have allowed participants to expend more of their energy on learning the training material.

Moreover, research on narrative has shown that combining narrative with interactivity can actually reduce learning outcomes. Interestingly, in the study by Greenwood-Ericksen (2008) described in Chapter 2, participants who were given instruction through a narrative format and who were able to interact with characters and objects in a synthetic learning environment performed significantly less well than participants who were only able to interact with the environment.

In the present study, participants in the multimedia-based fantasy conditions were able to interact with the program and information about EEO law was presented through stories told by different characters in the program. It is possible that the interaction between story and interactivity in these experimental conditions caused the lower than expected learning outcomes for these groups.

Whatever the reason, the results of this study suggest that incorporating game features into a training program does not necessarily mean that trainees will be more motivated to learn the material and, as a result, gain more knowledge during training than trainees who are given strict, fact-based presentations of the material. However, as this study only examined two game features (fantasy presentation format and reward) and the literature in this area is fairly new, this study needs to be examined in light of previous 
findings on games and game characteristics; in addition, more research needs to be done in this area before firm conclusions can be reached.

Another interesting finding in this study was that female participants tended to be more motivated during the training and to report feeling a greater satisfaction with the training as well as a greater sense of presence in the fantasy world. The sex differences on these variables do not appear to be due to male/female differences in level of interest in the training topic, as no significant sex differences were found for participant ratings of interest in learning about employment law.

All three of these findings involve affective reactions to the training program. Although the stereotype of women as being more emotionally expressive than men has not always been supported (Cherulnik, 1979; Vogel, Wester, Heesacker, Boysen, \& Seeman, 2006;), research has shown that women tend to perceive of themselves in this way (Brody, 1996; Wester, Vogel, Pressly, Heesacker, 2002). In fact, as Brody (1996) points out, "females may report more intense emotions because that is what they believe they are expected to report" (p. 142). It is possible that the female participants reported stronger emotions than the male participants in this study, because they believed that, as women, they were expected to express more emotion and feeling. Alternatively, the female participants might have responded more positively to the training than the male participants simply because the training appealed to them more.

An additional finding of interest relates to the amount of practice completed by participants during training. It was hypothesized that the number of practice exercises completed by participants would mediate the relationship between learner motivation and learning outcomes. Mediation was supported when declarative practice exercise 
performance was used as the measure of learning outcomes. This finding implies that when individuals are motivated to learn, they will complete more practice, which, in turn, will improve their performance during training. Although no support was found when mediation was examined with learning tests taken after training, motivation was still found to be significant predictor of skill-based learning test outcomes. Together, these findings suggest that motivation to learn can have a strong impact on training performance and learning test scores. Therefore, finding ways to increase motivation during training is critical for improving training outcomes.

Although the results of this study do not provide full support for Garris et al.'s (2002) model of games, motivation and learning, they do suggest that greater motivation improves learning outcomes, a link which is hypothesized by the second half of Garris et al.'s model and by other training motivation models, such as Colquitt et al. (2000) and Mathieu et al. (1992). In addition, the results of this study suggest that certain outcome variables in the motivation process (i.e., achievement and presence) can impact overall motivation, providing support for Pritchard and Ashwood's (2008) model of motivation. Although these motivational outcome variables were not found to result from the game features of multimedia-based fantasy and reward, it is likely that that other game features might impact these variables (more about this is discussed in the section on future research directions).

In the following sections, the limitations of this study are addressed as well as recommendations for future research on this topic. After that, implications for using game features in organizational training settings are discussed and are followed by overall study conclusions. 


\section{Study Limitations}

One area of concern that might be raised about this study is participant interest in the training topic. The topic of training in this study was employment law. The reason this topic was chosen was that it was expected to be a fairly novel topic to our student participants. It appears that this was indeed the case, as the average reported rating of familiarity with the ADA, ADEA, and Title VII was 1.920 out of $5(S D=.625 ; 1=$ Never heard of it, 5=Very familiar). A second reason that employment law was chosen as the training topic is that it is a rather technical topic with specific right/wrong answers. This allowed the training to involve practice with immediate feedback on the accuracy of responses. Moreover, because the training was so technical in nature, it lent itself well to presentation through a video game format.

Although participants reported a moderate interest level in the topic of employment law prior to participating in the study $(M=3.200$ out of $5, S D=1.034,1=N o t$ at all interested, 5=Very interested), these students were likely not as motivated to learn the topic as actual employees would have been. The course was described as being useful to participants when they graduate and seek employment, but, being that these participants were primarily first-year university students, the topic might not have been as appealing to them as it would have been to employees taking the course as a condition of employment. It is possible that the participants' moderate level of interest in the training topic impacted their motivation and learning outcomes. However, as this variable was measured prior to training and could, for the most part, be controlled in later analyses, it does not pose a significant threat to the overall study findings. 
In the training program, a second limitation was the inability to provide a nonlinear sequence to the training material. In an attempt to provide the same information to all participants in the same order, a linear sequence was chosen and participants were unable to alter their order in which they learned the material during training. Although participants in the multimedia-based fantasy conditions could walk around and explore the stores/businesses that their character some of the area around their characters, they were unable to stray very far from the path.

Research on learner control (i.e., an instructional design feature in which learners have direct power of various aspects of the learning experience) has shown that control of sequencing can have both positive and negative effects on learning outcomes. One study conducted by Tovar and Coldevin (1992) found that when measures of learning involved the immediate recall of facts, learners allowed to self-sequence did significantly better than learners given program-controlled sequencing. However, no benefit of selfsequencing was found when the measure of learning was immediate recall of procedures. Additionally, Gray (1989) found that learner control of sequencing had negative effects on learning during a computer-based course, such that learners allowed to self-sequence performed more poorly on learning tests than learners given a strict instructional path.

Similar mixed results have been found when learner satisfaction was the dependent variable of interest. In particular, researchers have found that learner control of sequencing can both enhance and reduce satisfaction with the learning experience (e.g., Carlson, 1991; Gray, 1987, 1989; Hintze, Mohr, \& Wenzel, 1988; Lai, 2001).

As the research on learner control of sequencing has been mixed, it is difficult to determine how changing the linear structure of the training program would have impacted 
the results. It is possible that self-sequencing would have improved results, but it is also possible that it would have had no effect or even reduced the results. What learner control of sequencing might have allowed for is greater exploration of the fantasy world. Exploration (i.e., the ability to search for new information in a game) has been identified as a motivating game feature (Belanich et al., 2004), although no research has specifically examined its impact on training outcomes. If self-sequencing resulted in greater exploration of the fantasy environment, therefore, it is possible that learner motivation might have increased. However, whether or not this increased exploration would have impacted learning and other training outcomes cannot be concluded at this time.

A third limitation involved the lack of variance on the skill-based practice and skill-based learning test items. Surprisingly, participants did very well on both of these learning measures, particularly on the skill-based learning test. In particular, almost 1/5 of the participants scored $100 \%$ on the skill-based learning test items.

It appears that the training was very effective in teaching participants how to apply their knowledge of the ADA, ADEA, and Title VII to the evaluation of job interview questions and application items. Due to the ceiling effect in performance on both the skill-based practice and skill-based learning test, it was impossible to find significant differences between the study conditions on the skill-based outcome variables.

It is important to note that adequate variance was found for the other dependent variables in the study. In fact, for certain variables (e.g., presence, number of practice exercises completed), standard deviations were very large, suggesting that participant responses and scores differed widely for these variables. If limited variance had been found for all dependent variables in the study, this might have explained the lack of 
between-group differences. However, in this study, an adequate amount of variance was found for a majority of the dependent variables, suggesting that other factors must have been at work.

\section{Directions for Future Research}

This study was one of the first to investigate the impact of individual game features on motivation and training outcomes. In this study, both the main and interactive effects of two game features (reward and multimedia-based fantasy) were examined in light of their influence on a variety of outcome variables, specifically, motivation, training satisfaction, the number of practice exercises completed, performance on practice exercises, and performance on learning tests.

Additional research in the study of games should continue to systematically investigate the effects of different game features so that a full understanding of the pros and cons of using games for learning is known. This information will provide us with a better understanding of which game features are beneficial for motivation and training and which ones are merely fun but lack substance.

Researchers should also explore which motivational outcomes result from particular game features. In this study, the Pritchard and Ashwood (2008) model was applied to help explain how the game features of reward and multimedia-based fantasy would motivate learners, and specific outcome variables in the motivation process (i.e., feeling of achievement, sense of presence in the fantasy world) were identified. This model can be used in future research to help explain how other game features motivate learners. 
It was predicted that the ability to earn rewards during the training would lead to greater feelings of achievement than being given feedback only and that multimediabased fantasy would result in enhanced feelings of presence than text-based fantasy. Neither of these hypotheses was supported but an interesting finding was that both feelings of achievement and feelings of presence were related to motivation. These findings suggest that both feelings of achievement and presence might be potential outcomes of game features in the motivational process; the specific game features that lead to these outcomes, however, remain still to be uncovered.

Additionally, research should focus on the potential benefits game features offer learners in terms of retention. To date, only one study that the researcher is aware of (Parker \& Lepper, 1992) investigated the impact of game features on learner retention. This study found that presenting basic graphics programming through a fantasy context led to greater retention of both the specific training content (i.e., how to program) and generalized training content (i.e., general geometric concepts) two weeks after the initial instruction than presenting the information without the fantasy context. Interestingly, the findings for immediate learning outcomes in Parker and Lepper's study were not as supportive of the fantasy context. Specifically, when learning was tested immediately after the instruction, fantasy context was only found to increase learning of specific training content, not generalized training content. These results suggest that game features, such as fantasy, might have delayed effects on learning and training outcomes.

It is likely that certain game features (e.g., interactivity, challenge, conflict) will aid learners in remembering the material presented during training, as these features are likely to create unique memory experiences for learners. In the future, researchers should 
investigate the effect of game features on retention, perhaps examining retention at one week, two weeks, 1 month, 3 months, and so on.

Research might also focus on the use of game features in skill-based learning programs. Although this study examined the impact of game features on both declarative knowledge and skill-based learning, the training was so effective in this study that the skill-based learning outcomes had limited variance. As a result, no between-group differences were found on this outcome variable.

Research findings by Parker and Lepper (1992) suggest that game features can increase skill-based learning outcomes for certain skills (i.e., graphics programming skills). Research should investigate whether this finding applies to other types of skills (e.g., judgment/ critical thinking skills, interpersonal skills) and which game features are the most beneficial for skill-based learning.

Prensky (2001a) suggests that certain types of training content might be better suited for game-based learning systems than others (e.g., training content that is both technical and difficult/challenging). I chose employment law as the topic of this training program, because I believed that the content was technical and that it would be challenging to student participants. In the end, although the topic was technical, it was not found to be as difficult as was originally thought, as participants performed particularly well on both the skill-based practice and the skill-based learning test.

The results of this study may not apply to content domains that are sufficiently difficult to master (e.g., high-level mathematics, foreign languages). Other researchers who have examined the impact of game features on learning have found that game features can improve learning of both African American history and graphics 
programming (Greenwood-Ericksen, 2008; Parker \& Lepper, 1992). It is likely that these topics offered learners a significant level of challenge during the training program. In the future, researchers investigating games and game features should carefully consider the type of training content that is provided in a game-based learning format, keeping in mind the recommendations provided by Prensky (2001a).

Researchers also need to carefully consider the types of practice that learners are given in game-based learning systems. In this study, learners were given the opportunity to practice what they had learned by answering declarative knowledge questions about the training content and then by applying what they had learned in the evaluation of interview questions and job application items. An alternative (and potentially more challenging) form of practice in this study might have involved a role-play in which participants could have acted as interviewers who needed to ask questions that complied with EEO law. Asking questions that violated employment law could have resulted in infractions by the EEOC or to the interviewer being terminated from his/her position. Offering this form of practice would have required that the role-play be embedded into the training as part of the "game" and that learners receive "real" consequences in the training program for not correctly applying the skills taught in the program. It is possible that providing this form of practice would have improved learning outcomes. In the future, researchers investigating the effectiveness of game-based learning systems should carefully evaluate the types of practice learners are given during the training to ensure that this practice both engages the trainee and reinforces the knowledge and skills taught in the training. 


\section{Practical Implications}

The results of this study suggest that training works if good learning principles (e.g., practice that permits mistakes, timely feedback) are used in training design and development. When these learning principles are followed, it does not appear to matter how material is presented to learners, whether through a game or PowerPoint.

In this study, all conditions were developed using the same methodology (i.e., learning objectives were mapped onto the training content, practice exercises, and learning test items), all presented declarative knowledge first as the basis for the skillbased learning, all allowed for mistakes, and all incorporated practice and feedback. Interestingly, the traditional PowerPoint-like version was found to lead to better declarative knowledge outcomes on the learning test than the most game-like version, although no differences were found between conditions on any of the other dependent variables. In other words, with the exception of performance on the declarative learning test items, participants in all conditions were equally motivated to learn, were equally satisfied with the learning experience, completed an equal number of practice exercises, performed equally well on the declarative knowledge and skill-based practice, and performed equally well on the skill-based learning test. This suggests that adding the "bells and whistles" of game features to a training program won't necessarily improve learner motivation and training outcomes.

The cost of adding these "bells and whistles" and the increased time it takes learners to complete game-based training also need to be considered. One report states that the budget of developing the Army's military recruiting game, "America's Army," was around $\$ 7$ million (Morris, 2002). In addition, in this study, the training versions 
with game features took approximately 12-18 minutes longer to complete than the traditional PowerPoint-like version. As participants in the traditional version only spent, on average, 17.47 minutes in the training, this essentially doubles the amount of time needed for training. The added cost along with the extra time needed for training suggests that instructional designers and organizational training specialists need to be cautious when deciding whether to incorporate game features into instructional programs.

\section{Conclusion}

The significant number of hours that children and young adults spend playing video games implies that video games will not disappear from American culture anytime soon. However, as the results of this and other studies imply, their use in training and instruction needs to be taken cautiously, as they do not always lead to increased motivation and learning outcomes.

Organizations and educational institutions planning on using electronic games for training need to first consider the costs associated with using games for learning. For instance, the financial investment required for developing training games, the increased time required of trainees for participating in training games, and the impact on declarative learning outcomes in comparison to traditional, computer-based training methods need to be considered before the decision is made to switch to a game-based learning platform. In addition, as the results of this study imply, attention and energy might be better focused on creating good instructional programs based on sound learning principles rather than on finding ways to incorporate game features into learning systems. Placing attention and energy on building effective learning programs will result in better learning outcomes for all trainees. 
As we know, technology will always outpace research on its effectiveness, and software/game developers will continue to create instructional programs without a full understanding of what works and what doesn't (Vogel et al., 2006). However, although we will likely always be playing catch-up, Vogel et al. point out that it is important for us to create a strong base of research on which computer-based training programs are most effective and efficient to use. This study contributes to the research on how games impact motivation and learning by investigating the influence of two game features: reward and fantasy presentation format. As research on the use of game features in learning accumulates, instructional designers and organizational training specialists will be better equipped to develop learning programs that engage trainees and motivate them to learn, and, at the same time, improve their learning of the instructional material. 


\section{APPENDIX A: INFORMED CONSENT}




\section{Employment Law Study Informed Consent Form for Students 18 Years Old and Older}

The purpose of this study is to examine the effectiveness of a training program designed to teach basic knowledge of employment law. As a participant in this study, you will be asked to complete a pretest about your employment law knowledge, a training program, a test of what you learned in training, questionnaires about your feelings toward the training, and demographic information. You will have the opportunity to win a $\$ 50$ gift certificate to the Oviedo Mall, Darden Restaurants, or BestBuy (whichever you choose) if you are one of the top performers in the study. The top performers will be determined by performance on the learning assessments given during the study. This study will take approximately 90 minutes; as a result, participation in this study will provide you with SIX Sona System points.

After participating in the laboratory portion of the study, you will have the opportunity to earn 1 additional Sona System point by agreeing to complete a measure about what you learned during this study one week later. You will be contacted about this opportunity via email and will have TWO days to complete the survey in order to earn the Sona System point.

Any information that you provide will be used strictly for the purpose of this research project. During the course of the study, all of your responses will be kept confidential. After everyone completes the study and prizes are distributed, your responses will be made anonymous, and only group-level (not individual) data will be reported in research papers resulting from this research.

From participation in this study, you will learn about the research process. In addition, you may learn something about employment law. This information may help you evaluate the legality of employment application and interview questions that might be asked when you graduate and seek employment. There are no anticipated risks associated with participation in this research beyond a potential breach of confidentiality (this is always a risk when identifying information is being collected). However, as no sensitive data will be collected during this study, this does not present a significant risk.

Research at the University of Central Florida involving human participants is carried out under the oversight of the Institutional Review Board. Questions or concerns about research participants' rights may be directed to the UCF IRB office, University of Central Florida, Office of Research \& Commercialization, 12201 Research Parkway, Suite 501, Orlando, FL 32826-3246, or by campus mail 32816-0150. The hours of operation are 8:00 am until 5:00 pm, Monday through Friday except on University of Central Florida official holidays. The telephone numbers are (407) 882-2276 and (407) 823-2901.

I have the full capacity to consent and do hereby volunteer to participate in this research, which is being conducted by Renée DeRouin-Jessen in partial fulfillment of the degree of doctor of philosophy in psychology. Ms. DeRouin-Jessen is supervised by Dr. Barbara Fritzsche, Department of Psychology, University of Central Florida. I acknowledge that I 
have the full capacity to consent; I am 18 years old or older; I have been informed of the nature, duration, and purpose of this research; and I understand my role as a participant. I have been given the opportunity to read, sign, and to ask questions concerning this research. Any such questions have been answered to my full and complete satisfaction. I have received a copy of this agreement. Should any further questions arise, I will be able to contact Renée DeRouin-Jessen. I understand that I may withdraw my consent and discontinue without penalty at any point during this research.

Printed Name

Signature

Date

\section{Contact Information}

Please Note: This information will only be used for the following:

1) To offer you the opportunity to earn one additional Sona System point a week later if you agree to complete an online measure of what you learned during today's study

AND

2) To let you know if you have won a prize, which will be determined at the conclusion of the study. All contact information will be destroyed after prizes are distributed.

Email Address

Phone Number 
APPENDIX B: DEMOGRAPHICS FORM 


\section{Employment Law Study \\ Demographics Form}

1. How old are you?

2. What is your sex?

a. Male

b. Female

3. What is your ethnic background?

a. African American

b. Asian American

c. Caucasian (non-Hispanic)

d. Hispanic/Latino

e. Native American

f. Other

4. If you answered "Other" to question 3, please give more information about your ethnicity.

5. What is your class standing?

a. Freshman (0-30 Credit Hours)

b. Sophomore (31-60 Credit Hours)

c. Junior (61-90 Credit Hours)

d. Senior (91-120 Credit Hours)

e. Graduate Student

f. Non-Degree Seeking

6. What is your major?

7. Do you have a job?
a. Yes
b. No

8. If you do have a job, how many hours a week do you work?

9. How many years have you been working (total number of years across all jobs)?

10. On a scale from 1 to 5 , how would you classify yourself in terms of computer knowledge?

1 ---------------2---------------3--------------4-----------5
Never Used


11. How many computer-based/web-based courses have you taken in the past?

12. How many hours a week you do play video or computer games?

13. Have you ever played Neverwinter Nights?
a. Yes
b. No

14. If you answered "yes" to the previous question, about how many hours a week do you play this game?

15. On a scale from 1 to 5 , how would you classify yourself in terms of your Neverwinter Nights expertise?

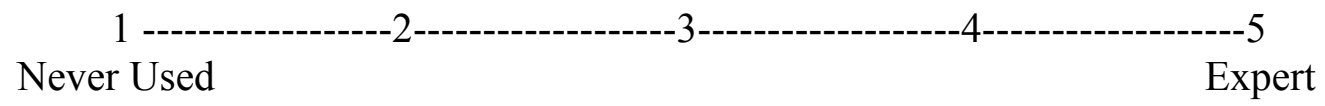

16. On a scale from 1 to 5 , how familiar are you with the following employment laws?

A) Americans with Disabilities Act

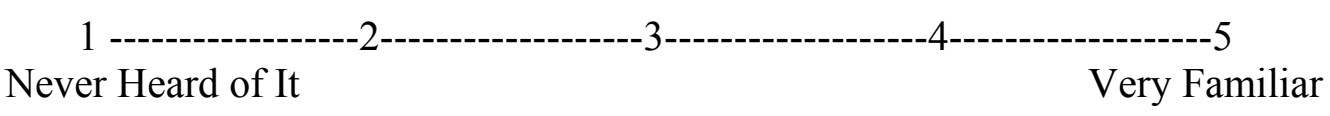

B) Age Discrimination in Employment Act

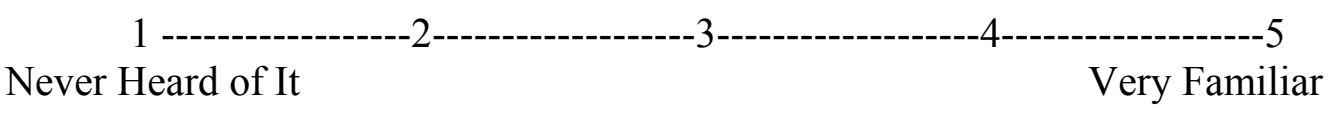

C) Title VII of the Civil Rights Act

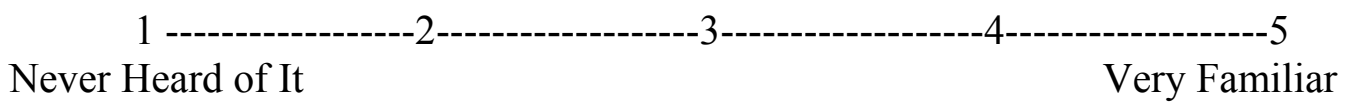

17. Have you ever taken a class that covered employment law?

a. Yes

b. No

18. On a scale from 1 to 5 , please rate your current level of interest in learning about employment law.

1 -----------------2------------------3------------------4------------------5 
APPENDIX C: LEARNING OBJECTIVES HANDOUT 


\section{Learning Objectives}

The learning objectives for the training program are listed below. Please read these objectives carefully so that you have an understanding of what you will be learning today.

*** Keep in mind that the top performers in the study will win a $\$ 50$ gift card to Darden Restaurants, BestBuy, or the Oviedo Mall, so please do your best! ***

\begin{tabular}{|c|c|}
\hline Employment Law Covered & $\begin{array}{l}\text { Objective } \\
\text { Upon completion of this training course, } \\
\text { participants will be able to: }\end{array}$ \\
\hline \multirow[t]{2}{*}{$\begin{array}{l}\text { Americans with Disabilities Act } \\
\text { of } 1990\end{array}$} & $\begin{array}{l}\text { Recognize basic facts about the ADA, including } \\
\text { what is considered to be a disability and who is } \\
\text { covered. }\end{array}$ \\
\hline & $\begin{array}{l}\text { Identify ADA violations in application and } \\
\text { interview questions. }\end{array}$ \\
\hline \multirow[t]{2}{*}{$\begin{array}{l}\text { Age Discrimination in } \\
\text { Employment Act of } 1967\end{array}$} & $\begin{array}{l}\text { Recognize basic facts about the ADEA, including } \\
\text { what age group is protected. }\end{array}$ \\
\hline & $\begin{array}{l}\text { Identify ADEA violations in application and } \\
\text { interview questions. }\end{array}$ \\
\hline \multirow[t]{2}{*}{$\begin{array}{l}\text { Title VII of the Civil Rights Act } \\
\text { of } 1964\end{array}$} & $\begin{array}{l}\text { Recognize basic facts about Title VII, including } \\
\text { the five protected classes. }\end{array}$ \\
\hline & $\begin{array}{l}\text { Identify Title VII violations in application and } \\
\text { interview questions. }\end{array}$ \\
\hline
\end{tabular}




\section{APPENDIX D: TRAINING DEBRIEFING FOR EXPERIMENTAL}

CONDITIONS 
The training program you participated in today was not meant to simulate an actual reallife experience. The primary purpose of the training was to provide you with a basic understanding of what constitutes legally defensible hiring practices. In the future, this information will help you if you are asked to participate in the hiring of new employees and when you personally graduate and seek employment.

The reason we asked you to visit each of the stores in the first part of the training was to teach you the fundamentals of three selection laws: the American with Disabilities Act, the Age Discrimination in Employment Act, and Title VII of the Civil Rights Act of 1964. We also provided you with a mentor so that you could practice answering questions about these laws.

The second part of the training involved evaluating interview questions and application items for compliance with federal employment laws. The reason you were asked to do this is so that you could practice applying your knowledge of the three employment laws to actual hiring tools.

Overall, we hope that this training improved your understanding of employment law. Next, you will be asked to complete several measures of your experiences and what you learned during training. 
APPENDIX E: TRAINING DEBRIEFING FOR TRADITIONAL, COMPUTER-BASED PROGRAM CONDITION 
The primary purpose of the training you received today was to provide you with a basic understanding of what constitutes legally defensible hiring practices. In the future, this information will help you if you are asked to participate in the hiring of new employees and when you personally graduate and seek employment.

In the first part of the training you learned about the fundamentals of three selection laws: the American with Disabilities Act, the Age Discrimination in Employment Act, and Title VII of the Civil Rights Act of 1964. You were also given the opportunity to practice answering questions about these laws.

The second part of the training involved evaluating interview questions and application items for compliance with federal employment laws. The reason you were asked to do this is so that you could practice applying your knowledge of the three employment laws to actual hiring tools.

Overall, we hope that this training improved your understanding of employment law. Next, you will be asked to complete several measures of your experiences and what you learned during training. 
APPENDIX F: STUDY DEBRIEFING 
In this study, you were asked to complete a pretest about your employment law knowledge, a training program, a test of what you learned in training, questionnaires about your feelings toward the training, and demographic information. We expect that all participants will improve their understanding of Equal Employment Opportunity laws as a result of this training but that for some groups, this learning gain may be greater than for others. Moreover, we expect that differences in motivation and training satisfaction will occur. We expect these differences to result from the inclusion of two different training design factors that we manipulated.

One of these factors is the way the training was presented to you. Some of you received the training through a multimedia-based training format (what looked like a video game) whereas others received it in a more traditional, text-based format. We expect that individuals receiving the multimedia-based format will do better on the practice exercises and on the learning test at the end than individuals in the text-based learning format. Moreover, we expect that motivation to learn will be greater in the group receiving the multimedia-based instruction.

Another training design factor that we manipulated was whether you received points (in the form of fake money) for answering questions correctly or whether you only received feedback about whether your answers were right or wrong and why. The reason we manipulated this variable was to find out whether including rewards within a training program increases learner motivation, training satisfaction, and learning outcomes. Like multimedia-based fantasy, we believe that getting points in a learning game increases learner motivation and satisfaction with the training. In addition, we believe that it might also increase how individuals perform on a post-training test, which gives us an indication of learning during training.

Games are becoming increasingly popular as a means of instruction. They are currently being used in military, corporate, and educational settings, and millions of dollars are spent each year on the research and development of game-based learning systems. Not all of these games have been found to be successful in increasing learning and training satisfaction. One of the likely reasons for this is that games are being developed without a clear understanding of which game features are most effective for increasing learning, and, thus, most important to include within a training program. We hope that this study will result in a better understanding of the factors that influence training success.

If you would like to speak to us regarding this study, your copy of the informed consent form provides you with Renée DeRouin-Jessen's contact information. The University of Central Florida Counseling and Testing Center is also available to speak with you. They are located at the Student Resource Center, Room 203, and their phone number is 407823-2811. If you want a copy of the results of this study, please leave your name and contact information. We will send you the results as soon as the study is completed. 
Additionally, research at the University of Central Florida involving human participants is carried out under the oversight of the Institutional Review Board. Questions or concerns about research participants' rights may be directed to the UCF IRB office, University of Central Florida, Office of Research \& Commercialization, 12201 Research Parkway, Suite 501, Orlando, FL 32826-3246, or by campus mail 32816-0150. The hours of operation are 8:00 am until 5:00 pm, Monday through Friday except on University of Central Florida official holidays. The telephone numbers are (407) 882-2276 and (407) 823-2901.

If you are one of the top performers in the study (based on your performance on the learning assessments given during the study), you will be contacted by the phone or email address you provided on the consent form about the $\$ 50$ gift certificate. At that time, you will be able to choose whether you would prefer a gift certificate to the Oviedo Mall, Darden Restaurants, or BestBuy.

Please note that one week after your participation in this study, you will be sent an email inviting you to complete a measure about what you learned during this study. If you agree to participate and complete the measure within TWO days of being contacted, you will receive ONE additional Sona point.

Thank you very much for your participation. This research is currently underway, so it is important that you not discuss the study with anyone other than the researchers, the Institutional Review Board, or the counseling center staff. 
APPENDIX G: ADDITIONAL EMPLOYMENT LAW RESOURCES 


\section{Additional Employment Law Resources}

For more information on equal employment legislation, please consult the following resources:

Byars, L. L., \& Rue, L. W. Human resource management $\left(6^{\text {th }}\right.$ ed. $)$. Boston: McGrawHill/Irwin.

Gutman, A. (2000). EEO law and personnel practices (2 ${ }^{\text {nd }}$ ed.). Newbury Park, CA: Sage Publications.

Cascio, W. F., \& Aguinis, H. (2004). Applied psychology in human resource management $\left(6^{\text {th }}\right.$ ed.). Upper Saddle River, NJ: Prentice Hall.

Gatewood, R., Field, H. S., \& Barrick, M. (2007). Human resource selection $\left(6^{\text {th }}\right.$ ed). South-Western College Pub.

U.S. Equal Employment Opportunity Commission. (2004). Federal Equal Employment Opportunity (EEO) Laws. Retrieved August 12, 2007, from http://www.eeoc.gov/abouteeo/overview_laws.html 
APPENDIX H: IRB APPROVAL LETTER 


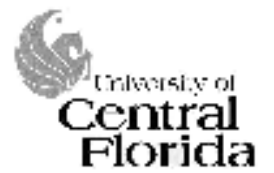

University of Central Florida Institutional Review Board

Office of Research \& Commercialization

12201 Research Parkway, Suite 501

Orlando, Florida 32826-3246

Telephone: 407-823-2901, 407-882-2901 or 407-882-2276

www.research.ucf edu/compliance/irb.html

\title{
Notice of Expedited Initial Review and Approval
}

\author{
From : UCF Institutional Review Board \\ FWA00000351, Exp. 5/07/10, IRB00001138 \\ To : Renee E DeRouin and Barbara Fritzsche \\ Date : February 01, 2008 \\ IRB Number: SBE-08-05389
}

Study Title: Do Multimedia-Based Fantasy and Reward Really Improve Motivation and Training Outcomes? An Empirical Analysis of Gaming Features within a Computer-Based Training Program

Dear Researcher:

Your research protocol noted above was approved by expedited review by the UCF IRB Vice-chair on 1/31/2008. The expiration date is $1 / 30 / 2009$. Your study was determined to be minimal risk for human subjects and expeditable per federal regulations, 45 CFR 46.110. The category for which this study qualifies as expeditable research is as follows:

7. Research on individual or group characteristics or behavior (including, but not limited to, research on perception, cognition, motivation, identity, language, communication, cultural beliefs or practices, and social behavior) or research employing survey, interview, oral history, focus group, program evaluation, human factors evaluation, or quality assurance methodologies.

The IRB has approved a consent procedure which requires participants to sign consent forms. Use of the approved. stamped consent document(s) is required. Only approved investigators (or other approved key study persomnel) may solicit consent for research participation. Subjects or their representatives must receive a copy of the consent form(s).

All data, which may include signed consent form documents, must be retained in a locked file cabinet for a minimum of three years (six if HIPAA applies) past the completion of this research. Any links to the identification of participants should be maintained on a password-protected computer if electronic information is used. Additional requirements may be imposed by your funding agency, your department, or other entities. Access to data is limited to authorized individuals listed as key study personnel.

To continue this research beyond the expiration date, a Continuing Review Form must be submitted $2-4$ weeks prior to the expiration date. Advise the IRB if you receive a subpoena for the release of this information, or if a breach of confidentiality occurs. Also report any unanticipated problems or serious adverse events (within 5 working days). Do not make changes to the protocol methodology or consent form before obtaining IRB approval. Changes can be submitted for IRB review using the Addendum/Modification Request Form. An Addendum/Modification Request Form sannot be used to extend the approval period of a study. All forms may be completed and submitted online at http://iris.research.ucf.edu -

Failure to provide a continuing review report could lead to study suspension, a loss of funding and/or publication possibilities, or reporting of noncompliance to sponsors or funding agencies. The IRB maintains the authority under 45 CFR 46.110(e) to observe or have a third party observe the consent process and the research.

On behalf of Tracy Dietz, Ph.D., UCF IRB Chair, this letter is signed by:

Signature applied by Joanne Muratori on 02/01/2008 09:16:03 AM EST

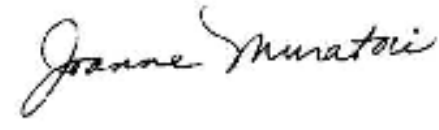

IRB Coordinator 
APPENDIX I: PERMISSION LETTER FROM SAGE PUBLICATIONS 


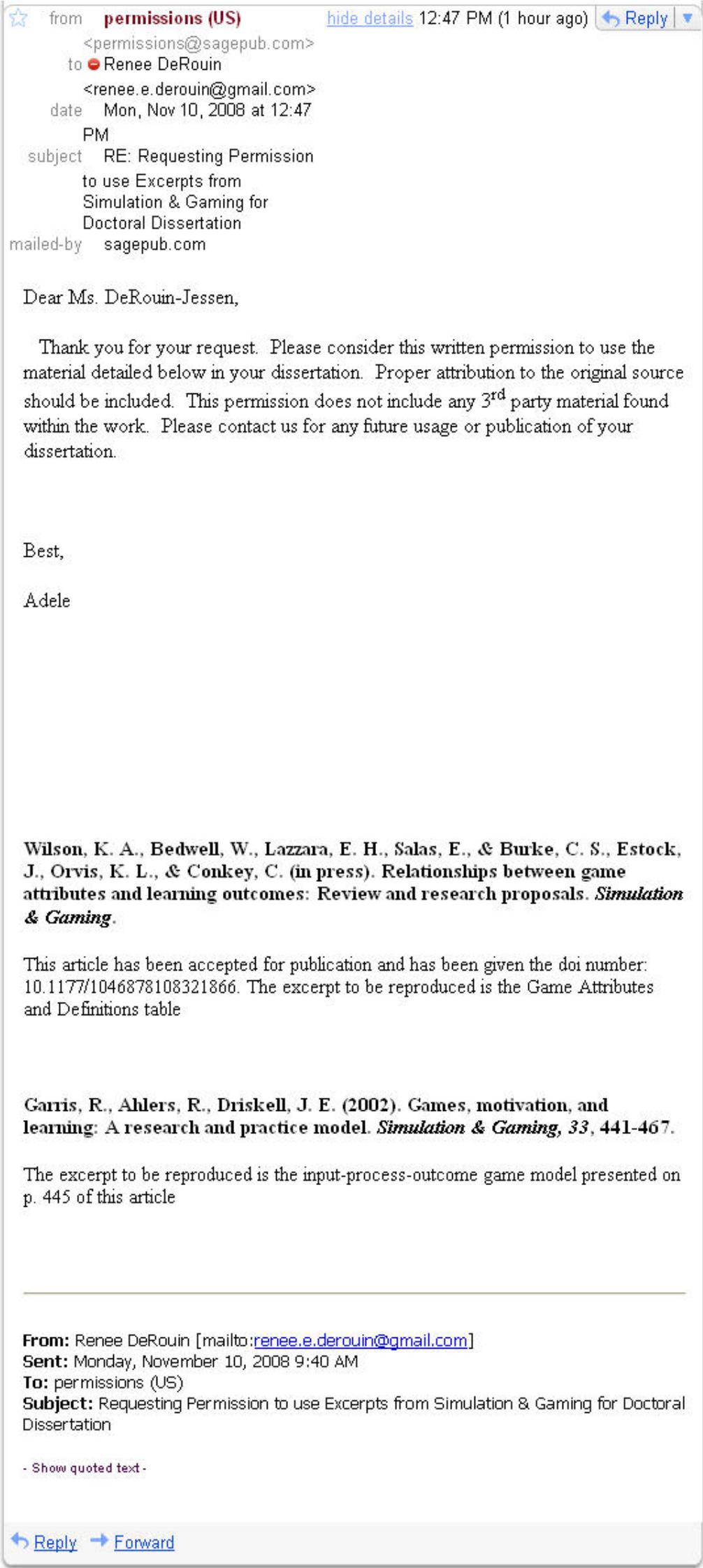


APPENDIX J: PERMISSION LETTER FROM TAYLOR \& FRANCIS 
$\therefore$ Back to view orders

\section{Copy order : Cancel Open Items:}

Confirmation Number: 1952115

Order Date: 11/10/2008

\section{Customer Information}

Customer: Renee DeRouin-Jessen
Add another item to this order
Print this page

Print terms \& conditions Print citation information (What's this?)

Search order details by:

Choose One

\section{Order Details}

\section{MANAGING MOTIYATION}

Order detail ID: $\mathbf{2 4 1 2 0 7 2 5}$

ISBN/ISSN: 9781841697895

Publication Year: 2008

Publisher: TAYLOR \& FRANCIS GROUP LLC

Rightsholder: Taylor \& Francis Group LLC

Buthor/Editor: Robert D. Pritchard \& Elissa

L. Ashwood (book authors)
Permission Status: $\mathcal{V}$ Granted

Comment: Please check the copyright line before republishing.

Permission type: Republish into a book, journal, newsletter..

Requested use: Dissertation

Republication title: GAME ON: THE IMPACT OF

GAME FEATURES IN COMPUTER-BASED TRAINING

Republishing organization: PROQUEST UMI

DISSERTATION PUBLISHING

Organization status: For profit

Republication date: 11/21/2008

Circulation/Distribution: 45000

Type of content: Figure, diagram, or table

Description of requested content: Figure 3.1 The

Expanded Motivation Model

Page range(s): p. 20

Requested content's publication date:

$05 / 13 / 2008$ 


\section{LIST OF REFERENCES}

Adams, J. S. (1963). Towards an understanding of inequity. Journal of Abnormal and Social Psychology, 67, 422-436.

Amory, A., Naicker, K., Vincent, J., \& Adams, C. (1999). The use of computer games as an educational tool: Identification of appropriate game types and game elements. British Journal of Educational Technology, 30, 311-321.

Anderson, C. A., Carnagey, N. L., Flanagan, M., Benjamin, A. J., Jr., Eubanks, J., \& Valentine, J. C. (2004). Violent video games: Specific effects of violent content on aggressive thoughts and behavior. In Mark P. Zanna (Ed.), Advances in experimental social psychology (Vol. 36, pp. 199-249). San Diego: Elsevier Academic Press.

Anderson, C. A., \& Dill, K. E. (2000). Video games and aggressive thoughts, feelings, and behavior in the laboratory and in life. Journal of Personality and Social Psychology, 78, 772-790.

Arendt, S. (2007, April 11). Guinness announces video game edition of world records book. Retrieved October 25, 2007, from http://blog.wired.com/games/2007/ 04/guinness announ.html.

Avedon, E. M., \& Sutton-Smith, B. (1971). The study of games. New York: John Wiley. Bandura, A. (1977). Social learning theory. Englewood Cliffs, NJ: Prentice Hall. Bangert-Drowns, R. L., Kulik, C.-L. C., Kulik, J. A., \& Morgan, M. (1991). The instructional effect of feedback in test-like events. Review of Educational Research, 61, 213-238. 
Baron, R. M., \& Kenny, D. A. (1986). The moderator-mediator variable distinction in social psychological research: Conceptual, strategic and statistical considerations. Journal of Personality and Social Psychology, 51, 1173-1182.

Belanich, J., Sibley, D. E., \& Orvis, K. L. (2004). Instructional characteristics and motivational features of a PC-based game. 2004, April). U.S. Army Research Institute for the Behavioral and Social Sciences. (Research Report 1822).

Bergerson, B. (2006). Developing serious games. Hingham, MA: Charles River Media. Bloom, B. (1956). Taxonomy of educational objectives: The cognitive domain. New York: Donald McKay.

Bobko, P., Bobko, D. J., \& Davis, M. A. (1984). A multidimensional scaling of video games. Human Factors, 26, 477-482.

Bouchard, S., St-Jacques, J., Robillard, G., \& Renaud, P. (2008). Anxiety increases the feeling of presence in virtual reality. Presence, 17, 376-391.

Bowman, R. F., Jr. (1982, September). A 'Pac-Man' theory of motivation: Tactical implications for classroom instruction. Educational Technology, 22, 14-16.

Borja, R. R. (2006, October). Video games can improve learning, scientists' report says. Education Week, 26, 12.

Broden, M., Hall, R. V., Dunlap, A., \& Clark, R. (1970). Effects of teacher attention and a token reinforcement system in a junior high school special education class. Exceptional Children, 36, 341-349.

Brody, L. R. (1996). Gender, emotional expression, and parent-child boundaries. In R. D. Kavanaugh, B. Zimmerberg, \& S. Fein (Eds.), Emotion: Interdisciplinary perspectives (pp. 139-170). Mahwah, NJ: Lawrence Erlbaum. 
Bruner, J. S. (1966). Toward a theory of instruction. Cambridge, MA: Belknap Press of Harvard University.

Byars, L. L., \& Rue, L. W. Human resource management $\left(6^{\text {th }}\right.$ ed.). Boston: McGrawHill/Irwin.

Byers, C. (2007). Playing to learn: Game-driven comprehension of complex content. International Journal of Teaching and Learning in Higher Education, 19, 33-42.

Carlson, H. L. (1991). Learning style and program design in interactive multimedia. Educational Technology, Research and Development, 39, 41-48.

Carnagey, N. L., Anderson, C. A., \& Bushman, B. J. (2007). The effect of video game violence on physiological desensitization to real-life violence. Journal of Experimental Social Psychology, 43, 489-496.

Carr, S. (2000). As distance education comes of age, the challenge is keeping the students. Chronicle of Higher Education, 46, A39-A41.

Chen, S., \& Michael, D. (2005, October 19). Proof of learning: Assessment in Serious Games. Gamasutra. Retrieved October 11, 2007, from http://www.gamasutra.com /features/20051019/chen_01.shtml.

Cherulnik, P. D. (1979). Sex differences in the expression of emotion in a structured social encounter. Sex Roles, 5, 413-424.

CNET Networks Entertainment. (2004, January 23). The greatest games of all time: The Oregon Trail. Retrieved August 7, 2007, from http://www.gamespot.com /gamespot/features/all/greatestgames/p-34.html. 
Colquitt, J. A., LePine, J. A., \& Noe, R. A. (2000). Toward an integrative theory of training motivation: A meta-analytic path analysis of 20 years of research. Journal of Applied Psychology, 85, 678-707.

Computer games 'do have benefits'. (2005). Retrieved May 23, 2007, from http://news .bbc.co.uk/2/hi/health/4682801.stm.

Crawford, C. (1984). The art of computer design. Berkeley, CA: Osborne/McGraw-Hill. Crookall, D., Oxford, R. L., \& Saunders, D. (1987). Towards a reconceptualization of simulation: From representation to reality. Simulation/Games for Learning, 17, $147-171$.

Cruickshank, D. R., \& Telfer, R. (1980). Classroom games and simulations. Theory into Practice, 19, 75-80.

Destineer gets \$12 million for game, 'serious game' funding. (2006, April 27).

Gamasutra. Retrieved October 11, 2007, from http://www.gamasutra.com/phpbin/news index.php?story $=9077$.

Dickey, M. D. (2006). Game design narrative for learning: Appropriating adventure game design narrative devices and techniques for the design of interactive learning environments. Educational Technology Research \& Development, 54, 245-263.

Dobnick, V. (2004). Surgeons may err less by playing video games. Retrieved May 23, 2007, from http://www.msnbc.msn.com/id/4685909/.

Dolliver, M. (2007). So that's where kids' time goes. Adweek, 48, 52.

Driscoll, M. P. (2000). Psychology of learning for instruction. Needham Heights, MA: Allyn \& Bacon. 
Driskell, J. E., \& Dwyer, D. J. (1984). Microcomputer videogame based training. Educational Technology, 24, 11-17.

Ebner, M., \& Holzinger, A. (2007). Successful implementation of user-centered game based learning in higher education: An example from civil engineering. Computers \& Education, 49, 873-890.

Entertainment Software Association. (2006). Essential facts about the computer and video game industry. Washington, D.C.: Same as author.

Federation of American Scientists. (2006). Summit on educational games: Harnessing the power of video games for learning. Washington, DC: Same as author.

Fischer, P., Kubitzki, J., Guter, S., \& Frey, D. (2007). Virtual driving and risk taking: Do racing games increase risk-taking cognitions, affect, and behaviors? Journal of Experimental Psychology: Applied, 13, 22-31.

Flood, (2002). Read all about it: Online learning facing 80\% attrition rates. Turkish Online Journal of Distance Education, 3.

Frash, Jr., R. Kline, S., Almanza, B., \& Antun, J. (2008). Support for a multi-level evaluation framework in hospitality training. Journal of Human Resources in Hospitality \& Tourism, 7, 197-218.

Gagne, R. M. (1984). Learning outcomes and their effects: Useful categories of human performance. American Psychologist, 39, 377-385.

Garris, R., Ahlers, R., Driskell, J. E. (2002). Games, motivation, and learning: A research and practice model. Simulation \& Gaming, 33, 441-467.

Gee, J. P. (2003). What video games have to teach us about learning and literacy. New York: Palgrave Macmillan. 
Gertz, B. (2003, September 29). CIA pursues video game: Antiterror tool to cost millions. Washington Times, p. A1.

Gray, S. H. (1987). The effect of sequence control on computer assisted learning. Journal of Computer-Based Instruction, 14, 54-56.

Gray, S. H. (1989). The effect of locus of control and sequence control on computerized information retrieval and retention. Journal of Educational Computing Research, $5,459-471$.

Greenwood-Ericksen, A. (2008). Learning African-American history in a synthetic learning environment. Unpublished doctoral dissertation, University of Central Florida, Orlando.

Habgood, M. P. J., Ainsworth, S.E., \& Benford, S. (2005). Endogenous fantasy and learning in digital games. Simulation \& Gaming, 36, 483-498.

Hergenhahn, B. R., \& Olson, M. H. (2005). An introduction to theories of learning $\left(7^{\text {th }}\right.$ ed.). Upper Saddle River, NJ: Prentice Hall.

High Paying Jobs in Female-Dominated Fields. (n.d). Retrieved October 20, 2008, from http://jobs.aol.com/gallery/female-dominated.

Hintze, H., Mohr, H., \& Wenzel, A. (1988). Students' attitudes towards control methods in computer-assisted instruction. Journal of Computer Assisted Learning, 4, 3-10.

Indira, A. (2008). Evaluation of training programs for rural development. Journal of Applied Quantitative Methods, 3, 139-150.

Iuppa, N. V., \& Borst, T. (2006). Story and simulations for serious games: Tales from the trenches. Boston, MA: Elsevier.

Jana, R. (2006, March 27). On-the-job video gaming. Business Week(3977), 43. 
Johnson, S. (2005). Everything bad is good for you: How today's popular culture is actually making us smarter. New York: Riverhead Books.

American Society for Training and Development. (n.d.). E-Learning Glossary. Retrieved November 18, 2008, from http://www.astd.org/LC/glossary.htm.

KCTS Television. (n.d.). History of gaming: A look at how it all began. Retrieved August 4, 2007, from http://www.pbs.org/kcts/videogamerevolution/history/timeline flash.html.

Keefe-Feldman, M. (2007). The cable news ticker, viewer comprehension, and information overload: Less is more. Unpublished master's thesis, Georgetown University, Washington, DC.

Kimble, G. A. (1961). Hilgard and Marquis' conditioning and learning (2nd ed.). New York: Appleton-Century-Crofts.

Kirkpatrick, D. L. (1976). Evaluation of training. In R. L. Craig (Ed.), Training and development handbook: A guide to human resource development (2nd ed., pp. 181-18-27). New York: McGraw-Hill.

Klein, G. A., \& Peio, K. J. (1989). Use of a prediction paradigm to evaluate proficient decision making. American Journal of Psychology, 102, 321-331.

Kraiger, K., Ford, J. K., \& Salas, E. (1993). Application of cognitive, skill-based, and affective theories of learning outcomes to new methods of training evaluation. Journal of Applied Psychology, 78, 311-328.

Lai, Shu-Ling. (2001). Controlling the display of animation for better understanding. Journal of Research on Computing in Education, 33, Retrieved June 13, 2001, from http://www.iste.org/jrte/33/5/lai.html. 
Liebermann, S., \& Hoffmann, S. (2008). The impact of practical relevance on training transfer: Evidence from a service quality training program for German bank clerks. International Journal of Training \& Development, 12, 74-86.

Locke, E. A., \& Latham, G. P. (1990). A theory of goal setting and task performance. Englewood Cliffs, NJ: Prentice Hall.

Lombard, M., \& Ditton, T. (1997). At the heart of it all: The concept of presence. Journal of Computer-Mediated Communication, 3. Retrieved November 2, 2007, from http://jcmc.indiana.edu/vol3/issue2/lombard.html.

Malone, T. W. (1980). What makes things fun to learn? A study of intrinsically motivating computer games. Xerox Palo Alto Research Center Technical Report No. CIS-7 (SSL-80-11), Palo Alto, California.

Malone, T. W. (1981). Toward a theory of intrinsically motivating instruction. Cognitive Science, 4, 333-369.

Malone, T. W. (1984). What makes computer games fun? Guidelines for designing educational computer programs. In D. Peterson (Ed.), Intelligent Schoolhouse (pp. 78-92). Reston, VA: Reston Publishing Company.

Malone, T. W., \& Lepper, M. R. (1987). Making learning fun: A taxonomy of intrinsic motivations for learning. In R E. Snow \& M. J. Farr (Eds.), Aptitude, Learning and Instruction: Vol. 3. Conative and Affective Process Analyses (pp. 223-253). Hillsdale, NJ: Erlbaum.

Mandler, J. (1984). Stories, scripts, and scenes: Aspects of schema theory. Hillsdale, NJ: Erlbaum. 
Mathieu, J. E., Tannenbaum, S. I., \& Salas, E. (1992). Influences of individual and situational characteristics on measures of training effectiveness. Academy of Management Journal, 35, 828-847.

Mayer, R. E. (1989). Systematic thinking fostered by illustrations in scientific text, Journal of Educational Psychology, 81, 240-246.

Mayer, R. E., \& Anderson, R. B. (1991). Animations need narrations: An experimental test of a dual-coding hypothesis. Journal of Educational Psychology, 83, 484-490.

Mayer, R. E., Bove, W., Bryman, A., Mars, R., \& Tapangco, L. (1996). When less is more: Meaningful learning from visual and verbal summaries of science textbook lessons. Journal of Educational Psychology, 88, 64-73.

Mayer, R. E., \& Gallini, J. K. (1990). When is an illustration worth ten thousand words? Journal of Educational Psychology, 82, 715-726.

Mazur, J. E. (2001). Learning and behavior ( $5^{\text {th }}$ ed.). Upper Saddle River, NJ: Prentice Hall.

Meister, J. C. (2006, October). Turning online learners into engaged learners [Electronic Version]. Chief Learning Officer. Retrieved June 29, 2007, from http://clomedia . com/content/templates/clo_article.asp?articleid=1540\&zoneid=53.

Michael, D., \& Chen, S. (2006). Serious games: Games that educate, train and inform. Boston, MA: Thompson Course Technology PTR.

Military training is just a game. (2003, October 3). Retrieved May 3, 2007, from http://www.wired.com/gaming/gamingreviews/news/2003/10/60688. 
Morris, C. (2002, June 3). Your tax dollars at play: U.S. Army gets into the gaming business. You're paying for it. Retrieved September 21, 2008, from the CNN website: http://money.cnn.com/2002/05/31/commentary/game_over/column gaming/.

Mott, B.W., Callaway, C. B., Zettlemoyer, L. S., Lee, S. Y., \& Lester, J. C. (1999). Towards narrative-centered learning environments. Proceedings of the 1999 AAAI Fall Symposium on Narrative Intelligence. Retrieved October 19, 2008, from http://people.csail.mit.edu/lsz/papers/mczll-Narrative-99.pdf.

Naish, R. (2003, April). Let's get serious. E.learning Age, 18.

Naylor, J. C., Pritchard, R. D., \& Ilgen, D. R. (1980). A theory of behavior in organizations. New York: Academic Press.

Nowak, K. L., Krcmar, M., \& Farrar, K. M. (2008). The causes and consequences of presence: Considering the influence of violent video games on presence and aggression. Presence, 17, 256-268.

O'Leary, K. D., \& Becker, W. C. (1967). Behavior modification of an adjustment class: A token reinforcement program. Exceptional Children, 33, 637-642.

Owen, M. (2004, September). An anatomy of games: A discussion paper. Retrieved October 11, 2007, from the Futurelab website: http://www.futurelab.org.uk /download/pdfs/research/disc_papers/Anatomy_of_Games_discpaper.pdf.

Parker, L. E., \& Lepper, M. R. (1992). Effects of fantasy contexts on children's learning and motivation: Making learning more fun. Journal of Personality and Social Psychology, 62, 625-633. 
Persky, S., \& Blaskovich, J. (2008). Immersive virtual video game play and presence: Influences on aggressive feelings and behavior. Presence, 17, 57-72.

Phillips, J. J. (1997). Return on investment in training and performance improvement programs. Houston, TX: Gulf Publishing.

Prensky, M. (2001a). Digital game-based learning. New York: McGraw-Hill.

Prensky, M. (2001b). Digital natives, digital immigrants. On the Horizon, 9, 1-2.

Pritchard, R. D. (2006, October 22). Overall motivation assessment plan. Unpublished manuscript.

Pritchard, R. D., \& Ashwood, E. L. (2008). Managing motivation: A manager's guide to diagnosing and improving motivation. New York: Routledge, Taylor \& Francis.

Puell, M. C., \& Barrio, A. (2008). Effect of driver distraction and low alcohol concentrations on useful field of view and frequency-doubling technology perimetry. Acta Ophthalmologica, 86, 634-641.

Randel, J. M., Morris, B. A., Wetzel, C. D., \& Whitehill, B. V. (1992). The effectiveness of games for educational purposes: A review of recent research. Simulation \& Gaming, 23, 261-176.

Reeves, T. C. (1992, May). Evaluating interactive multimedia. Educational Technology, $32,47-53$.

Ricci, K. E., Salas, E., \& Cannon-Bowers, J. A. (1996). Do computer-based games facilitate knowledge acquisition and retention. Military Psychology, 8, 295-307.

Roach, J. (2003, May 28). Video games boost visual skills, study finds. National Geographic News. Retrieved May 24, 2007, from http://news.nationalgeographic .com/news/2003/05/0528_030528_videogames.html. 
Rosas, R., Nussbaum, M., Cumsille, P., Marianov, V., Correa, M., Flores, P., et al. (2003). Beyond Nintendo: Design and assessment of educational video games for first and second grade students. Computers \& Education, 40, 71-94.

Ryan, R. M., Rigby, C. S., \& Przybylski, A. (2006). The motivational pull of video games: A self-determination theory approach. Motivation \& Emotion, 30, 347363.

Salas, E., Burgess, K. A., \& Cannon-Bowers, J. A. (1995). Training effectiveness techniques. In J. Weiner (Ed.), Research techniques in human engineering (pp. 439-471). Englewood, NJ: Princeton \& Hall.

Salas, E., \& Cannon-Bowers, J. A. (2000). Design training systems systematically. In E. A. Locke (Ed.), The Blackwell handbook of principles of organizational behavior (pp. 43-59). Malden, MA: Blackwell Publisher Ltd.

Salas, E., \& Cannon-Bowers, J. A. (2001). The science of training: A decade of progress. Annual Review of Psychology, 52, 471-499.

Sato, L., \& Hanscom, R. (2006). Simulating mistakes, realizing improvements. Forum, 24 , i.

Scanlon, J. (2007, August 14). Getting serious about gaming. Business Week Online, 10. Schollmeyer, J. (2006). Games get serious. Bulletin of the Atomic Scientists, 62, 34-39. Skinner, B. F. (1938). The behavior of organisms. New York: Appleton-Century-Crofts. Skinner, B. (1953). Science and human behavior. New York: MacMillan.

Skinner, B.F. (1969). Contingencies of reinforcement: A theoretical analysis. Englewood Cliffs, NJ: Prentice-Hall. 
Slagle, M. (2006, May 8). Poll: 4 in 10 Americans play video games [Electronic Version]. Washington Post. Retrieved May 9, 2007, from http://www.washington post.com/wp-dyn/content/article/2006/05/07/AR2006050700172.html.

Smith, D. K. (2007). Dynamic programming and board games: A survey. European Journal of Operational Research, 176, 1299-1318.

Sprenger, M. (1999). Learning and memory: The brain in action. Alexandria, VA: Association for Supervision and Curriculum Development.

Susi, T., Johannesson, M., \& Backlund, P. (2007). Serious games-An overview (Tech. Rep. HS-IKI-TR-07-001). Skövde, Sweden: University of Skövde, School of Humanities and Informatics.

Susskind, J. E. (2003). PowerPoint's power in the classroom: Enhancing students' self-efficacy and attitudes. Computers \& Education, 45, 203-215.

The NPD Group. (2008). 2007 U.S. video game and PC game sales exceed \$18.8 billion marking third consecutive year of record-breaking sales. The NPD Group Website. Retrieved October 21, 2008, from http://www.npd.com/press/releases /press_080131b.html.

Tennant, M. (1997). Psychology and adult learning ( $2^{\text {nd }}$ ed.). New York: Routledge.

Tovar, M., \& Coldevin, G. (1992). Effects of orienting activities and instructional control on learning facts and procedures from interactive video. Journal of Educational Computing Research, 8, 507-519. 
U.S. Transportation Security Administration. (2007, April 23). Statement of objectives for serious games initiative. Retrieved August 30, 2007, from http://fs1.fbo.gov /EPSData/DHS/Synopses/35287/Reference-Number-HSTS05-07-IOTT017/SeriousGamesSOO.pdf.

Video games boost vision. (2003). Optician, 225, 7.

Vogel, J. J., Greenwood-Ericksen, A., Cannon-Bowers, J., \& Bowers, C. A. (2006). Using virtual reality with and without gaming attributes for academic achievement. Journal of Research on Technology in Education, 39, 105-118.

Vogel, D. L., Wester, S. R., Heesacker, M., Boysen, G. A., \& Seeman, J. (2006). Gender differences in emotional expression: Do mental health trainees overestimate the magnitude? Journal of Social and Clinical Psychology, 25, 305-332.

Vogel, J. J., Vogel, D. S., Cannon-Bowers, J., Bowers, C. A., Muse, K., \& Wright, M. (2006). Computer gaming and interactive simulations for learning: A metaanalysis. Journal of Educational Computing Research, 34, 229-243.

Vroom, V.H. (1964). Work and motivation. New York: John Wiley \& Sons.

Walker, J. T. (1996). The psychology of learning. Upper Saddle River, NJ: Prentice-Hall.

Wester, S. R., Vogel, D. L., Pressly, P. K., Heesacker, M. (2002). Sex differences in emotion: A critical review of the literature and implications for counseling psychology. The Counseling Psychologist, 30, 630-652.

Wilson, K. A., Bedwell, W., Lazzara, E. H., Salas, E., \& Burke, C. S., Estock, J., et al. (in press). Relationships between game attributes and learning outcomes: Review and research proposals. Simulation \& Gaming. 
Wood, R. T. A., Griffiths, M. D., \& Parke, A. (2007). Experiences of time loss among videogame players: An empirical study. CyberPsychology \& Behavior, 10, 38-44.

Wu, C. (1992). Microcomputer-based welder training simulator. Computers in Industry, $20,321-325$.

Yee, N. (2006a). The demographics, motivations, and derived experiences of users of massively-multiuser online graphical environments. Presence: Teleoperators and Virtual Environments, 15, 309-329.

Yee, N. (2006b). Motivations for play in online games. CyberPsychology \& Behavior, 9, 772-775.

Yerushalmi, E., \& Polingher, C. (2006). Guiding students to learn from mistakes. Physics Education, 41, 532-538.

Yip, F. W. M., \& Kwan, A. C. M. (2006). Online vocabulary games as a tool for teaching and learning English vocabulary. Educational Media International, 43, 233-249. 